\title{
THE COMPLEMENTARITIES OF CHILD HEALTH ACHIEVEMENTS IN DEVELOPING COUNTRIES
}

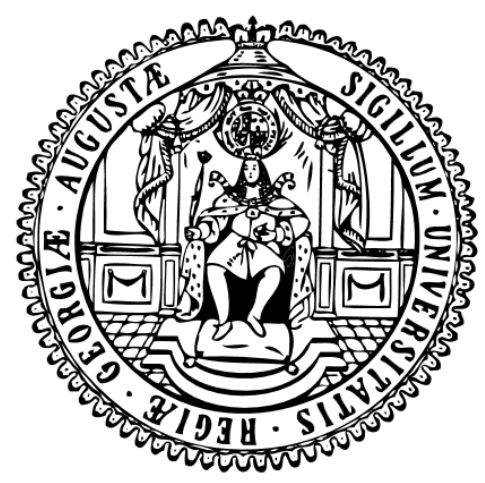

Dissertation zur Erlangung des wirtschaftswissenschaftlichen Doktorgrades der Wirtschaftswissenschaftlichen Fakultät an der Universität Göttingen

vorgelegt von

Maria Carmela Lo Bue

aus Palermo, Italien

Göttingen, 2015 
Erstgutacher: Prof. Stephan Klasen, Ph.D.

Zweitgutacher: Jun.Prof. Sebastian Vollmer, Ph.D.

Drittprüfer: Prof. Matin Qaim, Ph.D.

Tag der Abgabe: 08. Dezember 2014

Tag der Disputation: 06. Februar 2015 
A mia madre 
"...fatti non foste a viver come bruti, ma per seguir virtute e canoscenza".

["...You were not made to live like unto brutes, But for pursuit of virtue and of knowledge".]

Dante Alighieri, Inferno, canto XXVI; vv.119-120 


\section{Acknowledgements}

These past years towards the completion of the $\mathrm{PhD}$ have been, in my view, a great opportunity to grow as a person, and (I hope, at least!) as a researcher. The path has been sometimes scattered with pitfalls, but those good feelings growing every time that one realizes to have been able to overcome even one of those difficulties, is really priceless! There have been many good and valued moments on both the intellectual and the human or social side, and I definitely need to say thanks to several people who have contributed to make this experience so rich and worth to be lived.

I would like to express my special appreciation and heartfelt thanks to my advisor Professor Dr. Stephan Klasen. His advice and support have been really priceless. I would like to thank him for having believed and trusted in me when he gave me the opportunity to do my $\mathrm{PhD}$ at his Chair, for his contagious enthusiasm for his work, for the freedom and guidance that he gave to me, for having always encouraged my research and for allowing me to grow as a research scientist.

Similarly, I am very grateful to my second advisor, Jun. Professor Sebastian Vollmer for his scientific advice and knowledge and for the many insightful discussions and suggestions. And, I would also like to thank Professor Matin Qaim, for accepting to serve as the third advisor of my committee members even upon relatively short-notice.

I express my sincere gratitude to Prof. Inma Martinez Zarzoso for her precious comments on my papers and to Jun. Prof. Jann Lay for the interesting conversations that we had.

I am indebted to my many colleagues and friends who supported me throughout the course of this PhD Programme. Thanks to Friederike, Andreas, Nicole, Robert, Konstantin, Stephan D., Stefan M., Emre, Jan, Malte, Dimi, Ramona, Caroline, Anna Mü., Rajius, Rahul, Bumi, Marion, Jana, Atika, Nathalie, Merle and Steffen for all the thoughts and laughs shared during coffeebreaks, lunches and get-togethers that helped me to forget the stress of research. Very special thanks go to my officemate Simon. He's a friend that I deeply esteem for his invaluably constructive criticism and I thank him for this as well as for his friendly advices and for the good chats and laughs that we had. I am also sincerely grateful to Riva for her great support, to Sophia for her friendship and for her contagious positive and optimistic attitude which gave me lots of energies and to Anna especially for her candor and her sense of humour and for all her jokes which always put a smile in my face.

Above ground, I am indebted to my parents and my sister for their persistent confidence in me, for their unconditional support all these years and for their love which is the greatest source of energy of my life. This thesis is dedicated to my mother, for all of the sacrifices that she has made on my behalf. 


\section{Table of Contents}

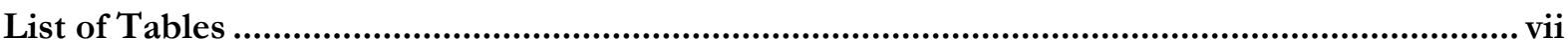

List of Figures .......................................................................................................................... ix

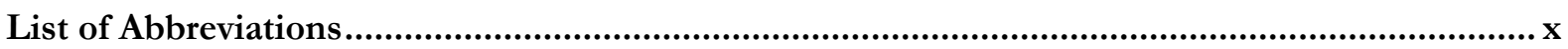

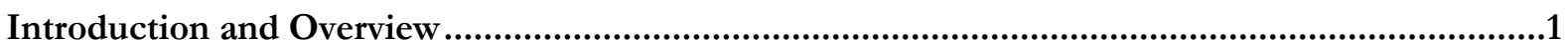

1. Identifying Synergies and Complementarities Between MDGs: Results from Cluster Analysis

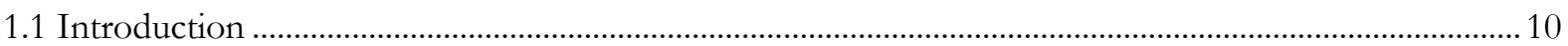

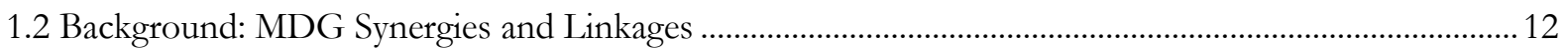

1.3 Exploring Inter-Linkages Between MDGs ......................................................................................... 15

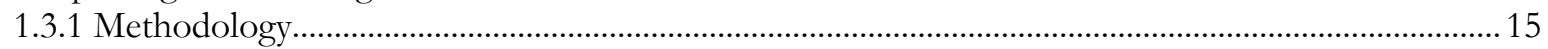

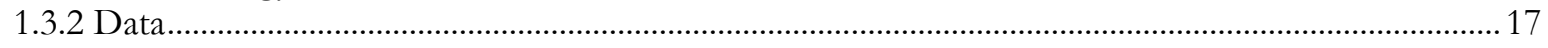

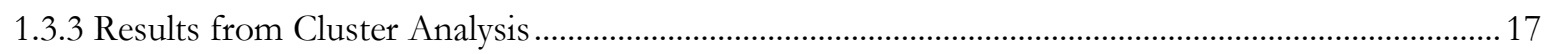

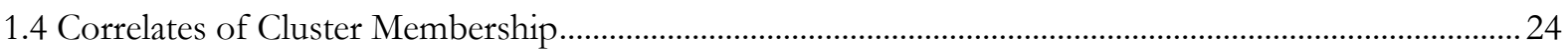

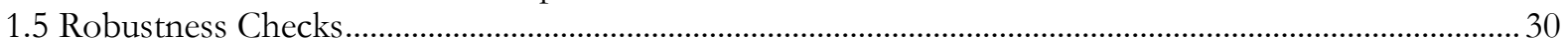

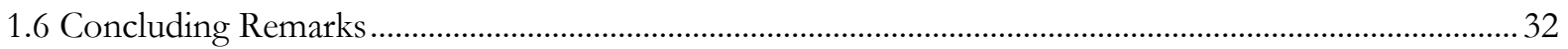

2. What drives child health improvements in Indonesian households? A longitudinal analysis. . 34

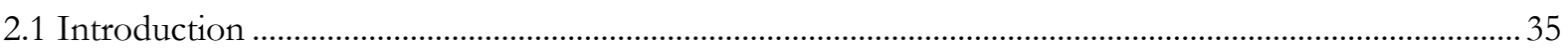

2.2 Drivers of child health achievements: theory and evidence ………............................................................ 37

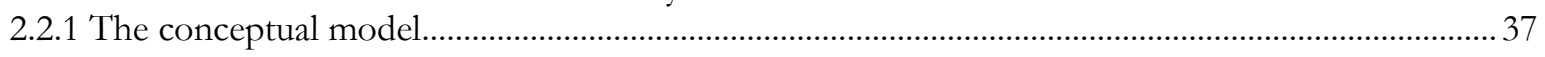

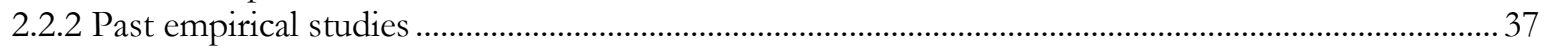

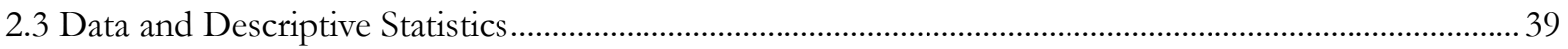

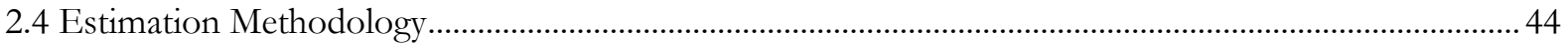

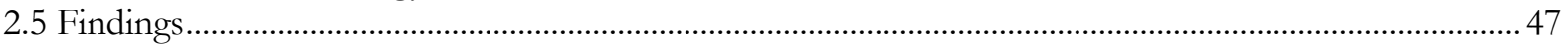

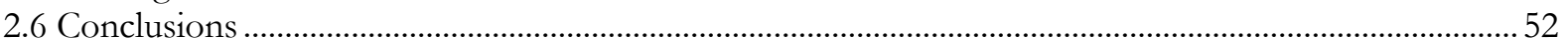

3. The Nutrition-Learning Nexus: Evidence from Indonesia................................................... 54

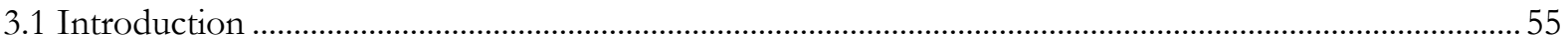

3.2 Theoretical framework and econometric implications ............................................................................56

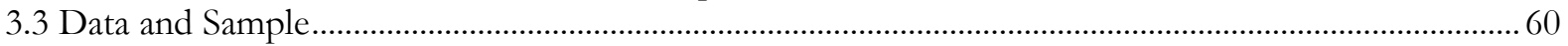

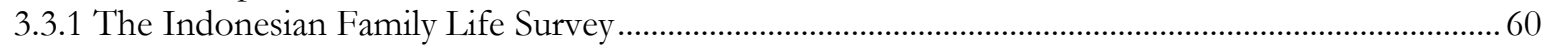

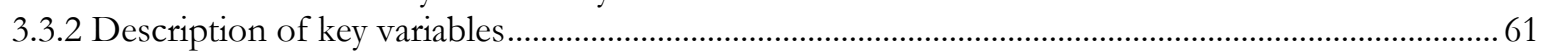

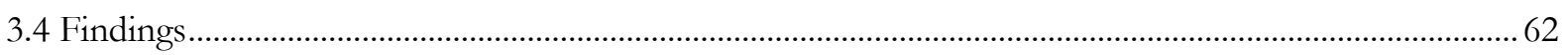

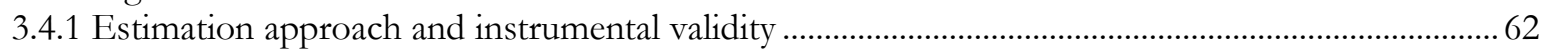

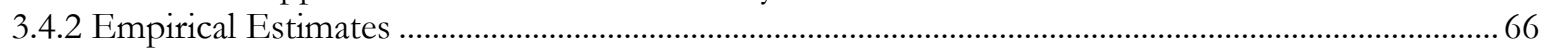

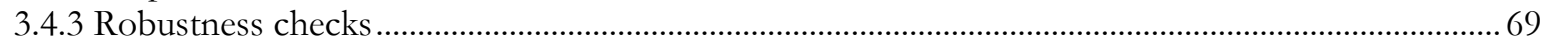

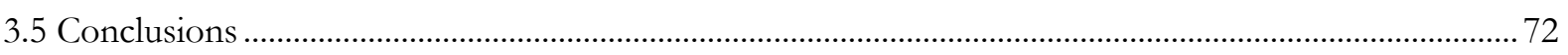

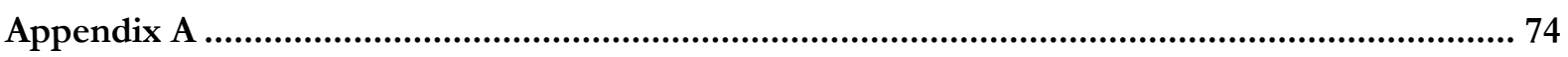

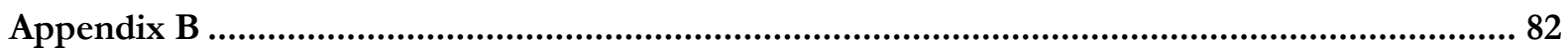


Appendix C .

Bibliography 


\section{List of Tables}

Table 1. 1 Overview of joint performance 23

Table 1. 2 Education and child mortality: Effects of country characteristics on group membership .........25

Table 1. 3 Education and maternal mortality: Effects of country characteristics on group membership...26

Table 1. 4 Education and educational gender gap: Effects of country characteristics on group membership

Table 1. 5 Educational gender gap and maternal mortality: Effects of country characteristics on group ..28

Table 1. 6 Educational gender gap and child mortality: Effects of country characteristics on group .........28

Table 1. 7 Child mortality and maternal mortality: Effects of country characteristics on group membership 29

Table 2. 1 Child health characteristics. Descriptive statistics..................................................................... 41

Table 2. 2 Maternal, households and community characteristics. Descriptive statistics ..............................43

Table 2. 3 The "gross-effect" of the socio-economic determinants of child nutrition .................................48

Table 2. 4 The determinants of child nutrition. Full-specified model. OLS and Mundlak estimates .......... 50

Table 2. 5 A comparison of the maternal education coefficient in baseline regressions with and without

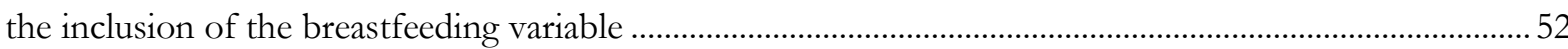

Table 3. 1 Review of previous panel data based studies on the nutrition-learning nexus............................59

Table 3. 2 Nutritional status of children surveyed in IFLS2, by gender and place of residence .................62

Table 3. 3 Mean educational achievements of children above and below moderate stunting and underweight thresholds

Table 3. 4 Effect of exposure to forest fires on child nutritional status. First stage estimates

Table 3. 5 The effect of child height for age on subsequent educational achievements. "Naïve" approaches

Table 3. 6 The effect of child height for age on subsequent educational achievements. Main Findings, based on the MFE-IV estimator

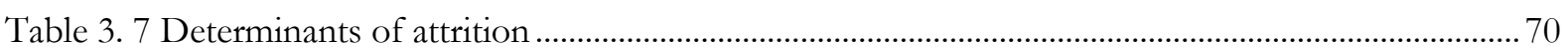

Table A 1 Regression results for the relative performance indicators ........................................................... 75

Table A 2 Primary Completion and Child mortality …................................................................................... 76

Table A 3 Performance in primary completion and in child mortality. Cluster Membership...................... 76

Table A 4 Primary Completion and Maternal mortality .............................................................................. 76

Table A 5 Performance in primary completion and in maternal mortality. Cluster Membership ............... 77

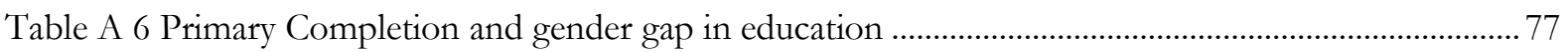

Table A 7 Performance in female-to male ratio of gross secondary school enrolment and in primary completion rate. Cluster Membership .78

Table A 8 Gender gap in education and child mortality .78 
Table A 9 Performance in female-to male ratio of gross secondary school enrolment and in Child

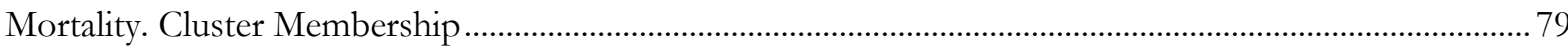

Table A 10 Gender gap in education and maternal mortality.................................................................. 80

Table A 11 Performance in female-to male ratio of gross secondary school enrolment and in Maternal Mortality. Cluster Membership .80

Table A 12 Child Mortality and Maternal Mortality …................................................................................ 81

Table A 13 Performance in child mortality and in maternal mortality. Cluster Membership ..................... 81

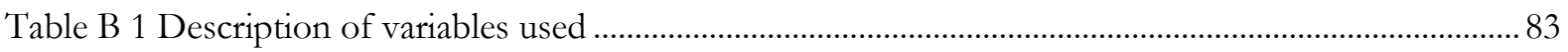

Table B 2 Test for systematic differences in sample composition............................................................... 84

Table B 3 Effect of mother education on the probability of breastfeeding ................................................. 84

Table B 4 Average percentage change in household-level variables between waves .....................................8 85

Table B 5 Scoring Coefficients for the HH Poorness Index (Principal Component Analysis) .................. 85

Table B 6 Between-households and within-household variation in time-varying variables .........................85

Table B 7 Robustness checks with alternative measures of household income and wealth........................86

Table C 1 Description of the variables used and descriptive statistics, IFLS (2-3-4) ................................. 88

Table C 2 The effect of forest fires on income and education expenditure. A test for the assumption of

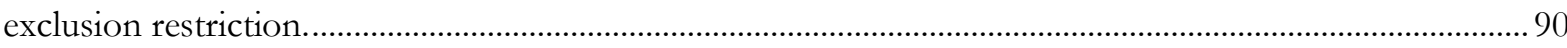

Table C 3 Robustness check 1: MFE-IV estimates of height-for-age on years of schooling. Additional covariates added

Table C 4 Robustness check 1: MFE-IV estimates of height-for-age on cognitive test score. Additional covariates added

Table C 5 Robustness check 1: MFE-IV estimates of height-for-age on age starting school. Additional covariates added

Table C 6 Robustness check 2: MFE-IV estimates of weight-for-age in baseline and alternative specifications.

Table C 7 Robustness check 3: MFE-IV estimates of height-for-age instrumented with exposure to forest fires during the 12-24 first months of life in baseline and alternative specifications 


\section{List of Figures}

Figure 1. 1 Linkages and complementarities between the MDGs: an illustrative framework......................12

Figure 1. 2 Clusters of performers in primary completion and child mortality .......................................... 18

Figure 1. 3 Clusters of performers in primary completion and maternal mortality .................................... 19

Figure 1. 4 Clusters of performers in educational gender gap and education..............................................20

Figure 1. 5 Clusters of performers in educational gender gap and child mortality .....................................20

Figure 1. 6 Clusters of performers in educational gender gap and maternal mortality ...............................21

Figure 1. 7 Clusters of performers in maternal mortality and child mortality..............................................22

Figure 1. 8 Clusters of performers in educational gender gap (1990-99) and maternal mortality (2000-08)

Figure 1. 9 Clusters of performers in educational gender gap (1990-2008) and maternal mortality (19902008)

Figure A 1 Relative annual changes in primary completion rate between 1990 and 2008 against initial levels.

Figure A 2 Relative annual changes in female-to-male ratio of gross secondary school enrolment between 1990 and 2008 against initial levels

Figure A 3 Relative annual changes in under-five mortality rate(per 1,000 live births) between 1990 and 2008 against initial levels.

Figure A 4 Relative annual changes in maternal mortality rate between 1990 and 2008 against initial levels

Figure B 1 Mean stunting z-score by age (three-month interval)

Figure C 1 Location and timing of the Indonesian wildfires 


\section{List of Abbreviations}

\begin{tabular}{|c|c|}
\hline AFE & Age Fixed Effects \\
\hline AIDS & Acquired Immune Deficiency Syndrome \\
\hline BMI & Body Mass Index \\
\hline $\mathrm{CH}$ & Calinski-Harabasz \\
\hline ED & Euclidian Distance \\
\hline ENSO & EL Nino Southern Oscillations \\
\hline Fath.Edu & Father Education \\
\hline GLS & Generalized Least Squares \\
\hline GDP & Gross Domestic Product \\
\hline HDR & Human Development Report \\
\hline $\mathrm{HH}$ & Household \\
\hline HHFE & Household Fixed Effects \\
\hline HIV & Human Immunodeficiency Virus \\
\hline IFLS & Indonesian Family Life Survey \\
\hline IV & Instrumental Variable \\
\hline MAMS & Maquette for MDG Simulations \\
\hline $\operatorname{Max}$ & Maximum \\
\hline MDG & Millennium Development Goals \\
\hline MFE & Mother Fixed Effects \\
\hline MGRS & Multicentre Growth Reference Study \\
\hline Min. & Minimum \\
\hline Moth.id & Mothers identifiers \\
\hline Moth.Edu & Mothers Education \\
\hline No. & Number \\
\hline Obs. & Observations \\
\hline OLS & Ordinary Least Squares \\
\hline PCE & Per Capita Expenditure \\
\hline PFE & Province Fixed Effects \\
\hline Prov.id & Provinces identifiers \\
\hline RPIs & Relative Performance Indicators \\
\hline Std. Dev. & Standard Deviation \\
\hline UN & United Nations \\
\hline UNDP & United Nations Development Programme \\
\hline WDI & Word Development Indicators \\
\hline WHO & World Health Organization \\
\hline ZHFA & Height for Age z scores \\
\hline
\end{tabular}




\title{
Introduction and Overview
}

\section{A new 'humanism' in the concept of development}

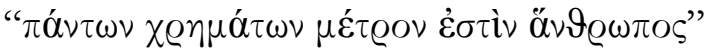 \\ ["Man is the measure of all things"] \\ (Plato, Theaetetus, 152, a)
}

Over the last three decades, the scientific and policy understanding of the concept and of the measurement of development has progressively abandoned the income-centred perspective which has extensively dominated the development research and agenda and has moved towards a human-centred perspective that considers human choices, aspirations and needs as the main focus of development.

This tendency to shift towards a new idea of development as something that "has to be woven around people" (and that) has to be (the) development of the people, by the people, for the people" (UNDP, 1991, p.13), shares some analogies to a change that happened seven centuries ago in Europe, when a cultural movement called Renaissance Humanism reacted against the utilitarian approach and the dogma which permeated the cultural and scientific debate in the Middle Ages and put humans and their dignity as the core interest of arts and sciences.

As indeed it was stated in one of the first human developments reports which have extensively contributed to the spread of this new wave of "humanism" in the development discourse, "for too long, the question has been: how much is a nation producing? Now the question must be: how are its people faring? The real objective of development is to increase people's development choices. Income is one aspect of these choices-and an extremely important one-but it is not the sum-total of human existence. Health, education, a good physical environment and freedom -to name a few other components of well-being- may be just as important" (UNDP, 1991, p.13).

Such a human-centred and multidimensional view towards development has been inspired by the thoughts of the Indian economist and philosopher Amartya Sen who has built a new notion of development as freedom or expansion of capabilities (e.g. Sen, 1999; 2003). According to Sen, each person is featured with a set of functionings that are her "beings" and "doings" (Sen, 1992, p.39), i.e., her actions and values, such as being healthy, educated, achieving self-respect and 
participating in social life. Whereas a person's set of functionings constitutes her actual achievements, the set of achievable functioning vectors makes up that person's capability set. The capabilities reflect the freedom that each person has to choose between different functionings bundles and, as such, they can be interpreted as the opportunities that people have to develop their human capital and reach their full potential. Therefore, according to Sen, in order to define poverty, one should focus not simply on low well being conditions, but on the "inability to pursue well-being" (Sen, 1992, p.110).

Sen's arguments introduced a very novel and interesting perspective to consider poverty and development. A perspective, which is deeply rooted on the concept of "human beings" and on the multitude of dimensions which characterize and determine people and their life.

This multiplicity of aspects that constitutes human development has nowadays been widely accepted and applied in the empirical research of poverty and development (e.g. World Bank, 2000; Bourguignon and Chakravarty, 2002) and has been explicitly taken on board by the United Nations, as testified by the adoption of measures such as the Human Development Index (HDI) or the Millennium Development Goals (MDGs) which all reflect fundamental dimensions of human well-being.

\section{The state of human development}

The concept of human development and the UN Millennium Declaration which laid down the basis for the issue of the MDGs, both share a common multidimensional vision which is rooted on the values of freedom, dignity, solidarity, tolerance, and equity among people and nations and which considers people as agents of development and not as mere passive beneficiaries of progress (Fukuda-Parr, 2004). The eight MDGs (poverty, education, gender equality, child mortality, maternal health, HIV/AIDS and other diseases, environment, and global partnership) which -according to the United Nations- are "the most broadly supported, comprehensive and specific poverty reduction targets the world has ever established" (UN Millennium Project, 2005, p.2), have been unquestionably successful in mobilizing and maintaining support for global poverty reduction (Fukuda-Parr et al. 2014; Waage et al. 2010) and in disseminating the vision of human development.

We are now just one year away from the MDG target date at the end of 2015 and it can be said that over the last fifteen years many countries have realized significant improvements in their socio-economic conditions. At the global level, the goals of universal primary education and of halving income poverty have been largely achieved but this result would probably not have been possible without the outstanding growth performance of China. Progress in other dimensions 
(e.g. child nutrition and mortality; maternal mortality), however, has been relatively weaker. The proportion of undernourished people in the developing regions has gone down from $24 \%$ in the early 90 s to $14 \%$ in 2011-2013. Over the same period, child chronic undernutrition decreased from 40 to 25 percent (United Nations, 2014). Although larger rates of reductions are recorded in child and maternal mortality (i.e., about $-50 \%$ and $-45 \%$ respectively), more progress is definitely needed also in these areas (United Nations, 2014).

\section{Child health as a key component of human development}

"Malesuada Fames ac turpis Egestas"

(Virgilio, Eneide, VI, 276)

Although is no doubt that all the dimensions of human development (as those that, for example, are encapsulated in the MDGs) are equally important and necessary to conduct a decent life, it can be argued that child health may be a special issue to be concerned about and there are at least three main reasons in support of this statement.

First, the state of children today will unavoidably influence the state of our society in the near future. Whether a child is not healthy and inadequately nourished, will she be able to fulfil her potential as a student, a worker, a parent and a citizen? No one would argue against a negative answer to this question. Of course, bad health conditions are an immense burden for both adults and children, but the damage that poor health conditions inflict on children is not only confined to their present but it also has large repercussions in their future, by means of influencing their probability of survival, their health status as adults and their productivity as students and as workers. Therefore, to deprive a child of the ability to fully develop her talents throughout life is not only an ethical issue which has its own relevance but it is also a matter of social welfare: a society which doesn't ensure basic health rights to its children is likely to be divested of its development perspectives.

Second, children, by reason of their "physical and mental immaturity" (UN General Assembly, 1989) are more vulnerable and therefore more likely to be the ones who pay the highest price for exposure to shocks (Boyden et al., 2014).

Third, looking at the age structure of the population living in least developed countries, despite a decline in fertility rates that has been going on over the last two decades, the proportion of children is still relatively large, making up nowadays about 40 percent of the total population of that region (United Nations, 2013). 
As noted before, all the dimensions of human development are, by nature, very closely connected. Child undernutrition, for example, is not merely caused by lack of adequate nutritious food, but also by inadequate care and feeding practices and inadequate health services which are all factors that are likely to be determined by the socio-economic status of the households, namely by parents' wealth and education. Poor child nutritional status, on the other hand, may entail some short term drawbacks (e.g. mortality, morbidity, and disability) and long term adverse consequences in terms, for example, of adult health, cognitive ability, economic productivity and reproductive performances (see, inter alia, Mosley and Chen, 1984 and Glewwe and Miguel, 2008).

This thesis, which is grounded on a human-centred and multidimensional vision of development, aims at analyzing empirically the interdependencies of human well-being achievements through the lens of child health.

This thesis contains three essays, which will be introduced below in more detail, each of them addressing specific research questions in order to contribute to a better understanding of the mechanisms that relate several dimensions of human development.

In particular, I start by taking a broader perspective and analyzing at the macro-level the interlinkages and possible synergies among progress in different MDGs, such as MDG 2 (achieve universal primary education), MDG 3 (promote gender equality and empower women), MDG 4 (reduce child mortality) and MDG 5 (reduce maternal mortality). The main question is therefore, whether there are such synergies and which factors are associated with them. This first explorative analysis paves the way to a set of more specific research questions which can only be answered using a micro-level perspective. I ask therefore: 'how strong are such complementarities?' And, more specifically: 'how strong are they with respect to child health achievements?'; 'How important are household wealth and maternal education in driving child health achievements in the short and in the long term?'; 'By which channels do they operate?'; 'What are the effects of child nutrition on later educational attainments?'; 'What are the short and long term consequences of exposure to environmental shocks on children well being?'

In order to address these issues, I use a longitudinal household survey dataset from Indonesia that, besides being a tool to answer my research questions, allows me to focus on a very interesting context to investigate. Indonesia is a country which has been growing remarkably over the last 20 years and which is recently experiencing large reductions in poverty rates. Large supply side interventions in social development combined with economic growth have benefited the country in many areas of human development: over the last two decades, life expectancy at birth increased by 12.2 years; mean years of schooling increased by 4.4 years; and gender parity in 
tertiary education and in adult literacy rates has been achieved (UNDP, 2013). However, faster progress is still needed in many other areas (such as child nutrition, maternal mortality, access to water and sanitation) and high levels of inequality in standards of well being emerge between regions and areas. This thesis, therefore, while analyzing trends in human development in the country and explaining with rigorous econometric methods its achievements in child nutritional status and in education, contributes to a better understanding of the factors that may play a key role for further development.

\section{Empirical analysis of the interdependencies of the MDGs}

The first Essay, which is based on a joint work with Stephan Klasen, is concerned with the interlinkages and the synergies among progress in several non-income MDG indicators.

The MDGs represent key aspects of human well-being, and as such, they should be closely interlinked. Nevertheless, despite the substantial theoretical case for large synergies between MDG goals, empirically the heterogeneity of the linkage of progress across different MDGs can be quite substantial (see, for example, Bourguignon et al., 2008a).

The central research question in Essay 1 is therefore whether one can identify clear clusters of countries where such synergies exist (and those where they do not exist), and what drives membership in these clusters.

To achieve this, first, Essay 1 defines MDG progress in terms of relative performance indicators which describe the rate of change that exceeds the empirically 'expected' rate of change, given initial conditions. Such a measure allows us to essentially ask whether countries that succeeded in achieving extraordinary progress in MDG achievements were benefiting from synergies or not.

Second, in Essay 1 we apply cluster analysis to these indicators of relative performance on the following non-income MDG indicators: MDG 2 (achieve universal primary education), MDG 3 (promote gender equality and empower women), MDG 4 (reduce child mortality) and MDG 5 (reduce maternal mortality). Whether the relative performance indicators explicitly take into account the fact that relative performance should be conditional on initial conditions, by applying cluster analysis we are able to distinguish countries where the pair of indicators move in the same direction ('good' or 'bad' performers) from countries where the pair of indicators moved in opposite directions ('partial' performers). Last, we investigate possible determinants of group membership.

The results from cluster analysis suggest that there are synergies, but these only apply to a restricted group of countries (the 'good' performers where progress goes hand in hand, and the 'bad performers' where regress goes hand-in-hand). On the other hand, we find that in a sizable 
number of countries synergies are weak or absent, leading to contrary movements in MDG progress at least in one or two pairs of non-income MDG indicators. This group of 'partial' performers mainly includes countries located in Latin America and in the Europe and Central Asia region, although there are country examples throughout. As our regression results show this partial performance is largely explained by rising inequality and low institutional quality. On the other hand, economic growth, which seems to be the most robust determinant of cluster membership, is particularly able to distinguish the good from bad performers.

A key implication of Essay 1's findings (which might be particularly relevant for the post-2015 development agenda) is that in order to achieve broad progress in non-income dimensions of well-being, policies need to explicitly take into account the strength (or weakness) of the existing synergies and try to maximize them.

\section{Empirical analysis of the determinants of child health achievements}

Reducing child malnutrition represents a key challenge for the development community and has rightly been included as one of the MDGs. While child malnutrition clearly implies poor health conditions and is one of the most important causes of child mortality (see, for example, Pelletier et al.1995), other MDGs, such as promoting education, reducing gender gaps in education, and providing water and sanitation access are likely to affect nutrition outcomes. However, as noted before, empirically the strength of these complementarities is not robustly supported by the studies relying on cross-country data. A plausible explanation for this could be related to the fact that important child and household characteristics which represent the bulk of the models of child health are lost in the aggregation process at the national level.

The micro-based literature, on the hand, has extensively argued that there exist deep interlinkages between child health and socio-economic factors (i.e. mother education and household income) and that this relationship is likely to be mediated by a range of proximate factors (e.g. maternal health, use of improved water and sanitation conditions, immunization, breastfeeding, parental health knowledge). However so far, whether the micro empirical evidence on this issue (which is largely based on cross sectional datasets) has largely proven the presence of correlations, there is relatively weaker empirical support for assessing causation mechanisms. A first reason for this is that the determinants of child health operate in a dynamic framework involving substantial time lags which can only be captured using longitudinal data. Second, the estimation of a child health production function entails some endogeneity issues which may not be always so easy to be addressed. 
Essay 2 analyzes the short and long term determinants of child health achievements, based on longitudinal data from the Indonesia Family Life Survey (IFLS). In particular, based on the analytical framework proposed by Mosley and Chen (1984), Essay 2 investigates the effects of a set of child-specific, household and community characteristics on child nutritional status, measured by her height-for-age $z$-scores.

The use of panel data offers a remarkable advantage over cross-sectional datasets, since it allows to analyze the intertemporal connections between child health and its determinants and to answer therefore the question of what drives the evolution of child health over time.

Moreover, this analysis applies a methodology (i.e. the Mundlak approach of household-average fixed effects) which not only delivers robust and unbiased estimates but also allows me to contribute to prior literature by identifying the short and long term effects of proximate and socio-economic determinants of child health.

The analysis in Essay 2 suggests that maternal education has a positive and long term effect on child health which is partly reflected in reproductive behaviour and partly conveyed through child caring practices (i.e. breastfeeding). On the other hand, while temporal increases in income allow for improved expenditure capacity and therefore to better nutritional status, there isn't any long term effect of income, apart from the one that is conveyed through the acquisition and use of the intermediate inputs such as improved sanitation infrastructure which strongly and significantly affect child health status. Overall, the findings suggest that income povertyalleviating policies complemented with investment in basic health infrastructure might strongly contribute to improving children health conditions, Also, as the linkages between maternal education, child nurturing practices and child health are found to be particularly strong, policies which are aimed at enhancing the quality of education can remarkably improve the nutritional status of children.

\section{Empirical analysis of the impact of child nutrition on later educational achievements}

The last Essay of this thesis aims at further considering these complementarities in human development aspects by analyzing the role that early childhood nutrition plays on later educational achievements.

There are sound theoretical arguments that indicate that better child nutrition crucially influence an individual's learning abilities and performance in school. Poor nutritional status implies indeed weaker physical conditions and so more vulnerability to disease which is likely to affect readiness to enter school as well as school attendance and ability to learn. Moreover, given that 
cognitive development and school achievements are two important components of human capital, the long term consequences of poor nutritional status will also likely to be reflected in worse outcomes on labor productivity and on life time earnings.

On the empirical side, nevertheless, the evidence on this relationship is relatively weak and, in the vast majorities of the cases, it is only able to proof for correlations but not for causality. In Essay 3, therefore, I seek to overcome the weakness of previous studies and offer some robust evidence on the strength of the nutrition-learning nexus.

Essay 3 is based on a micro-econometric analysis on a long term panel dataset collected in 13 Indonesian provinces over the period 1997 to 2007. Its econometric strategy relies on an instrumental variable-mother-fixed-effects estimator where differences in nutritional status among siblings are identified by the exposure to an exogenous shock, namely to the drought associated with the late 1997's Indonesian forest fires.

The use of this identification strategy helps us to address endogeneity issues entailed in the estimation of the educational achievement function but also it gives us the opportunity to accrue current knowledge on the long-run impact that shocks such as exposure to environmental disasters can have on a person's life.

The main findings of Essay 3, which are confirmed by robustness checks, suggest that good nutritional status in childhood significantly contributes to improved, school attainments either in terms of years of education and of cognitive development. This imply that from a policy perspective, school and nutrition objectives should not be seen as competing goals but are closely interlinked. Therefore, financial resources devoted to child nutrition policies do not necessarily compete with those for the education agenda; instead, as implied in this essay, they can be regarded as a more cost effective way to raise present and future socio-economic development. 


\title{
Essay 1
}

\section{Identifying Synergies and Complementarities Between MDGs: Results from Cluster Analysis}

\begin{abstract}
The MDGs are interlinked: acceleration in one goal is likely to speed up progress in others. Nevertheless, these synergies are not always visible, and may differ across countries. Using bivariate cluster analysis, this paper investigates whether distinct groups of developing countries can be identified, using statistical methods, on the basis of the correlation of changes in main MDG indicators over the 1990-2008 period. Identified groups include: (1) "good performers", characterized by strong positive synergies in MDGs indicators; (2) "poor performers", where there are synergies in poor progress towards the MDGs and (3) "partial performers" countries where progress in one MDG went along with regress or stagnation in another. We then study the determinants of cluster membership. While growth in GDP per capita is, unsurprisingly, best able to distinguish between "good" and "poor" performers, a poor institutional framework and deteriorations in the income distribution is a notable correlate of partial progress, thus apparently undermining synergies in reaching the MDGs. In light of the current discussions about the post-MDG system, our results suggest that synergies between MDG progress can be achieved but they cannot be taken for granted. Improving institutional performance and reducing inequality appear particularly important drivers of promoting such synergies.
\end{abstract}

Based on a joint work with Stephan Klasen.

Published as: Maria C. Lo Bue and Stephan Klasen (2013). Identifying Synergies and Complementarities Between MDGs: Results from Cluster Analysis, Social Indicators Research, Springer, vol. 113(2), pages 647670, September. 


\subsection{Introduction}

While the MDGs were constructed as separate goals covering different aspects of the quality of life of people, it is clear that they are related to each other. But the extent of these synergies and the heterogeneity of these synergies across countries remains an open question.

This paper explores interlinkages and possible synergies among progress in different MDGs. It thereby builds, on the one hand, on the long-standing literature on the interlinkages between health, education, poverty, and gender. For example, the analysis of possible causal relationships between female education and infant and child mortality has been one of the more thoroughly researched issues (starting with the pioneer works of Caldwell 1979; Mosley and Chen 1984; Bourne and Walker 1991). On the other hand, it builds on the literature that is mainly focused on measuring achievement of the goals, on the speed of progress, and post-2015 projections (see among others: Abu-Ghaida and Klasen 2004; Clemens et al. 2007; Lange and Klasen 2011, White and Blöndal 2007; Fukuda-Parr and Greenstein 2010; Lay 2010). In this context, various country classifications were used to assess progress, either using the pace of progress relative to the target path or other benchmarks (e.g. UNDP 2003; Lange and Klasen 2011).

Here we assess possible synergies and complementarities in progress towards different MDGs over the past two decades. More specifically, we seek to identify countries' performance in pairs of non-income MDG indicators applying cluster analysis and distinguish countries where the pair of indicators move in the same direction ('good' or 'bad' performers) from countries where the pair of indicators moved in opposite directions ('partial' performers); in the former case, we see this as evidence of synergies or complementarities in MDG achievement ${ }^{1}$. In particular our study applies measures of relative performance between 1990 and 2008 in MDG 2 (achieve universal primary education), MDG 3 (promote gender equality and empower women), MDG 4 (reduce child mortality) and MDG 5 (reduce maternal mortality). The focus on this specific subset of MDGs is justified by an abundant literature which-both at the micro and the macro level-has confirmed the presence of linkages existing between achievements in education, gender inequality, and health outcomes ${ }^{2}$.

A related attempt to classify countries using cluster analysis can be found in Anderson and Morrissey (2006) and Anderson (2007). Here the authors identify clusters of performers

\footnotetext{
${ }^{1}$ Looking at pairs of MDGs indicators-instead of opting out for some overall achievement index-allow us to have a closer inspection on possible synergies which may uniquely derive from achievements in two different human development dimensions. Hence, we avoid the risk (intrinsic in more complex multidimensional indices) of losing precious information on the direction of improvements and on the strength of complementarities between related spheres of human development.

2 Because of data availability constraints we were not able to include in our analysis any indicator for child malnutrition which is also been proven by the related literature to exhibit strong connections with the other MDGs indicators.
} 
considering both levels and changes in some welfare indicators in order to identify groups of countries where both levels and progress is low and distinguish them from others. Our paper differs from this approach by focusing exclusively on changes in welfare indicators. Also, we focus on the MDG indicators to be able to specifically investigate synergies and trade-offs in achieving MDG progress. We also differ from the literature by using a relative performance indicator for MDG progress that considers the different and arguably unequal starting points of developing countries when measuring progress (e.g. Easterly 2009; Harttgen and Klasen 2012; Lange and Klasen 2011).

After having applied the cluster analysis to these relative performance measures, we then investigate the possible determinants of group membership. In particular, we look at some structural factors such as institutions, ethnic fractionalization as well as changes in political violence and in income levels and distribution and analyze how these can affect membership in these three groups. We find that growth in GDP per capita is particularly important in distinguishing between good and bad performers, while a poor institutional framework and deteriorations in the income distribution increase the likelihood of being a partial performer where synergies are lacking.

The identification of such linkages and complementarities between different MDGs is also of crucial importance for framing a post-2015 process. In the past years, indeed, the true multidimensional essence of the MDGs has been somewhat neglected and-as in the case of the MDG "costing exercise" - the millennium goals have been used as a tool to design costly vertical programs which target financial resources for progress in single indicators (see, as an example, the 2005 report from the UN Millennium Project headed by Jeffrey Sachs). The ongoing debate on the effectiveness of the so-called Millennium Villages testifies the weaknesses of this moneyfocused approach (see, for example, Clemens and Demombynes 2011), and, indeed, such a narrow view totally glosses over the presence of transmission channels existing between the goals. At the same time, these linkages cannot be taken for granted and may differ across countries. As a result, a post- MDG system might want to explicitly build on existing linkages by devising a multidimensional goal system that explicitly incorporates the strength (or weakness) of existing synergies. It might also want to focus policy attention on strengthening these synergies.

This paper is structured as follows: Sect. 1.2 provides an overview on possible synergies and interlinkages between MDGs. Section 1.3 presents the methodological framework applied to our data and discuss our results from cluster analysis. In Sect. 1.4 we illustrate the results of multivariate regression analysis. Section 1.5 provides robustness checks and lastly our concluding remarks are stated in Sect. 1.6. 


\subsection{Background: MDG Synergies and Linkages}

Exploring linkages and possible synergies among different MDGs implies, basically, recognizing the existence of transmission channels that, working as catalyst forces, can speed up progress towards MDG achievements. The framework shown in Fig. 1.1 presents graphically the subset of non-income MDGs that we analyze and the possible links which, according to previous literature, may generate complementarities in progress between them. For example, improving the share of girls in schools might speed up progress in achieving universal primary completion rates (MDG 2) as educated women tend to invest more in the education of their children. Similarly, greater female education reduces early marriage and improves health knowledge, thereby helping to reduce maternal mortality.

While below we discuss some of the literature related to these linkages, it is important to emphasize that such synergies are likely to depend on country characteristics, the nature of policy interventions to reach MDGs, as well as the strength of particular transmission channels that link progress of different MDGs. There may also be time lags involved, an issue we examine in a robustness check below.

Figure 1. 1 Linkages and complementarities between the MDGs: an illustrative framework

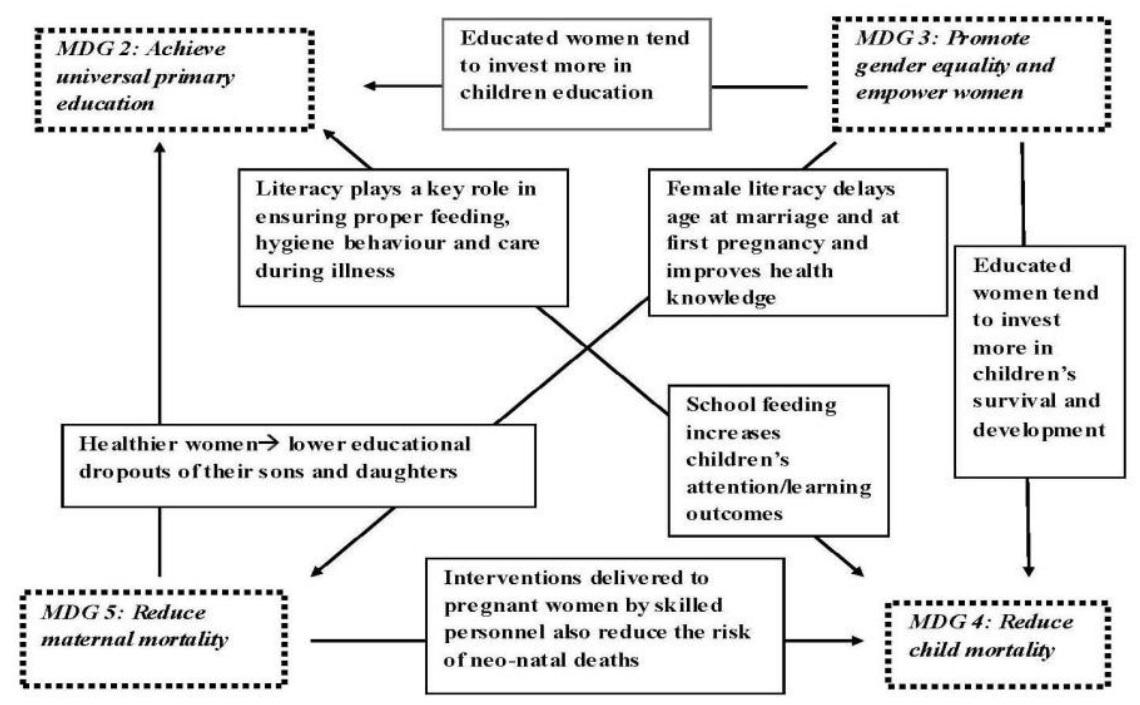

A comprehensive and innovative contribution which attempts to directly investigate these interlinkages comes from the so called "MAMS studies" (see Bourguignon et al. 2008b). These are simulations based on an economy wide framework designed to analyze the interactions between services, MDGs, economic growth, and aid. Hence by directly examining how different goals can complement one another while at the same time competing for resources, these 
MAMS are able to identify strategies and policies which can hamper or raise intersectoral synergies. Moreover, there are many examples which can be provided in order to show the existence of this heterogeneous interdependence among MDGs. This framework provides an interesting ex ante assessment of the likely synergies and trade-offs that explicitly considers country characteristics.

Apart from this ex ante approach, there is a substantial literature that has posited (implicitly or explicitly) linkages between different MDG indicators. For example, a substantial theoretical and empirical literature has argued that closing the gender gap in education (MDG 3) can be regarded as a "leading" item among the MDGs by promoting income poverty reduction, child mortality reduction, and the education of children (see Summers 1994; Abu-Ghaida and Klasen 2004; Klasen 2005; Lay and Robilliard 2009).

With respect to possible synergies coming from reductions in child mortality (MDG 4), it is widely recognized that school feeding increases children's attention and learning outcomes (e.g. Kazianga et al. 2009).

As discussed in detail in King et al. (2009), improving maternal health is a critical item for ensuring neonatal survival as well as the survival of under-five children. Interventions delivered by skilled personnel in order to reduce maternal mortality will also help to lower the risk of deaths in the first month of life. Healthier, better nourished women would also presumably have fewer complications during pregnancy and childbirth. Moreover, better maternal health implies lower education drop out. This is true especially for girls who usually have to replace their mother in carrying on the household burdens and care of siblings.

Thus there is ample potential for synergies in MDG achievements. Policy interventions (such as broad-based health and nutrition programs) as well as structural factors can additionally affect such synergies by addressing several MDGs at the same time. On the other hand, this would imply that if complementarities and interlinkages among goals are not visible empirically, there must be some factor which delays or hampers those synergetic processes. For instance, in some cases intersectoral programmes have failed in raising synergies between health and educational spheres by focusing on narrow targets or compartmentalized programs (e.g. White and Masset 2006).

It is also important to note that interdependencies between different human development spheres may even be stronger when achievements in some dimensions are reached not only with respect to quantitative, easy-measurable targets (i.e. school enrolment or completion rates) but also with respect to outcomes related to quality. For example, many African countries have implemented since the mid 1990s programmes devoted to achieve universal primary education, 
which mainly consisted in the elimination of school fees. But the evidence regarding the effectiveness of these programmes is quite mixed. For examples, while Nishimura et al. (2008) find that the Universal Primary Education policy in Uganda has contributed to increase enrolment and completion rates, they also point out the existence of internal inefficiency, raising concern of a possible deterioration in the quality of public primary schools ${ }^{3}$ and also of a resulting inequality in the quality of education between different villages. Such effects might reduce or even eliminate possible synergies between education, poverty, and health goals. Also, the distribution of benefits among the population and the possible existence of inequalities in access to health or education may be a barrier to realize synergies. As suggested by Minujin and Delamonica (2003) in their analysis on the differentials in child mortality by wealth level and other social dimensions, in most of the cases, reductions in the average under five mortality rate are driven by the reduction experienced by the middle and top social groups. In such an environment, the benefits of these reductions only affect a minority of a population, thereby limiting potential synergies.

Despite the substantial theoretical case for large synergies between MDG goals, empirically the heterogeneity of the linkage of progress across different MDGs can be quite substantial as shown, for example, by Bourguignon et al. (2008a). They show that there is little correlation between poverty reductions and changes in under-five mortality rates or in primary school completion rates and hardly any correlation between progress in some pairs of non-income MDG indicators. Furthermore they also show evidence of lack of correlation between those non-income MDG indicators and GDP per capita growth suggesting that any progress along non-income MDG is less likely to be merely driven by economic growth. This rather negative result begs the question, however, whether one can identify clear clusters of countries where such synergies exist (and those where they do not exist), and what drives membership in these clusters. ${ }^{4}$ This is indeed, the central subject of investigation in this paper.

\footnotetext{
${ }^{3}$ Analogous conclusions have been conveyed by Deininger (2003).

4 It is important to underline that our study relies on a narrow definition of synergy i.e. on the simultaneous achievements occurring in two dimensions which, deriving from strong complementarity in those two dimensions, would ensure that progress in one dimension will facilitate progress in another.
} 


\subsection{Exploring Inter-Linkages Between MDGs}

\subsubsection{Methodology}

In a first step, we need to develop a measure of MDG progress. As argued by Easterly (2009) and others, performance on the basis of just absolute or proportional changes (or reductions in distance to target) can be misleading. For example, considering absolute changes, a reduction in maternal or child mortality in country A from 1000 to 950 will arguably be easier to achieve than a reduction from 100 to 50 in country B. Conversely, considering relative changes, a $5 \%$ reduction in mortality (50 in country A and only 5 in country B) will be harder to achieve when the initial level is very high as argued by, inter alia, Kakwani (1993) (see also Lange and Klasen 2011).

Similarly, when considering MDG 2, investments in primary education, may yield very high improvements in countries featuring low initial rates of enrolment, but as enrolment rates approach universal coverage, it may become ever harder to reach all out-of-school children. Indeed, as noted by Prennushi et al. (2002), "as a general rule, performances become more difficult as levels improve".

Moreover, individual performance should be also measured and judged by using as a frame of reference not ideally some abstract or predetermined target but considering some measure of real achievements expected given the initial level, hence global performance and deviations from its average could be taken into account. We try to solve these issues by following Anderson and Morrissey (2006) and using a "conditional" approach that mainly consists in using the residuals from a regression of the form:

$$
\Delta y_{i}=\alpha+\beta y_{i}+e_{i}
$$

where, for country $i, y_{i}$ is the initial level of the indicator (i.e. in 1990 or earliest year available) and $\Delta y_{i}$ are average relative annual change occurred over the 1990-2008 period.

In this way, we take into account the fact that relative performance should be conditional on initial conditions in the country. Thus we define MDG progress in terms of relative performance indicators (RPIs) which describe the rate of change that exceeds the empirically 'expected' rate of change, given initial conditions, i.e. the residual $e_{i}$ in the above equation. ${ }^{5}$ Thus we are essentially asking whether countries that succeeded in achieving extraordinary progress in MDG achievements were benefiting from synergies or not. Since the MDGs were about accelerating progress to meet these welfare goals, we believe that this is a sensible way to proceed. This

\footnotetext{
${ }^{5}$ For other ways to define progress, see Clemens et al. (2007) and Lange and Klasen (2011). The results here are largely robust to defining changes in these ways.
} 
approach effectively ensures that when achievements in MDG 2 and MDG 3 are considered, the lower the starting level the higher the expected relative rate of improvement, suggesting sensibly that large relative improvements are easier for countries starting with low levels (also known as "catch-up effect").

In contrast, for the two health-related indicators (MDGs 4 and 5) the rate of reductions is expected to be lower for countries which started with higher initial levels. This mainly means that countries characterised by an initially high under-five and maternal mortality rate would be expected to perform worse than others. ${ }^{7}$ As a result, countries with low initial mortality rates are expected to have a higher rate of reduction and the residual only considers extraordinary progress, over and above this expected progress.

After defining progress, we turn to our cluster analysis. The method we apply to classify countries is bivariate cluster analysis. The main purpose of this method is the natural grouping of pairs of observations. ${ }^{8}$ Several general types of cluster analysis methods are available depending on different types of distance measures.

First, in order to build clusters we use the Euclidian distance (ED) as a measure of similarity or dissimilarity between countries. Given that $\Delta x$ and $\Delta y$ are two RPIs in country $i$ and $j$, this measure of distance could be written as:

$$
E D_{i j}=\sqrt{\left(\Delta x_{i}-\Delta x_{j}\right)^{2}+\left(\Delta y_{i}-\Delta y_{j}\right)^{2}}
$$

Secondly, the distance between any two clusters should be determined. Here, we choose to apply the Ward's linkage approach. Hence, the method starts by identifying each cluster's central value $\left(\Delta x_{c}, \Delta y_{c}\right):$

$$
\left(\Delta x_{c}, \Delta y_{c}\right)=\left(\frac{1}{n_{c}} \sum_{i=1}^{n} \Delta x_{c i}, \frac{1}{n_{c}} \sum_{i=1}^{n} \Delta y_{c i}\right)
$$

\footnotetext{
${ }^{6}$ See Fig. A1 and A2 in Appendix A.

7 With respect to this last point, it should be noted that, if absolute changes are regressed against initial levels a positive relationship is found (i.e. the greater the initial level, the larger is the associated rate of reduction). In other words, in absolute terms, in high mortality countries larger achievements are due to the immediate effect of some basic, cheap and easy-available policies whereas to reduce mortality rates even further would require much more efforts. While this affects the expected improvements, the residuals from these regressions are not dramatically different and do not materially affect the results of the cluster analysis.

8 Cluster analysis is mainly an exploratory data-analysis technique. As stated by Everitt (1993) "Clustering methods are intended largely for generating rather than testing hypotheses".
} 
where, $n_{c}$ is the number of countries in cluster $c$ and $\Delta x_{c i}$ and $\Delta y_{c i}$ are two RPIs computed over the relevant period for country $i$ in cluster $c$. After computing the sum of the squares of the distances between all countries in the cluster and the central value ("within-cluster" sum of squares), the distance between two clusters is computed as the increase in the error sum of squares after combining two clusters into a single cluster.

Lastly, the number of clusters should be determined. Here, as well, there are several rules that can be applied. We follow the Calinski-Harabasz rule $(\mathrm{CH})$. Indeed, this is one of the most applied criterions in cluster analysis. ${ }^{9}$ The aim here is to maximize $\mathrm{CH}(c)$ over the $c$ clusters:

$$
\mathrm{CH}(c)=\frac{\frac{\text { trace } B}{(c-1)}}{\frac{\text { trace } W}{(n-c)}}
$$

where trace $B$ is the between cluster sum of squares and cross-products matrix and trace $W$ is the within clusters sum of squares and cross-products matrix. So, large values of CalinskiHarabasz pseudo-F index indicate distinct clustering (Calinski and Harabasz 1974).

\subsubsection{Data}

The Cluster analysis is applied to our relative performance measure between 1990 and 2008 in MDG 2 (achieve universal primary education), MDG 3 (promote gender equality and empower women), MDG 4 (reduce child mortality) and MDG 5 (reduce maternal mortality).

In order to compute this measure of performance we rely on data from the World Development Indicators (WDI) database (World Bank 2010) for the primary completion rate and the female to male ratio of gross secondary school enrolment, and the under-five mortality ratio (deaths per 1,000), while the maternal mortality rate (per 100,000 live births) we take from Hogan et al. (2010). Our sample includes 142 countries classified by the World Bank as low or middle income in 2009.

\subsubsection{Results from Cluster Analysis ${ }^{10}$}

We run six different bivariate cluster analyses taking into account all possible pairs of RPIs ${ }^{11}$

obtained for the following MDG indicators:

1. Primary completion rate and child mortality rate;

2. Primary completion rate and maternal mortality rate;

\footnotetext{
${ }^{9}$ In a simulation study, Milligan and Cooper (1985) found that the Calinski-Harabasz criterion recovered the correct number of groups most frequently.

${ }^{10}$ For each analysis, Figs. 1.2-1.7 provided here below show the results in a graphical form. For further details, see Appendix A where we report for each cluster the means and the range of changes in the two indicators as computed under the conditional approach (i.e. standardised residuals).

11 As a robustness check, we have repeated these bivariate cluster analyses using standardised residuals from regressions with absolute annual changes in given MDG indicators (instead of relative annual changes). Also, we have performed multivariate cluster analyses (with three indicators per each). Our original results appear quite robust even though the composition and the location of groups changes slightly.
} 
3. Primary completion rate and the female to male ratio of gross secondary school enrolment;

4. Female to male ratio of gross secondary school enrolment and child mortality rate;

5. Female to male ratio of gross secondary school enrolment and maternal mortality rate;

6. Child mortality rate and maternal mortality rate.

For the first analysis we find evidence of three distinct groups (see Fig. 1.2). A group of good performers (" 1 ") is located at the bottom-right corner of the graph. The group is composed of 22 countries, all characterised by strong improvements in terms of reducing child mortality rate and in increasing the primary completion rate. A second group of 22 countries ("2") show instead a partial performance i.e. where countries show improvements in education but hardly any improvements or even deteriorations in health. The bad performers ("3") appear at the topleft corner of the graph. In this group we see synergies, but in a negative sense with poor trends in health and education indicators. ${ }^{12}$

Figure 1. 2 Clusters of performers in primary completion and child mortality

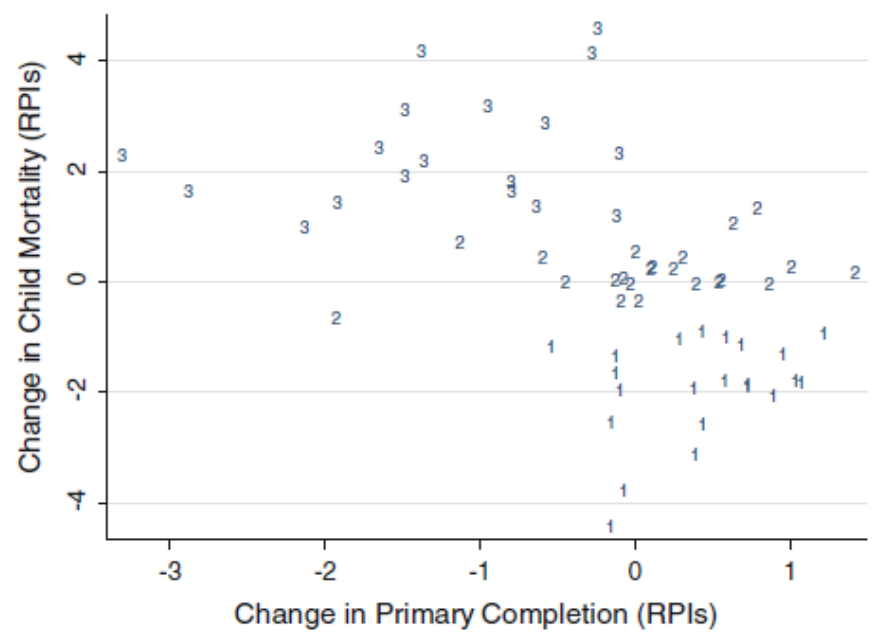

When primary completion and maternal mortality (Fig.1.3) are considered, we find evidence of four groups. The first two groups are larger (in terms of the number of countries included). These are the good performers ("1") and the partial performers ("2") that despite improvements in the education sphere did not reduce maternal mortality much.

While the third group can be regarded as poorly performing, the fourth group (containing only four observations) seems to show some deterioration in the education indicator while performance in the maternal mortality indicator is not as bad as in group " 3 ".

\footnotetext{
12 One needs to bear in mind that we are using our relative performance measure. So these countries with negative residuals in education might still have improved enrolment rates, but less than expected given initial conditions.
} 
Figure 1. 3 Clusters of performers in primary completion and maternal mortality

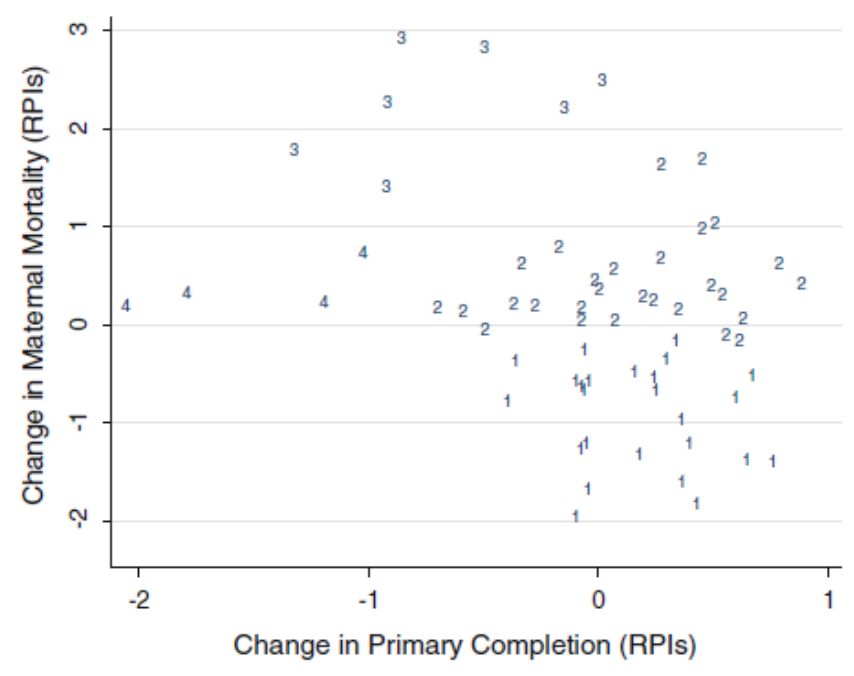

A third cluster analysis uses the primary completion performance indicator and the gender gap in education performance indicator. Three main groups result: at the top right corner of the graph (Fig. 1. 4), the good performers' (" 1 ") is composed by 23 countries. An example of two countries belonging to this group can be illustrative: Mauritania seems to have been relatively fast in closing the gender gap at school (with an average relative annual change of more than $4 \%$ ) and Togo (that has started with a low primary completion rate of roughly $35 \%$ in the 1990s) has made large improvements in overall education. In these two countries progress in one dimension was accompanied by improvements in the other dimension. So, Togo also made some progress in reducing the gender gap at school (i.e. the average relative annual change was around $3.4 \%$ ) and improvements in education have also been made in Mauritania given its low initial value in the primary completion rate in the 1990s (around $30 \%$ ).

On the other hand, there is a group ("2") of 29 countries in which performance has been not very good in the gender gap indicator, whereas improvements in the education-related indicator have been similar to the good performers' group ("1"). Lastly, 11 countries have been categorised as bad performers (group "3") in both indicators. This group includes mainly African countries among which Congo and Djibouti figure out as particularly bad performers.

When pairs of gender gap related indicator and child or maternal mortality indicator are analysed a clear unambiguous distinction between very good and very bad performers somehow vanishes and partial or "moderate" performers seem to be prominent. 
Figure 1. 4 Clusters of performers in educational gender gap and education

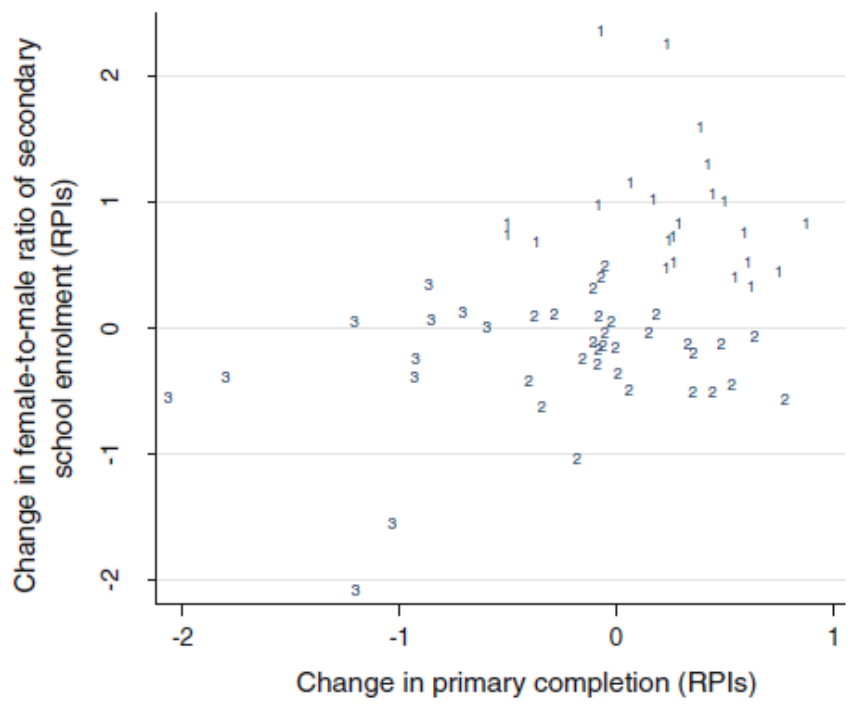

Figure 1.5 shows the cluster analysis of the standardized residuals of both relative average annual changes in the female to male ratio of gross secondary school enrolment and in under-five mortality.

Figure 1. 5 Clusters of performers in educational gender gap and child mortality

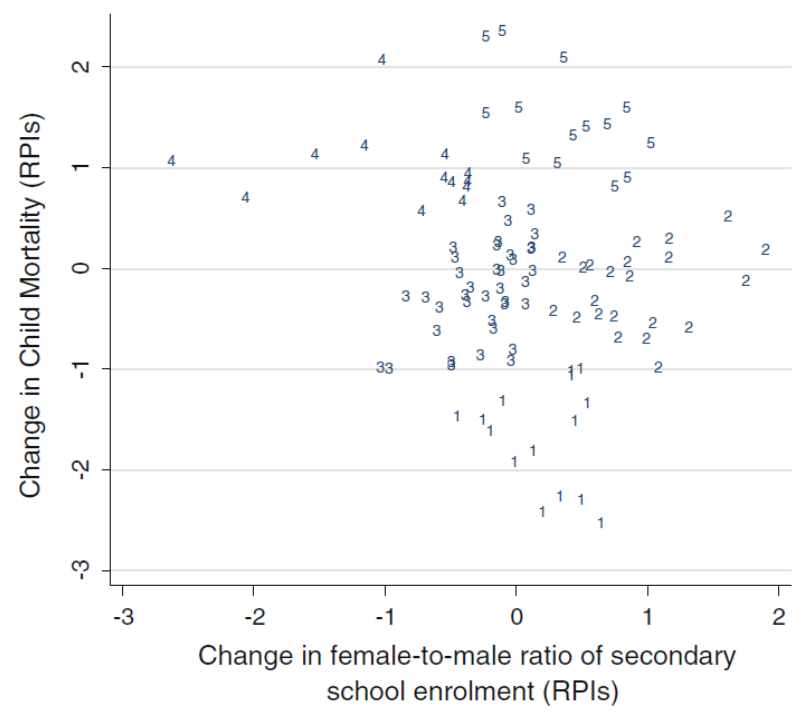

The number of groups, as determined by the larger value of the Calinski/Harabasz pseudo F, is five. Group 1 identifies the "partial-good" performers, i.e. those countries which managed to reduce child mortality and almost closed the gender gap at school. A second group of "partialgood" performers identifies a set of 22 countries that despite larger improvements in the gender gap indicator did not attain large reductions in the under five mortality rate. Group 3 ("partialbad" performers) has a mean value of the child mortality relative performance indicator that is pretty similar to the value of group 2 (see table A8 in Appendix A) but improvements in the gender gap indicator are much worse. This group is larger in terms of countries included and, 
interestingly, many transition economies belong to it. A fourth group of 13 countries is characterised by the "worst performers" in the gender gap indicator as well as in the under-five mortality rate performance indicator.

Lastly, a fifth group ("partial-bad") identifies 14 countries that despite experiencing positive changes in the gender gap relative performance indicator can be considered as the worst performers in child mortality. This group seems to unite heavily AIDS affected countries in Southern Africa (South Africa, Lesotho, Swaziland, and Zimbabwe) and a range of Pacific Island states.

Analysing countries' performance with respect to the educational gender gap and in maternal mortality (Fig.1.6) provides evidence of four possible clusters. Here again, group "1" identifies the "partial-good" performers, while there is a second group which shows a good mean performance in terms of maternal mortality reduction but not in terms of achievements in the gender gap indicator. Symmetrically, a group of 25 simultaneous bad achievers in maternal health and good performers' into the gender-equity dimension appears at the top-right of graph 1.6. Interestingly, the group featuring a joint bad performance in the two indicators gathers some of the very least developed economies (i.e. Sierra Leone, Congo, Central African Republic) as well as many transition economies (i.e. Azerbaijan, Bulgaria, Kyrgyz Republic or Ukraine among others).

Figure 1. 6 Clusters of performers in educational gender gap and maternal mortality

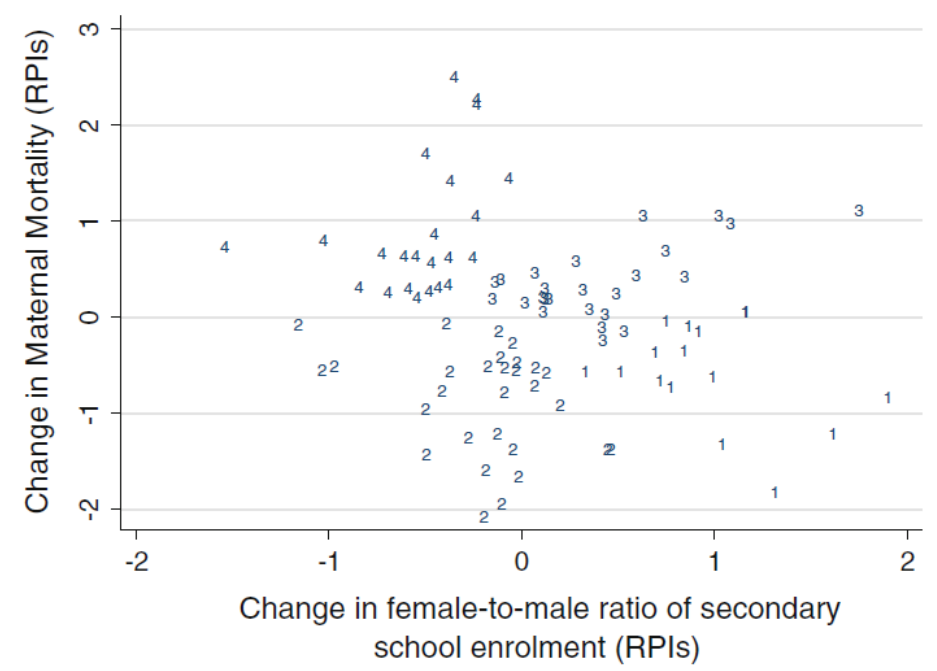

Lastly we consider possible synergies in the achievement of maternal and child mortality goals (Fig. 1.7). The Calinski/Harabasz rule suggests evidence of four distinct clusters. 
There is a group of good performers (group "1") that is characterised by large reductions in both indicators (i.e. RPIs are both ranged below the zero-mean). Conversely, at the top-right corner of graph 10 we can find a group of bad performers mainly composed by sub- Saharan African countries (15 out of 20$)$. At the top-left corner of the graph a group of partial performers is located. These are countries in which progress in the maternal mortality dimension has been accompanied by little progress in the child mortality dimension.

Conversely, a fourth group of 50 countries shows improvements in the child mortality goal but not in the maternal mortality one.

An overview of performance in all of the six bivariate cluster analyses is provided in Table 1.1, where we list how often countries show up in the 'good', the 'bad', and various forms of 'partial' clusters. ${ }^{13}$ While countries like Cape Verde, China, Iran, Laos, Malaysia, Nepal, Syria, Tunisia and Turkey can be highlighted as countries where there are mostly positive synergies in the sense of belonging to the 'good' performance clusters, a group of sub-Saharan countries (Congo, Congo DRC, Swaziland, Central African Republic, Cameroon, Burundi, South Africa and Zimbabwe) plus Guyana have 'negative' synergies and find themselves in the bad cluster in most or all of the analyses. On the other hand, many Latin American countries (like Colombia, Costa Rica, Paraguay, Venezuela and Uruguay) consistently fall in the grey area of partial performance; and transition countries are notable for appearing in a broad range of categories, suggesting that their performance is really quite dependent on the indicator chosen. While we already examined cluster membership in a descriptive sense, it would be useful to have a more formalized assessment of determinants of cluster membership. This is a subject to which we now turn.

Figure 1. 7 Clusters of performers in maternal mortality and child mortality

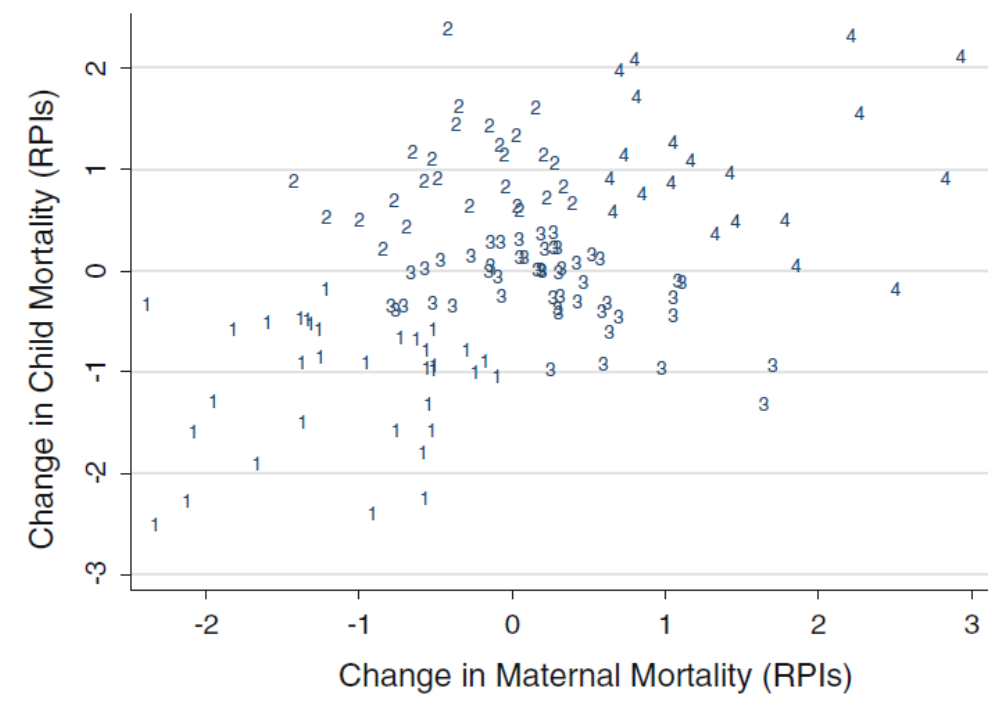

\footnotetext{
${ }^{13}$ Here we only show countries for which we were able to do all six cluster analyses; for all other countries, please see the individual cluster analyses in Appendix A.
} 
Table 1. 1 Overview of joint performance

\begin{tabular}{|c|c|c|c|c|c|}
\hline COUNTRY & "Good" & $\begin{array}{l}\text { "Partial- } \\
\text { good" }\end{array}$ & "Truly Partial" & $\begin{array}{c}\text { "Partial- } \\
\text { bad" }\end{array}$ & "Bad" \\
\hline Algeria & 2 & 1 & 3 & & \\
\hline Belarus & & & 5 & 1 & \\
\hline Bolivia & 3 & & 2 & 1 & \\
\hline Botswana & & & 2 & 1 & 3 \\
\hline Bulgaria & & & 4 & 1 & 1 \\
\hline Burkina Faso & & & 4 & 1 & 1 \\
\hline Burundi & & & 1 & 1 & 4 \\
\hline Cameroon & & & & & 6 \\
\hline Cape Verde & 4 & 1 & 1 & & \\
\hline Central African Republic & & & 1 & 1 & 4 \\
\hline Chad & 1 & & 3 & 1 & 1 \\
\hline China & 4 & 1 & 1 & & \\
\hline Colombia & 1 & & 5 & & \\
\hline Congo, Dem. Rep. & & & & 1 & 5 \\
\hline Congo, Rep. & & & 2 & & 4 \\
\hline Costa Rica & & & 5 & 1 & \\
\hline Cuba & 1 & & 3 & 1 & 1 \\
\hline El Salvador & 3 & 1 & 2 & & \\
\hline Ghana & & & 4 & 1 & 1 \\
\hline Honduras & 1 & 1 & 4 & & \\
\hline India & 2 & 1 & 3 & & \\
\hline Indonesia & 2 & & 4 & & \\
\hline Iran, Islamic Rep. & 4 & 1 & 1 & & \\
\hline Jamaica & & & 3 & 1 & 2 \\
\hline Jordan & 2 & & 3 & 1 & \\
\hline Lao PDR & 3 & 1 & 2 & & \\
\hline Madagascar & & & 4 & 1 & 1 \\
\hline Malaysia & 3 & 1 & 2 & & \\
\hline Mauritius & 1 & & 3 & & 2 \\
\hline Mexico & 2 & 1 & 3 & & \\
\hline Morocco & 3 & & 2 & 1 & \\
\hline Mozambique & 1 & & 3 & 1 & 1 \\
\hline Nicaragua & 2 & & 4 & & \\
\hline Niger & 3 & 1 & 2 & & \\
\hline Papua New Guinea & 1 & 1 & 2 & 1 & 1 \\
\hline Paraguay & & & 5 & 1 & \\
\hline Philippines & 1 & 1 & 4 & & \\
\hline Poland & 3 & & 2 & 1 & \\
\hline Romania & 3 & & 2 & 1 & \\
\hline Sao Tome and Principe & 2 & 1 & 1 & 1 & 1 \\
\hline Senegal & & & 3 & 1 & 2 \\
\hline Solomon Islands & 2 & 1 & 2 & 1 & \\
\hline South Africa & & & 1 & 1 & 4 \\
\hline Sri Lanka & 1 & & 4 & 1 & \\
\hline St. Lucia & 1 & & 4 & 1 & \\
\hline Swaziland & & & & 1 & 5 \\
\hline Syrian Arab Republic & 4 & & 2 & & \\
\hline Tanzania & & & 4 & 1 & 1 \\
\hline Togo & 1 & & 5 & & \\
\hline Tonga & 1 & & 4 & 1 & \\
\hline Tunisia & 4 & 1 & 1 & & \\
\hline Ukraine & & & 3 & & 3 \\
\hline Uruguay & & & 5 & 1 & \\
\hline Venezuela, RB & & & 5 & 1 & \\
\hline
\end{tabular}

Note: Figures reported in cells show the number of cluster analyses for which a given country was identified as "good", "partial good", "truly partial", "partial bad" or "bad". The categories "partial-good" and "partial bad" emerged only in three bivariate cluster analyses and identify countries showing little change in one indicator and sizable improvements (partialgood) or deteriorations (partial-bad) We only show countries for which we were able to perform all six cluster analyses; see the individual cluster analyses in Appendix A for all other countries. 


\subsection{Correlates of Cluster Membership}

In this section we use multinomial logit models to examine the determinants of cluster membership. In particular we investigate the effects of initial (i.e. early 1990s) conditions.

While the literature on the determinants of economic performance is abundant and provides with a long set of possible determinants of performance, here the dependent variable consists of cluster membership on the basis of performance in progress in pairs of non-income indicators.

Our interest is mainly directed towards the effect of institutions, history and the misallocation of resources. Thus we seek to analyze whether these factors affect synergies or trade-offs in MDG progress.

The set of covariates we retained in our analysis includes:

- Institutions measured in terms of government effectiveness. This is an index that could be defined as "the quality of public services, the quality of the civil service and the degree of its independence from political pressures, the quality of policy formulation and implementation, and the credibility of the government's commitment to such policies" (source: Kaufmann et al., 2003). We refer to the 1996 value that is first year available;

- Heterogeneity measured by the index of ethno-linguistic fractionalization provided by Alesina et al. (2003);

- HIV-prevalence given by the percentage of population aged 15-49 who are HIV positive in the early 1990s (source: WDI, 2011);

- Female education relative to male education measured by the female to male ratio of average years of schooling (source: author's calculation based on Barro and Lee, 2010).

We also take into account changes that occurred in the GDP per capita and in the distribution of income. Further, the effect of conflict and political violence is considered in dynamic terms:

- Income inequality absolute changes in the Gini index of income inequality during the 19902008 period serve as proxy variable (source: Povcal);

- Economic growth given by the average annual rate of growth in GDP per capita during the 1990-2000 period (source: WDI, 2011);

- Conflict measured by change in main episodes of political violence occurred during the first decade analyzed (1991-2001) and over the whole period (1991-2008) (source: Marshall and Cole, 2011).

On the basis of the six cluster analyses presented above we run multinomial logistic regressions, considering membership to the good performer group as a reference category. 
Just in two cases (cluster analyses on educational gender gap and child mortality and educational gender gap and maternal mortality) we use the worst performers group as a reference category. ${ }^{14}$ One should point out that we have a rather small numbers of observations and multicollinearity can be a problem here. Thus the results should be interpreted with some caution.

Furthermore, as it is likely that observations belonging to the same region might violate the assumption of independence, we run our regressions correcting for the effects of clustered data and thus obtaining robust standard errors. Our results seem to be robust to other specifications (i.e. inclusion of regional dummies).

Table 1.2 shows the results of multinomial logistic regressions for membership in clusters of performers in education and child health. We report always two specifications, one with GDP growth and one without; the latter specification implies that the effects of some of the independent variables (e.g. institutions, conflict, or income inequality) affect cluster membership via their effect on economic growth. As it is shown below, the specifications without growth tend to show larger and more significant effects.

High growth reduces the likelihood of being in the group of partial or poor performers. When growth is left out, the regressions show that increases in inequality, poor institutions, and high HIV prevalence increase the likelihood of belonging to a partial performer (with poor synergies).

Table 1. 2 Education and child mortality: Effects of country characteristics on group membership

\begin{tabular}{|c|c|c|c|c|}
\hline \multirow{3}{*}{ Economic Growth } & \multicolumn{2}{|c|}{$\begin{array}{l}\text { G2: Partial Performers (child mortality- } \\
\text { lopsided) }\end{array}$} & \multicolumn{2}{|c|}{ G3: Bad performers } \\
\hline & $-0.50^{*}$ & & $-0.64 *$ & \\
\hline & -1.89 & & -1.69 & \\
\hline \multirow[t]{2}{*}{ Conflict } & 0.08 & 0.38 & $0.15^{*}$ & $0.32^{* * *}$ \\
\hline & -0.49 & -1.13 & -1.73 & -3.89 \\
\hline \multirow[t]{2}{*}{ Income inequality } & 0.97 & $1.54^{*}$ & -0.72 & -0.26 \\
\hline & -1.31 & -1.71 & -1.59 & -0.35 \\
\hline \multirow{2}{*}{ Female Education } & $2.90 * * *$ & $-3.05^{* * *}$ & 1.24 & -3.14 \\
\hline & -2.86 & -4.42 & -0.69 & -1.39 \\
\hline \multirow[t]{2}{*}{ Institutions } & -0.16 & $1.69^{* *}$ & -0.16 & 0.62 \\
\hline & -0.21 & -2.56 & -0.18 & -1.03 \\
\hline \multirow{2}{*}{ Fractionalization } & -0.02 & $-0.07 * * *$ & 0.01 & -0.03 \\
\hline & -1.17 & -3.13 & -0.26 & -0.91 \\
\hline \multirow[t]{2}{*}{ HIV } & & $0.57 * *$ & & $0.68^{*}$ \\
\hline & & -2.28 & & -1.76 \\
\hline $\mathrm{N}$ & 51 & 35 & 51 & 35 \\
\hline
\end{tabular}

Note: T stat in italics. Group 2 (child mortality lopsided) is the cluster of partial performers featuring improvements in education and any improvement or even deterioration in child mortality indicator.

Left-out category: good performers ${ }^{*} \mathrm{p}<0.10$; ${ }^{* *} \mathrm{p}<0.05$; ${ }^{* * *} \mathrm{p}<0.01$

Results for membership in clusters of performers in education and maternal health (see Table 1.3) suggest that three main factors could have influenced the partial performance (i.e. relative bad achievements in terms of maternal mortality reduction but not in terms of primary

\footnotetext{
14 While the identification of a group of bad performers is pretty clear in these last two cases, defining a group of best performers to be used as a reference category is not straightforward.
} 
completion rates): increasing levels of political violence, high rates of HIV prevalence, and poor female/male education ratios. Lower rates of economic growth are correlated instead with the two groups of bad performers.

Table 1. 3 Education and maternal mortality: Effects of country characteristics on group membership

\begin{tabular}{|c|c|c|c|c|c|c|}
\hline \multirow[b]{2}{*}{ Economic Growth } & \multicolumn{2}{|c|}{$\begin{array}{c}\text { G2: Partial Performers } \\
\text { (maternal mortality- } \\
\text { lopsided) }\end{array}$} & \multicolumn{2}{|c|}{$\begin{array}{c}\text { G3: Bad } \\
\text { Performers }\end{array}$} & \multicolumn{2}{|c|}{$\begin{array}{l}\text { G4: Partial-Bad } \\
\text { performers }\end{array}$} \\
\hline & $\begin{array}{c}0.08 \\
-0.11\end{array}$ & & $\begin{array}{c}-2.04 * * \\
-2.01\end{array}$ & & $\begin{array}{c}-9.96^{* * *} \\
-13.52\end{array}$ & \\
\hline Conflict & $\begin{array}{c}1.39 * * * \\
-4.89\end{array}$ & $\begin{array}{c}1.44 * * * \\
-5.44\end{array}$ & $\begin{array}{c}1.16^{* * *} \\
-2.69\end{array}$ & $\begin{array}{l}1.50 * * * \\
-5.49\end{array}$ & $\begin{array}{c}12.29 * * * \\
-14.58\end{array}$ & $\begin{array}{c}15.19 * * * \\
-15.77\end{array}$ \\
\hline Income inequality & $\begin{array}{l}-0.92 \\
-0.53\end{array}$ & $\begin{array}{l}-0.99 \\
-0.58\end{array}$ & $\begin{array}{l}-1.49 \\
-1.05\end{array}$ & $\begin{array}{l}-0.68 \\
-0.44\end{array}$ & $\begin{array}{c}-7.31 * * * \\
-4.75\end{array}$ & $\begin{array}{c}-3.05^{*} \\
-1.78\end{array}$ \\
\hline Female education & $\begin{array}{c}-6.73 * * \\
-2.10\end{array}$ & $\begin{array}{l}-7.37 * * \\
-2.17\end{array}$ & $\begin{array}{l}-5.91 * \\
-1.86\end{array}$ & $\begin{array}{c}-7.03 * * \\
-2.10\end{array}$ & $\begin{array}{c}-40.99 * * * \\
-14.31\end{array}$ & $\begin{array}{c}-131.21^{* * *} \\
-20.94\end{array}$ \\
\hline Institutions & $\begin{array}{l}-1.12 \\
-0.34\end{array}$ & $\begin{array}{l}-1.09 \\
-0.47\end{array}$ & $\begin{array}{l}3.77 \\
-0.98\end{array}$ & $\begin{array}{l}1.69 \\
-0.72\end{array}$ & $\begin{array}{l}1.57 \\
-0.52\end{array}$ & $\begin{array}{c}-46.53 * * * \\
-7.55\end{array}$ \\
\hline Fractionalization & $\begin{array}{c}-0.10^{* * *} \\
-2.92\end{array}$ & $\begin{array}{c}-0.10^{* * *} \\
-3.62\end{array}$ & $\begin{array}{c}-0.13^{* * *} \\
-3.80\end{array}$ & $\begin{array}{c}-0.10^{* * *} \\
-3.54\end{array}$ & $\begin{array}{c}-0.35^{* * *} \\
-12.57\end{array}$ & $\begin{array}{c}-1.01 * * * \\
-20.08\end{array}$ \\
\hline HIV & $\begin{array}{l}5.73 * * \\
-2.06\end{array}$ & $\begin{array}{l}6.05^{*} \\
-1.89\end{array}$ & $\begin{array}{c}6.62^{* *} \\
-2.48\end{array}$ & $\begin{array}{c}6.72 * * \\
-2.2\end{array}$ & $\begin{array}{c}8.30 * * * \\
-3.11\end{array}$ & $\begin{array}{c}16.86^{* * *} \\
-5.34\end{array}$ \\
\hline $\mathrm{N}$ & 34 & 34 & 34 & 34 & 34 & 34 \\
\hline
\end{tabular}

Table 1.4 shows results for regressions run on membership in clusters of performance in education (improvements in primary completion rate) and gender gap at school (improvements in closing the female to male ratio of secondary school enrolment). The higher the increase experienced in income inequality the more likely will be the risk of experiencing a trade-off in the two dimensions, i.e. of advancing towards universal primary education but lagging behind in terms of ensuring gender parity at secondary educational level. This shows that rising inequality can significantly disrupt synergies between MDG achievements in the education field. Moreover, we find a positive effect of female years of education on the likelihood to belong to the partial performer group. This suggests that countries with relatively low initial gender gaps in schooling performed relatively worse in further closing gender gaps, relative to their success in overall educational expansion.

Lastly, the group of partial performers is associated with a decrease in main episodes of political violence. This result seems to be driven mainly by countries which — until the early 1990s—all experienced dramatic episodes of civil or ethnic conflict (i.e. South Africa, Sri Lanka, Turkey and Mozambique) or of political unrest (i.e. El Salvador and the Philippines), with strong negative repercussions on the education system. Once these countries embarked on a transition path towards more peaceful regimes, all the progress made in the reconstruction of the education 
system necessarily appeared to be relatively fast even though the efforts made in closing the gender gap at school have been, at best, less remarkable.

Table 1. 4 Education and educational gender gap: Effects of country characteristics on group membership

\begin{tabular}{|c|c|c|c|c|c|c|}
\hline \multirow[b]{2}{*}{ Economic Growth } & \multicolumn{3}{|c|}{ G2: Partial Performers (education-lopsided) } & \multicolumn{3}{|c|}{ G3: Bad Performers } \\
\hline & 0.29 & & 0.08 & $-1.82^{*}$ & & $-1.60 * *$ \\
\hline \multirow{3}{*}{ Conflict } & -0.71 & & -0.19 & -1.78 & & -2.20 \\
\hline & $-0.32^{* * *}$ & $-0.34 * * *$ & $-0.28 * * *$ & -0.41 & -0.11 & -0.66 \\
\hline & -6.20 & -4.92 & -2.86 & -0.42 & -0.45 & -0.61 \\
\hline \multirow[t]{2}{*}{ Income inequality } & 2.72 & 2.4 & $2.57 *$ & -4.29 & -1.93 & -4.48 \\
\hline & -1.47 & -1.49 & -1.83 & -0.73 & -0.74 & -0.83 \\
\hline \multirow{2}{*}{ Female education } & $5.68^{* *}$ & 4.36 & 3.27 & 6.78 & 0.89 & 7.89 \\
\hline & -2.12 & -1.49 & -1.24 & -0.99 & -0.63 & -1.38 \\
\hline \multirow[t]{2}{*}{ Institutions } & -0.05 & 0.69 & 0.69 & -1.25 & -2.4 & -1.45 \\
\hline & -0.22 & -0.89 & -1.08 & -0.39 & -1.04 & -0.54 \\
\hline \multirow{2}{*}{ Fractionalization } & 0.03 & 0.02 & & -0.02 & -0.02 & \\
\hline & -0.75 & -0.61 & & -1.00 & -1.05 & \\
\hline \multirow[t]{2}{*}{ HIV } & 0.09 & 0.12 & 0.24 & -0.37 & 0.07 & -0.45 \\
\hline & -0.57 & -0.84 & -1.63 & -0.42 & -0.22 & -0.64 \\
\hline $\mathrm{N}$ & 32 & 32 & 32 & 32 & 32 & 32 \\
\hline
\end{tabular}

Note: T stat in italics. Group 2 (education lopsided) is the cluster of partial performers featuring improvements in education and any improvement or even deterioration in educational gender gap indicator.

Left-out category: good performers. ${ }^{*} \mathrm{p}<0.10 ; * * \mathrm{p}<0.05 ; * * * \mathrm{p}<0.01$

Considering the possible drivers of synergies in clusters of performers in educational gender equity and maternal health (Table 1.5), we observe from the analysis that while there are two groups of partial performers (group " 2 ", relatively good in achievements in maternal health and group " 3 ", relatively good in the gender dimension), one group ("4") clearly performing bad in both dimensions, and another group ("1") of "partial-good" countries showing large improvements in the gender dimensions but narrow improvements in maternal health, there is no clear picture of joint good performance at all. Hence, as pointed out above, the reference group is the group of worst performers. Interestingly, here again, the two truly partial performers have experienced a deterioration in the income distribution.

In other words, as income inequality rose, improvements in closing gender gaps or in reducing maternal mortality did not promote the other goal.

Also, partial performance in the bi-dimensional cluster of child health and gender equity (taking the worst group as the benchmark) seems to be associated with increase in income inequality whereas a key driver for joint bad performance (i.e. our reference category) can be found in the poor institutional framework (see Table 1.6). 
Table 1. 5 Educational gender gap and maternal mortality: Effects of country characteristics on group membership

\begin{tabular}{|c|c|c|c|c|c|c|}
\hline \multirow{3}{*}{ Economic Growth } & \multicolumn{2}{|c|}{$\begin{array}{l}\text { G1: Partial-Good } \\
\text { Performers (educational } \\
\text { gender equity -lopsided) }\end{array}$} & \multicolumn{2}{|c|}{$\begin{array}{l}\text { G2: Partial Performers } \\
\text { (maternal health- } \\
\text { lopsided) }\end{array}$} & \multicolumn{2}{|c|}{$\begin{array}{l}\text { G3: Partial Performers } \\
\text { (educational gender } \\
\text { equity-lopsided) }\end{array}$} \\
\hline & $0.55^{* * *}$ & & $1.07 * *$ & & 0.31 & \\
\hline & -4.53 & & -2.04 & & -0.72 & \\
\hline \multirow[t]{2}{*}{ Conflict } & 0.65 & 0.39 & -0.93 & $-0.48^{*}$ & $1.75^{* * *}$ & $1.61^{* * *}$ \\
\hline & -1.47 & -1.46 & -1.13 & -1.77 & -8.89 & -14.14 \\
\hline \multirow[t]{2}{*}{ Income inequality } & $4.54 * * *$ & $3.96 * * *$ & $10.63^{* * *}$ & $7.96^{* * *}$ & $5.56 * * *$ & $4.76^{* * *}$ \\
\hline & -24.48 & -10.18 & -2.98 & -4.62 & -4.93 & -9.55 \\
\hline \multirow[t]{2}{*}{ Female education } & $-8.41 * *$ & -6.91 & 24.35 & $12.15^{* *}$ & -3.06 & -2 \\
\hline & -1.98 & -1.60 & -1.3 & -2.2 & -0.59 & -0.71 \\
\hline \multirow[t]{2}{*}{ Institutions } & -0.15 & 1.32 & -1.54 & -0.05 & 0.56 & 0.95 \\
\hline & -0.06 & -0.72 & -1.35 & -0.07 & -0.63 & -0.86 \\
\hline \multirow[t]{2}{*}{ Fractionalization } & -0.04 & -0.03 & -0.02 & -0.03 & -0.01 & -0.01 \\
\hline & -0.96 & -0.85 & -1.62 & -1.28 & -0.33 & -0.36 \\
\hline \multirow[t]{2}{*}{ HIV } & 0 & 0.05 & $-0.58^{* * *}$ & $-0.50^{* * *}$ & $-0.50 * *$ & $-0.46 * * *$ \\
\hline & -0.1 & -0.46 & -5.36 & -7.24 & -2.34 & -2.74 \\
\hline $\mathrm{N}$ & 40 & 40 & 40 & 40 & 40 & 40 \\
\hline
\end{tabular}

Note: T stat in italics. Group 2 (maternal health lopsided) is the cluster of partial performers featuring improvements in the maternal mortality indicator and any improvement or even deterioration in the educational gender gap indicator. Group 3 (educational gender equity lopsided) is the cluster of partial performers featuring improvements in the educational gender gap indicator and any improvement or even deterioration in the maternal mortality indicator. Left-out category: bad performers. ${ }^{*} \mathrm{p}<0.10 ; * * \mathrm{p}<0.05 ; * * * \mathrm{p}<0.01$

Table 1. 6 Educational gender gap and child mortality: Effects of country characteristics on group membership

\begin{tabular}{|c|c|c|c|c|c|c|c|c|}
\hline \multirow{3}{*}{ Economic Growth } & \multicolumn{2}{|c|}{$\begin{array}{l}\text { G1: Partial-Good } \\
\text { Performers (child } \\
\text { health-lopsided) }\end{array}$} & \multicolumn{2}{|c|}{$\begin{array}{l}\text { G2: Partial-Good } \\
\text { Performers } \\
\text { (educational gender } \\
\text { equity-lopsided) }\end{array}$} & \multicolumn{2}{|c|}{$\begin{array}{c}\text { G3: Partial-bad } \\
\text { Performers } \\
\text { (educational gender } \\
\text { gap-lopsided) }\end{array}$} & \multicolumn{2}{|c|}{$\begin{array}{c}\text { G5: Partial Bad } \\
\text { Performers (child } \\
\text { mortality-lopsided) }\end{array}$} \\
\hline & 0.67 & & 0.34 & & 0.21 & & -0.08 & \\
\hline & -0.69 & & -0.33 & & -0.21 & & -0.1 & \\
\hline \multirow[t]{2}{*}{ Conflict } & -1.06 & $-0.93 * * *$ & -0.79 & -0.61 & -1.05 & -0.87 & -1.07 & -0.89 \\
\hline & -0.96 & -3.02 & -0.64 & -1.36 & -0.78 & -1.53 & -0.74 & -1.29 \\
\hline \multirow[t]{2}{*}{ Income inequality } & $1.15^{* * *}$ & $1.25^{* *}$ & $2.16^{* * *}$ & $2.19 * * *$ & $2.15^{* * *}$ & $2.06^{*}$ & 1.23 & 1.07 \\
\hline & -2.73 & -2.21 & -3.66 & -13.41 & -2.71 & -1.65 & -1.57 & -0.76 \\
\hline \multirow{2}{*}{ Female education } & -2.67 & $-2.48^{*}$ & $-5.63 * * *$ & $-5.70 * * *$ & $-4.05^{* * *}$ & $-3.99 * *$ & 0 & -0.17 \\
\hline & -1.04 & -1.74 & -3.90 & -4.74 & -4.08 & -2.42 & 0 & -0.05 \\
\hline \multirow[t]{2}{*}{ Institutions } & 2.83 & 4.12 & 4.21 & 4.92 & $3.41 *$ & 3.82 & 4.54 & 4.3 \\
\hline & -1.31 & -1.17 & -1.4 & -1.12 & -1.78 & -1.16 & -1.15 & -0.94 \\
\hline \multirow[t]{2}{*}{ Fractionalization } & 0 & -0.02 & 0 & 0 & -0.02 & -0.02 & $-0.04 * * *$ & -0.04 \\
\hline & -0.04 & -0.61 & -0.02 & -0.07 & -0.37 & -0.47 & -2.58 & -1.56 \\
\hline \multirow[t]{2}{*}{ HIV } & -0.21 & -0.18 & 0.07 & 0.12 & 0.01 & 0.04 & -0.09 & -0.03 \\
\hline & -0.59 & -0.45 & -0.42 & -0.54 & -0.07 & -0.16 & -0.55 & -0.14 \\
\hline $\mathrm{N}$ & 44 & 44 & 44 & 44 & 44 & 44 & 44 & 44 \\
\hline
\end{tabular}

Note: T stat in italics. Groups 1 and 2 are the cluster of partial—good performers featuring relatively better achievements in child health ("child-health lopsided") or in the educational gender gap indicator ("educational gender equity lopsided"). Groups 3 and 5 are the cluster of partial—bad performers featuring any improvement or even deterioration in the educational gender gap indicator ("educational gender gap lopsided") or in the child mortality indicator ("child mortality lopsided"). Left-out category: bad performers. ${ }^{*} \mathrm{p}<0.10 ;{ }^{* *} \mathrm{p}<0.05$; ${ }^{* * *} \mathrm{p}<0.01$

Lastly, results displayed in Table 1.7 for membership in cluster of performers in both child and maternal health suggest that three main factors would increase the risk of partial performance: 
low institutional level, high HIV prevalence and increasing levels in political violence during the first decade.

Table 1. 7 Child mortality and maternal mortality: Effects of country characteristics on group membership

\begin{tabular}{|c|c|c|c|c|c|c|}
\hline \multirow{2}{*}{ Economic } & \multicolumn{2}{|c|}{$\begin{array}{l}\text { G2: Partial Performers } \\
\text { (child mortality lopsided) }\end{array}$} & \multicolumn{2}{|c|}{$\begin{array}{c}\text { G3: Partial Performers } \\
\text { (maternal mortality - } \\
\text { lopsided) }\end{array}$} & \multicolumn{2}{|c|}{$\begin{array}{c}\text { G4: Bad } \\
\text { Performers }\end{array}$} \\
\hline & & & & & & \\
\hline \multirow{2}{*}{ Growth } & -0.22 & & 0.11 & & -0.41 & \\
\hline & -1.24 & & -0.37 & & -0.86 & \\
\hline \multirow[t]{2}{*}{ Conflict } & 0.77 & $0.72 *$ & 0.25 & 0.23 & 0.67 & $0.46^{*}$ \\
\hline & -0.96 & -1.81 & -0.79 & -0.76 & -1.4 & -1.77 \\
\hline \multirow[t]{2}{*}{ Income inequality } & -1.39 & -1.48 & -1.41 & -1.33 & -1.36 & -1.41 \\
\hline & -1.21 & -1.19 & -1.34 & -1.57 & -1.11 & -1.30 \\
\hline \multirow[t]{2}{*}{ Female education } & -0.77 & -1.44 & 0.15 & 0.38 & $5.41 * * *$ & $5.23^{* *}$ \\
\hline & -0.21 & -0.39 & -0.08 & -0.18 & -3.14 & -2.12 \\
\hline \multirow[t]{2}{*}{ Institutions } & -0.87 & -1.16 & $-0.60^{*}$ & -0.48 & 1.02 & 0.18 \\
\hline & -0.95 & -1.55 & -1.91 & -0.91 & -0.74 & -0.19 \\
\hline \multirow[t]{2}{*}{ Fractionalization } & -0.01 & -0.01 & 0.02 & 0.02 & $0.04 *$ & $0.05^{* *}$ \\
\hline & -0.32 & -0.35 & -1.11 & -1.34 & -1.65 & -2.08 \\
\hline \multirow[t]{2}{*}{ HIV } & 0.9 & 0.99 & $1.27 *$ & $1.28^{*}$ & $1.55^{* *}$ & $1.49^{* *}$ \\
\hline & -1.29 & -1.38 & -1.69 & -1.65 & -2.03 & -2.17 \\
\hline $\mathrm{N}$ & 55 & 55 & 55 & 55 & 55 & 55 \\
\hline
\end{tabular}

Note: T stat in italics. Group 2 (child mortality lopsided) is the cluster of partial performers featuring improvements in maternal health and any improvement or even deterioration in the child mortality indicator. Group 3 (maternal mortality lopsided) is the cluster of partial performers featuring improvements in child health and any improvement or even deterioration in maternal mortality indicator. Left-out category: good performers ${ }^{*} \mathrm{p}<0.10 ;{ }^{* *} \mathrm{p}<0.05 ; * * * \mathrm{p}<0.01$

Moreover, we find a positive correlation between initial levels of female education and bad performance. This last finding is a bit surprising to us since we expected that the effect of female education would benefit both child health and education. This result seems to be driven by a small group of countries such as South Africa, Swaziland, Kenya, Jamaica, Gabon, Panama, Fiji, Ukraine, Tonga, Zimbabwe and Congo that-despite having started with a relatively high average female years of schooling experienced the largest increase in child mortality rates. This fact is probably highly due to high infectious disease prevalence including HIV/AIDS, wars, epidemics and famines.

Summarizing the findings across the analyses suggests that economic growth, not surprisingly, seems to be a very robust driver of determining whether countries are in a group of good versus bad performers. In low growth environments, negative synergies feed on each other, while in high growth environments the opposite is the case. More interestingly, increases in inequality and poor institutional quality are particularly important in weakening synergies between MDG achievements, thus placing more countries in the group of mixed performers. 


\subsection{Robustness Checks}

Presumably, the positive effect with which a given MDG (i.e. education) could influence the speed or the intensity of the improvement in another MDG (i.e. health) could not be immediate. From a micro-perspective we know that some time is needed in order to translate knowledge and skills learnt at school into "good" practices concerning, for example, proper feeding, care during illness, hygiene behaviour, not to mention even future decision on investment on own children's health and education.

As our RPIs used in the cluster analyses refer to quite long time period of 18 years, shorter time lags in the transmission of MDG progress are already taken into account in the analysis we presented above.

Nevertheless, as a robustness check, we performed several additional cluster analyses which try to more carefully address this time lag issue. Specifically, worthy of note are four cluster analyses in which we matched our RPIs computed for the education and the educational gender gap goal over the first decade (1990-1999) to those related to child and maternal mortality over the second period of analysis (2000-2008).

The majority of countries which in earlier cluster analyses stood out as good or bad performers keep the same label when time lags are taken into account. Nevertheless in a few cases the classification changes. China, Morocco and Turkey, for example, which were listed as "good" performers in education and child health, displayed only partial performance in the time-lags cluster analysis of these two dimensions. This is mainly attributable to the fact that progress in education in the first decade in these countries was not as large as the improvements made in reducing child mortality during the following period; another way of saying this is that these countries managed to achieve reductions in child mortality in the second decade without much prior expansion in education in the first. On the other hand, Swaziland moves from the bad to the partial performer category since despite negative values of its education RPI in the first decade, the country experienced substantial achievements in reducing child mortality (in the period 2000-2008).

Last, another interesting case is Thailand which — for the bivariate cluster analysis of educational gender gap and maternal mortality — moves from the group of partial performers (being lopsided towards positive achievements in the gender equity dimension) to the group of bad performers. Indeed, when considering time lags, as it is also visible from Fig. 1.8, this country made relatively low progress in closing the gender gap during the first decade and also performed badly in the maternal mortality dimension during the following period. 
When looking at the whole period (Fig. 1.9) we can see that this country, despite maintaining its bad performance in maternal mortality, recorded over the years 1990-2008, extraordinary good achievements in the gender equity dimension. To the extent that synergies exist, one could hope for faster improvements in reducing maternal mortality after 2008.

Figure 1. 8 Clusters of performers in educational gender gap (1990-99) and maternal mortality (2000-08)

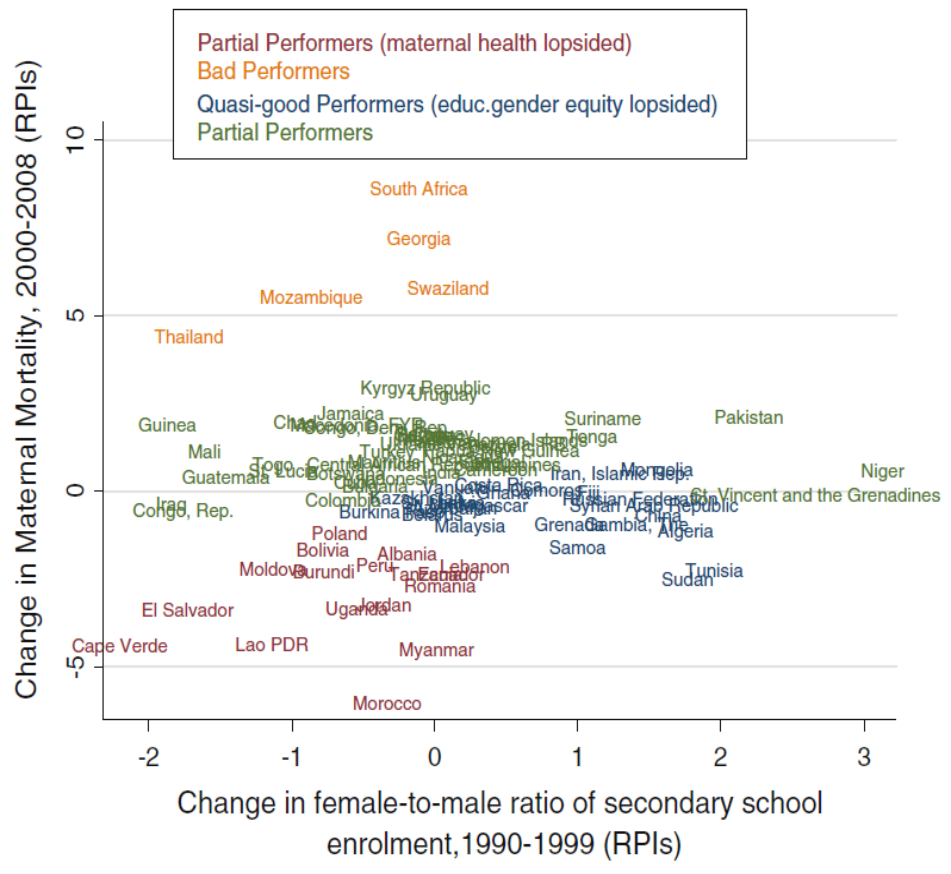

Figure 1. 9 Clusters of performers in educational gender gap (1990-2008) and maternal mortality (19902008)

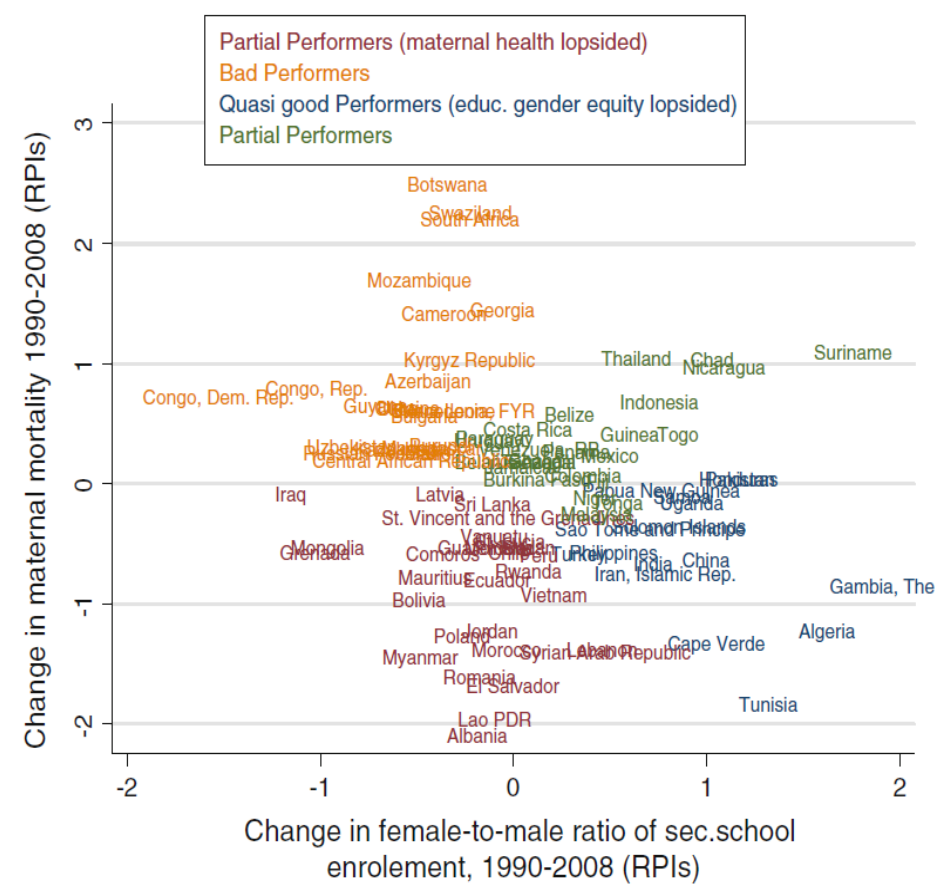


In short, this brief discussion suggests two things. First, the key findings from our cluster analysis are rather robust to considering longer time lags; cluster membership does not change much when time lags are considered. Second, there are notable exceptions which are well worth investigating further as they point to interesting dynamics in the relationship between the two MDG variables.

\subsection{Concluding Remarks}

In this paper we investigate synergies and complementarities between MDGs in order to evaluate whether indeed there are close synergies in reaching MDGs. As our cluster analysis has shown, there are synergies, but only for a restricted group of countries (the 'good' performers where progress goes hand in hand, and the 'bad performers' where regress goes hand-in-hand). For a sizable number of countries, the synergies seem to be weak or absent, leading to contrary movements in MDG progress in non-income MDGs. In fact, it appears that for a majority of countries, there are such contrary movements at least in one or two pairs of MDG indicators. Such 'partial' performers are particularly concentrated in Latin America and transition countries, but there are country examples throughout. Our robustness analysis investigates time lags and finds them to play only a small role in the assigning cluster membership.

When investigating the determinants of cluster membership, we first note that GDP growth is the most robust determinant of cluster membership. It is particularly powerful in distinguishing good from bad performers, but also has some impact on distinguishing good from partial performers. When it comes to partial performers, changes in inequality and institutional quality are key variables. Rising inequality and low institutional quality are key factors affecting partial performers.

We should mention that this is largely a descriptive exercise that cannot make definitive statements on causality. Also, there are some data-related problems that suggest caution in interpreting the results. For example, some indicators require careful interpretation, including the primary enrolment rate and the gender gap both of which can exceed $100 \%$.

Also, the majority of developing countries are very close to (or have already reached) the MDG 2 and MDG 3 related-targets but, since the rationales of these two goals should embody the high intrinsic value of education and of gender parity, real performance should take into account some measure of educational quality, that is certainly not a minor issue for the consolidation of human capital. As it was also implicitly noted by Caldwell's seminal paper (1992), in order to really find out how the education-health link works a greater focus on educational quality is needed. Second, our RPIs can be considered as a better measure of actual performance than 
absolute change or distance to goal. But of course there are other ways to formulate benchmarks to measure progress.

Third, cluster analysis itself has some limitations. Observations situated in the border line between two clusters (but finally assigned by the algorithm to one of them) are not greatly different to adjacent observations. Yet, to simply establish ex ante cut-offs for delimiting groups could be even a more problematic and arbitrary approach.

Fourth, the realm of possible determinants of group membership may well be larger than the set of covariates we referred to in our analysis. Physical infrastructures, actual access to medical, sanitation and education facilities are, for example, interesting factors that could have influenced transmission channels among different MDGs. Still, we were limited by the lack of reliable and/or available data for early 1990s.

Nonetheless, our first exploration in the area of partial MDG performance can allow us to trace out clearly some elements which have hindered transmission channels between some of the millennium goals. These suggestive results can provide for more detailed analyses of these linkages at the micro level.

A key message from our findings is that economic growth, accompanied by steady or declining inequality, and a strong institutional framework is not only critical for income poverty reduction but appears to also improve synergies between MDG achievements. For the post-2015 framework, our results suggest that one cannot presume that focusing on a few goals will, via synergies and complementarities, achieve broad progress in non-income dimensions of wellbeing. Thus one needs either to ensure that policies target achievements in a broad set of dimensions or that a policy framework is adopted that maximizes these synergies. Our analysis here may guide further research to develop such a policy framework. 


\title{
Essay 2
}

\section{What drives child health improvements in Indonesian households? A longitudinal analysis.}

\begin{abstract}
Using panel data from Indonesia, this paper analyzes the short and long-term determinants of child undernutrition. I estimate a random effect model modified with Mundlak's corrections in order to control for endogeneity biases that may arise due to correlation of unobserved heterogeneity and observed explanatory variables. Results show that maternal education has a positive and long term effect on child health which is partly reflected in reproductive behaviour and partly conveyed through child caring practices. Whereas lack of sanitation and access to health facilities also strongly affect children in terms of anthropometric outcomes, the effect of household income appears to be present only in the short term.
\end{abstract}




\subsection{Introduction}

It is well documented that malnutrition is damaging to child development, with negative repercussions on a number of human development dimensions at current and later stages of a child's life (Aldermann et al., 2001a; Glewwe et al., 2001; Grossmann, 2006).

Inspired by the pioneering article by Caldwell (1979), previous empirical research has extensively argued that one of the most important factors that can contribute to improving a child's health or nutritional status is maternal education. Better educated mothers are indeed supposed to be more capable of earning money and might also be better at processing information and acquiring skills to take care of the children (Victora, Smith, Vaughan, 1986; Clealand and Van Ginneken, 1988; Defo, 1997). Alternatively, income alone may play an independent role in enhancing a child's health as having more resources available to a household should translate into higher expenditures on food and health. Moreover, lack of access to material resources and meager living conditions may actually represent the most important obstacle to being adequately nourished and healthy (see, inter alia, Esrey et al., 1991; Rutstein, 2000; Wang 2003).

Nonetheless, the mechanisms lying behind the relationship that links child health, mother's education and household wealth still remains an important field of research as up until present day; there seems to be no clear consensus on the transmission channels that lead to better health outcomes. In particular, a number of studies have failed to find a strong causal association between maternal education and child health outcomes and to indisputably determine the mechanisms through which this relationship works (Aslam and Kingdon, 2012). The main reason for this mixed evidence relates to the econometric challenges in the estimation of the child health production function which relates health outcomes to endogenous inputs.

This paper uses longitudinal survey data from Indonesia to explain the variation that occurs over time and across households in child nutritional status and to explore the channels though which mother's education and household income exert their effect on child health. I estimate a random effect model modified with the Mundlak's corrections in order to better account for the relatively larger 'between' variation that is found in the data, and to address most relevant concerns on endogeneity bias.

This article contributes to improving the previous literature on the determinants of child health in a number of aspects which have thus far only received limited attention. First, I argue that these determinants of undernutrition operate in a dynamic framework involving substantial time lags, an idea that is rarely captured in the literature. The vast majority of published studies on this issue has solely relied on cross-sectional data -which although being useful in providing information on the total effect of maternal education and income-arguably does not inform us of 
the pathways through which these variables operates. Repeated observations which are available in longitudinal data have the advantage of improving the efficiency through which the relationship between these key factors can be assessed, as this data allows one to control for both the observables and the unobservables that often invalidate purely cross-sectional analyses. Moreover, the use of panel data offers a great advantage over cross-sectional datasets, since it allows one to analyse the intertemporal connections between child health and its determinants and to answer, therefore, the question of what drives the evolution of child health over time.

Second, the econometric model I use allows us to properly identify the short and long term effect of community, household and individual level variables on child health outcomes while accounting for household-level unobserved heterogeneity and-at the same time-considering the variation occurring between households.

Third, as the main focus of this study is on the dynamics of the relationship that links child nutrition, household income poverty and female education, this paper also aims at advancing our understanding of the complementarities which exist at the household level between different Millennium Development Goals (or MDGs, hereafter).

Currently, the studies relying on cross-country data provide us with quite mixed evidence supporting the existence and strength of the complementarities between child health and other income and non-income related MDGs indicators (Bourguignon et al., 2008a; Lo Bue and Klasen, 2013). A plausible explanation for these mixed findings provided in the macro studies could be related to the fact that important child and household characteristics which represent the bulk of the variation in models of child health are lost in the aggregation process at the national level.

Last, this study contributes to analyzing past trends and dynamics of development in child health in Indonesia focusing specifically on the role played by several socio-economic and infrastructural factors in hampering or fuelling improvements in child health conditions. While now some progress has been made, malnutrition still remains a serious challenge for the country (Unicef, 2013). The results of this study may therefore contain some indications for policy makers on the sectors where resources can be invested in order to accelerate reductions in child malnutrition.

The remainder of this paper proceeds as follows: the next section provides the literature background on the determinants of child health, from both theoretical and empirical perspectives. Section 2.3 describes the data and outlines the main trends in child health outcomes and its determinants. In Section 2.4 I discuss the empirical methodology used while in Section 2.5 I present the empirical findings. Section 2.6 concludes. 


\subsection{Drivers of child health achievements: theory and evidence}

\subsubsection{The conceptual model}

Based on Mosley and Chen (1984) as well as Schultz (1984), child health attainments can be seen as the outcomes of a production process which can be formalized as:

$$
H_{i}=f\left(b_{i}, E_{i}, S E_{i}, I_{i}\right)
$$

where $b_{i}$ is the biological endowment of the child, $E_{i}$ is the local health environment where the child lives including exogenous supplied health inputs at the community level (i.e. availability of health posts), and $S E_{i}$ is a vector of the socioeconomic determinants of child health. These last variables are set at the household level and include the parental level of education and household income (or wealth).

Household's wealth or income mainly contributes to enhancing child health outcomes via raising expenditures on food and health goods. Parental education, on the other hand, exerts an indirect positive role on child health through its effect on household income as well as through better skills and knowledge on child caring practices which directly translate into better child health outcomes. $I_{i}$ represents a vector of proximate or intermediate determinants of the health status of the child which include factors that are common across children living in the same household (e.g. access to piped water, sanitation, and maternal health conditions) as well as inputs which are child specific (e.g. maternal age at birth and child care practices such as breastfeeding).

It is of crucial importance to note that household and individual characteristics not only interact with each other but also with external factors, such as those linked to social norms, and traditions which can directly influence parental decisions regarding, for example, nutrition choices and health practices for their offspring. On the other hand, the effect of some crucial community-level variables such as the availability of vaccines and the presence of a health facility can interact positively or negatively with household and individual-level characteristics such as the willingness to use and the ability to pay for health services.

\subsubsection{Past empirical studies}

A large number of studies have analyzed empirically the determinants of child health; but they have done so using different approaches (Hill, Bicego et al., 2001; Lay and Robilliard, 2009). Many of them have only partially relied on the Mosley and Chen's framework by investigating either the relationship between the socio-economic factors and the proximate determinants of child health or the relationship between these latter and child health outcomes. 
There is, however, a strand of the empirical literature that has attempted to include both socioeconomic and proximate determinants in the estimation strategy. This approach appears to be more complete since it empirically traces all the links identified in the above-specified theoretical framework.

Some of these studies (i.e. Caputo et al., 2003 and Foraita et al., 2008) have relied on graphical chain models to model the dependence chain of the immediate, intermediate and underlying factors affecting undernutrition and find that mother's education has strong indirect linkages to undernutrition through the effect that it has on important proximate factors such as the access to vaccination, the availability of water and breastfeeding practices.

Several other contributions have instead applied regression models and similarly found birth intervals, breastfeeding, birth order and maternal health to be significant on child stunting once controlling for important socio-economic variables such as maternal education or household wealth (Sommerfelt and Stewart, 1994; Forste, 1998; Boerma et al., 1991; Harttgen et al., 2013). Lastly, part of this literature has linked the socio-economic factors and child health outcomes through focusing more on the role of certain mediating factors such as mothers' health knowledge (Thomas, Strauss and Henriques; 1991; Glewwe, 1999), modern attitudes about health care, autonomy, reproductive behaviour (Frost et al., 2005) and immunization decisions (Aslam and Kingdon, 2012).

While all of these studies have undoubtedly contributed to a better understanding of the determinants of child health in developing countries, it is worth noting the presence of some limitations in this empirical literature.

As of today, the vast majority of published studies in this field have solely relied on crosssectional data and thus has not been able to follow the child's growth process over time and to examine the time-varying effects of the explanatory variables. In other words, while much is known about the total effect of key variables on child health, relatively less attention has been paid so far to the dynamics through which this effect is conveyed over time.

Moreover, as also pointed out in Lay and Robilliard (2009), in practice data availability constraints and measurement problems do not allow for a complete inclusion of all the possible determinants of child health. Even in cases where most of the proximate determinants are controlled for, the validity of the results may be questioned (Aslam and Kingdon, 2012). This is basically because of endogeneity issues which only a relatively small numbers of studies attempted to solve with the inclusion of household or community fixed effects (e.g. Strauss; 1990; Desai and Alva, 1998) or with instrumental variables approaches (e.g. Thomas, Strauss and Henriques; 1991; Sahn and Aldermann, 1997; Glewwe, 1999; Aslam and Kingdon, 2012). 
Lastly, in many studies the variables associated with the local health environment or any other kind of community level variables have not always been included. This may be one of the main reasons why-as noted by Frost et al. (2005)-the arguments which have propped up the thesis that reproductive factors are the transmission channels linking socio-economic variables and child morbidity or mortality have found mixed empirical support.

This paper aims at extending prior literature and overcoming some of its limitations, by means of employing longitudinal data and applying a consistent econometric methodology in order to explain the variation over time and across households in child nutritional status. The study will additionally assess the role played by income and parental education and identify the channels though which these socio-economic determinants influenced child health achievements.

\subsection{Data and Descriptive Statistics}

The data used in this analysis are from the Indonesia Family Life Survey (IFLS), a panel of individuals, households, communities and facilities that were traced in 1997 (IFLS2), 2000 (IFLS3), and 2007 (IFLS4) $^{15}$.

This data is representative for about 83 percent of the Indonesian population, covers 13 major provinces out of a total of 33 in Indonesia and shows a relatively low rate of attrition between waves (Strauss et al., 2009).

This survey suits my research questions well as it contains a wealth of information collected at the household and community level, including indicators of socio-economic well-being (expenditure, assets, housing conditions, education), in addition to information on fertility, anthropometric characteristics, immunization, health status, as well as access and use of health services. Moreover, the ten-year time period on which this study is based spans several different events such as the dramatic economic and political upheavals in the late 1990s at the time of the Asian Crisis, and some natural disasters (e.g., the Indonesian forest fires in late 1997 or the 2004 Indian Ocean tsunami) which unexpectedly affected the Indonesian population.

Since the main variable of interest is the nutritional status of children, I only keep observations for households with children who are equal to or less than 15 years old in the last wave in which they are observed and that have their height-for-age z-score in the plausible range of -5 to 3 (as recommended in WHO, 1995 and O' Donnell et al., 2008). Furthermore, constructing child-level panel data from the three surveys, I had to screen out observations recorded in multiple households (multiple memberships) as well as observations with missing data in the main

\footnotetext{
${ }^{15}$ Despite the availability of a first wave of data (IFLS1) administered in 1993, I restrict the sample to only include data from IFLS2, IFLS3, and IFLS4, mainly because the expenditure module in IFLS1 is not comparable to the next rounds of IFLS (see also Pangaribowo and Tsegai, 2011).
} 
variables of interest. Hence, my panel is restricted to 2,648 individuals: 31.04 percent of them were followed in all the three waves; 38.52 percent in 1997 and 2000, and 30.44 percent in 2000 and $2007^{16}$.

The original data from several different IFLS files has been organized so that the level of observation in the panel is the individual child to which I link information regarding several households, community and individual characteristics. Based on height and age data, the dependent variable is the child's height-for-age z-score which was constructed by using the international standards provided in the World Health Organization Multicentre Growth Reference Study (WHO-MGRS) ${ }^{17}$. As also noted by Gillespie and Haddad (2001), child z-scores represent a fine anthropometric measure to capture a child's nutritional status as it reflects pre and post-natal growth with its deficit (i.e. stunted ${ }^{18}$ ) showing the long-term, cumulative effects of inadequacies in nutrition and/or health.

Table B1 in Appendix B describes the main variables that will be used in the regression analysis and Table 2.1 provides descriptive statistics for the anthropometric individual characteristics together with some information on the share of children (separately for boys and girls) who are stunted and extremely stunted (i.e. where the z-score is below the -3 standard deviation of the height-for-age norm). Additionally, Table 2.1 shows figures on the weight-for-age z-score and on the percentage of children who are underweight and extremely underweight. Average height-forage $z$-scores are low and close to the stunting threshold, confirming the findings of several studies on this issue for the whole South-East Asian region (see, inter alia, Klasen, 2008; Harttgen and Misselhorn, 2006; Gillespie and Haddad, 2000) which point to the unusually high rates of undernutrition in South and South-East Asia for which various theories have been proposed (e.g. Smith et al., 2003; Klasen, 2008). But note also that the Z-scores have improved substantially between 1997 and 2007, for both boys and girls.

Consistent with the findings provided in the empirical literature on child undernutrition (e.g. O’Donnell et al. 2008; Klasen, 1996), Figure B1 (reported in Appendix B) shows that height-for-

\footnotetext{
${ }^{16}$ It is worth noting that a test was made in order to check whether there are systematic differences between the group of children followed in all the three waves and those followed in just two waves. I run a linear probability model where the dependent variable (i.e. a dummy taking value 1 if the child was observed in the three waves and 0 otherwise) is regressed against basic demographic characteristics (i.e. sex, residence, and initial age), height-for-age zscore and parental education (averaged over time). The results, shown in Table B2 in Appendix B, indicate that while it is more likely to observe in all the three waves children with initially lower age, there are no remaining significant differences in basic demographic and socio-economic characteristics.

${ }^{17}$ These standards are considered to be universally applicable as they are based on a sample of children from a diverse set of countries which has a considerable built-in ethnic or genetic variability as well as cultural variation in how children are nurtured. Furthermore, by being standards (and not references) they clearly define how children should grow and identify deviations from the pattern as abnormal growth (WHO, 2006).

${ }^{18}$ According to the National Center for Health Statistics/World Health Organization International Growth Reference, children whose z-score is two standard deviations below the median height-for age curve are classified as stunted (Dibley et al., 1987).
} 
age z-scores decrease as the child's age increases. Also, the percentages of children who suffer from stunting seem to be quite high, especially for boys.

These results are consistent with those presented in Kevane and Levine, 2003; Ralston, 1997; Frankeberg et al., 1996; Deolalikar, 1990; Basuni, 1989 and may hint at the presence of a genderbias (disadvantaging boys) in anthropometric failures which characterize several regions of this country. The main reason for this gap, however does not lay in the inequality in treatment of boys and girls, but rather can be attributed to different activity patterns which increase male children's exposure to disease (Kevane and Levine, 2003).

Among the "proximate determinants" of child health, there are two child specific variables that will be included in the regression analysis as hypothesized pathways relating mothers' socioeconomic status to child health: maternal age at birth and breastfeeding. Descriptive statistics are reported in the bottom rows of Table 2.1 .

Table 2. 1 Child health characteristics. Descriptive statistics

\begin{tabular}{|c|c|c|c|c|c|}
\hline Individual characteristics & & Mean & 1997 & 2000 & 2007 \\
\hline \multirow[t]{6}{*}{ Height for Age z-score } & & -1.56 & -1.75 & -1.63 & -1.46 \\
\hline & & $(1.09)$ & $(1.21)$ & $(1.22)$ & $(1.08)$ \\
\hline & boys & -1.58 & -1.76 & -1.65 & -1.45 \\
\hline & & $(1.17)$ & $(1.30)$ & $(1.24)$ & $(1.12)$ \\
\hline & girls & -1.59 & -1.74 & -1.63 & -1.48 \\
\hline & & $(1.10)$ & $(1.17)$ & $(1.17)$ & $(1.03)$ \\
\hline \multirow[t]{3}{*}{ Stunting $(\%)$} & & 37.30 & 42.76 & 38.99 & 30.88 \\
\hline & $\%$ of boys & 38.25 & 44.66 & 49.97 & 31.37 \\
\hline & $\%$ of girls & 36.29 & 40.87 & 37.94 & 30.34 \\
\hline \multirow[t]{3}{*}{ Extreme Stunting $(\%)$} & & 11.15 & 14.35 & 12.01 & 7.57 \\
\hline & $\%$ of boys & 11.55 & 15.28 & 12.58 & 7.52 \\
\hline & $\%$ of girls & 10.73 & 13.43 & 11.41 & 7.62 \\
\hline \multirow[t]{6}{*}{ Weight for Age z-score } & & -1.32 & -1.43 & -1.26 & -1.25 \\
\hline & & $(1.89)$ & $(1.79)$ & $(2.33)$ & $(1.25)$ \\
\hline & boys & -1.32 & -1.44 & -1.28 & -1.24 \\
\hline & & $(1.89)$ & $(1.23)$ & $(2.31)$ & $(1.31)$ \\
\hline & girls & -1.31 & -1.43 & -1.24 & -1.28 \\
\hline & & $(1.88)$ & $(1.11)$ & $(2.36)$ & $(1.17)$ \\
\hline \multirow[t]{3}{*}{ Underweight (\%) } & & 29.48 & 31.28 & 28.73 & 28.28 \\
\hline & $\%$ of boys & 30.70 & 32.57 & 30.14 & 28.88 \\
\hline & $\%$ of girls & 28.13 & 29.94 & 27.17 & 27.50 \\
\hline \multirow[t]{3}{*}{ Extreme Underweight (\%) } & & 7.06 & 7.47 & 7.21 & 5.68 \\
\hline & $\%$ of boys & 6.95 & 7.45 & 6.99 & 5.81 \\
\hline & $\%$ of girls & 7.20 & 7.48 & 7.46 & 5.50 \\
\hline \multirow[t]{2}{*}{ Mother's age at birth } & & 27.29 & & & \\
\hline & & $(6.08)$ & & & \\
\hline \multirow[t]{3}{*}{ Breastfed $(\%)$} & & 44.60 & & & \\
\hline & $\%$ of boys & 46.66 & & & \\
\hline & $\%$ of girls & 44.55 & & & \\
\hline
\end{tabular}

Note: Total Sample Size is 2,648 children: 822 children are followed in waves 1,2 and 3; 1020 children are followed in waves 1 and 2; 806 children are followed in waves 2 and 3.

Standard Deviations in parentheses. Source: own elaboration on IFLS data. 
It can be observed that the average age at birth of mothers is not dramatically low, but it should also be noted that about 20 percent of women gave birth at ages which are considered riskier for child health (i.e. below 21 years) ${ }^{19}$.

The variable used for breastfeeding in this analysis is a dummy that takes the value 1 if the mother reported ever having breastfed her child and no food/beverages or water was introduced before the first month of life $\mathrm{e}^{20}$.

As also extensively confirmed by numerous medical studies, breastfeeding is an important input to child development since the breast milk contains several nutrients which make the child more resistant to diseases. While there may be a number of other channels through which maternal education exerts its effect on child health, this variable is arguably better than the others that have been used thus far in the literature (i.e. exposure to mass-media, general health knowledge) for defining the concrete pathway through which maternal education is transformed into knowledge and practice of child health seeking behaviour. Moreover, contrary to variables such as general health knowledge (which are potentially endogenous, as parents of an unhealthy child can improve their health knowledge "through experience") breastfeeding is unlikely to be endogenous to child health since mothers usually start breastfeeding shortly after they give birth, thus too early to realize about their child's health conditions and change their behaviour.

Table B3 in Appendix B shows estimates from a linear probability model where the "breastfed" dummy variable was regressed against mothers' education and some controls such as sex of the child, residence, household expenditure or wealth and the number of midwives in the village. Results, which clearly indicate that more educated mothers are significantly more likely to practice breastfeeding, give us the first piece of evidence for the existence of this transmission channel $^{21}$.

The upper part of Table 2.2 reports descriptive statistics related to mothers' health and education. The prevalence of mothers whose nutritional status is weak seems to be relatively low given the high prevalence of anthropometric shortfall for their children. Some degree of

\footnotetext{
${ }^{19}$ According to the medical literature, pregnancies carried at younger ages have a higher risk of poor birth outcomes; including low birth weight and prematurity (see Gilbert et al., 2004; Conde-Agudelo et al., 2005; Fraser et al., 1995). Also, younger mothers may be less experienced and less able to provide the necessary care for their babies (Smith et al. 2003).

${ }^{20}$ Whether this variable can be considered too rough to capture the whole health benefits of breastfeeding, the lack of adequate information and/or missing observations in relevant variables prevented me from constructing finer indicators of optimal breastfeeding, which according to the World Health Organization, should: be initiated within one hour of birth; be exclusive (i.e. no water, formula, milk and food are given to the infant) up to the age of 6 months and continued through 24 months (Kramer and Kakuma, 2007; Labook and Krasovec, 1990; WHO, 2008). ${ }^{21}$ Of course, showing that breastfeeding is a transmission channel for mothers' education doesn't necessarily imply that it can't be a pathway also for other maternal characteristics (i.e., health, employment and wealth status). Whether in the main regression analysis I will control for some of these factors, here the main concern is on the relationship between maternal education and child health-seeking behaviour.
} 
improvement in educational achievement over time is recorded in the higher levels of schooling (i.e. junior and senior high school as well as university). It should be noted that the intertemporal variation of these figures can be partially attributed to the unbalanced nature of our panel. Still, even if we look at the figures for each sub-sample (see Table B4 in Appendix B) we see a very similar picture suggesting a slight improvement in educational achievement for these women. Since the mothers interviewed were aged 15-49 in the first wave where they were observed, it is likely that the younger cohorts among them were still in school and actually-as these descriptive statistics suggest-continued to go to school during the latest survey's years.

At the household level, it can be observed that ownership of proper sanitation facilities has increased over time while the use of piped water remains at low levels, hence around 80 percent of these household were indeed lacking access to improved water sources. When looking at the presence and access to health facilities, it can be observed that if -on average- access to health facilities seems not to be a big problem, and the number of health posts has improved, then the fact that the standard deviation of these figures is particularly high suggests that many families living in rural remote areas do not actually have adequate access to the health infrastructure.

Table 2. 2 Maternal, households and community characteristics. Descriptive statistics

\begin{tabular}{lrrrr}
\hline \hline & & & & \\
Maternal characteristics & Mean & 1997 & 2000 & 2007 \\
\hline Body Mass Index $\leq$ 18.5 (\%) & 7.53 & 8.74 & 8.80 & 5.44 \\
No education (\%) & 5.81 & 6.2 & 5.3 & 6.39 \\
Incomplete primary education (\%) & 24.46 & 28.71 & 24.89 & 21.61 \\
Primary Education (\%) & 28.9 & 31.36 & 29.68 & 26.44 \\
Incomplete Junior High School (\%) & 3.44 & 3.56 & 3.2 & 3.76 \\
Junior High School (\%) & 13.08 & 9.85 & 13.53 & 14.04 \\
Incomplete Senior High Schol (\%) & 1.55 & 1.64 & 1.74 & 1.22 \\
Senior High School (\%) & 21.7 & 17.78 & 20.78 & 25.13 \\
\hline Household characteristics & & & & \\
\hline Household Size & 4.90 & 5.08 & 4.84 & 4.85 \\
& $(1.60)$ & $(1.68)$ & $(1.67)$ & $(1.48)$ \\
Piped water (\%) & 23.92 & 24.53 & 24.47 & 22.37 \\
Own Toilet (\%) & 68.82 & 63.44 & 65.18 & 79.12 \\
Log monthly per capita expenditure & 12.320 & 12.253 & 12.232 & 12.505 \\
& $(0.67)$ & $(0.67)$ & $(0.66)$ & $(0.63)$ \\
\hline Community characteristics & & & & \\
\hline Number of Midwives & 1.23 & 1.26 & 1.13 & 1.33 \\
Number of Health Posts & $(1.03)$ & $(1.37)$ & $(0.75)$ & $(0.98)$ \\
& 7.8 & 7.61 & 7.69 & 8.13 \\
\hline \hline Note: Total Sampl Size & $(6.64)$ & $(6.68)$ & $(6.47)$ & $(6.84)$ \\
\hline
\end{tabular}

Note: Total Sample Size is 2,648 children: 822 children are followed in waves 1,2 and 3; 1020 children are followed in waves 1 and 2; 806 children are followed in waves 2 and 3. Standard Deviations in parentheses. Source: own elaboration on IFLS data. 
Next, the average figures for household per capita expenditure ${ }^{22}$, which is used in this study as a measure of wealth/income ${ }^{23}$, suggest that over this 10-years period, Indonesian households experienced a remarkable improvement in their income conditions ${ }^{24}$. This result goes hand in hand with the high economic growth rates (about a 4 to 5\% growth in GDP rates per year ${ }^{25}$ ) that the country has recorded in the years which followed the Asian financial crisis. Lastly, addressing a potential source of concern regarding the possible endogeneity of expenditure, I have, following Filmer and Pritchett (2001), also constructed an indicator of household assets' using principal components analysis including information on household ownership of durable goods and household dwelling conditions. As the signs of the scoring coefficients suggest, higher values of the index correspond to lower values of household wealth (see Table B5 reported in Appendix B).

\subsection{Estimation Methodology}

In order to obtain consistent estimates of the structural production function in (1) it should be taken into account that-as discussed in Section 2.2- there might be a correlation between the unobserved variables and the observed ones. More specifically, household-level variables such as parental education and income might be correlated with household level factors (i.e. culture, beliefs, and preferences) which are unobserved in the data. If this is the case, then the pooled ordinary least squares models and random effect models will yield biased estimates. A possible solution would hence be to use household-level fixed effects which, by controlling for unobserved heterogeneity within the household, would sweep out the bias. Unfortunately, there are two important limits entailed in the fixed effects specification. First, when the ratio of withinto-between variance declines to 0 , the fixed effects methods cannot estimate coefficients for variables that have no within-subject variation, implying that household-level variables that do not differ by child and are time-invariant would be eliminated by that procedure. Second, fixed effects are equivalent to considering only deviations from individual means and thus ignore the cross-sectional variations of the means themselves (Nerlove, 2002). Neglecting the variation that occurs between households, however, may not be a desirable option from both an econometric and economic perspective. The econometric reason is that this procedure can yield standard errors that are considerably higher than those produced by methods that look at both the within and the between variation. From an economic perspective, instead, it is important to capture the

\footnotetext{
22 Excluding expenses on medicine and health goods.

${ }^{23}$ It should be noted that since the data in real terms is available for all the waves except for 2007, the 2007 series of log real per capita expenditure was estimated by using the available data in nominal terms and taking into account changes that occurred in the price index over the last period in order to obtain the temporal deflator.

${ }^{24}$ See also the corresponding figures on changes in expenditure reported in Table B4 in the Appendix B.

25 World Bank, 2010.
} 
variation occurring between households as it is exactly in there that the very bulk of heterogeneity takes place (see Table B6 in Appendix B). While the variation over time in some of the explanatory variables (e.g. expenditure) is more likely to have a transitory effect on the nutritional status of child, the variation across households is mainly related to household specific factors that vary very little over time and therefore can better explain differences in the dependent variable both cross-sectionally and over-time.

By using the Mundlak model (1978) - I opt for a "compromise" between the fixed and the random effect models. Essentially, the Mundlak model relaxes the assumption of no correlation between the observed and unobserved variables by exploiting the knowledge that the only portion of the time constant variation in the explanatory variables that can be correlated with the error term must be correlated with only the time average values of these explanatory variables for each individual (or household). By accounting for potential correlation between unobserved household-specific heterogeneity and the explanatory variable, the Mundlak approach tries to address any possible endogeneity bias which is due to household-invariant unobserved factors and -under strict assumptions on the structure of the error term- it is able to deliver consistent parameter estimates $^{26}$ (Wooldridge, 2002).

The child health production function in Eq. (1) can thus be transformed into the following econometric specification:

$$
H_{i t}=\alpha+\beta_{1} S E_{i t}+\beta_{2} \overline{S E}_{i}+\beta_{3} I_{i t}^{h h}+\beta_{4} \bar{I}_{i}^{h h}+\beta_{5} I_{i}^{i}+\beta_{6} Z_{i}+\beta_{7} E_{i t}+v_{i t}
$$

where $S E_{i t}$ is a vector of household-level time-varying socio-economic variables, (such as household expenditure and wealth as well as mother's and father's education); $I_{i t}^{h h}$ represents the vector of time-varying inputs which are common across children of the same household (i.e. household sanitation and water conditions); $\overline{S E}_{i}$ and $\bar{I}_{i}^{h h}$ is the corresponding vector of timeaveraged values of $S E_{i t}$ and $I_{i t}^{h h}$ respectively and $I_{i}^{i}$ represents health inputs that are childspecific and do not vary over time (i.e. breastfeeding and mother's age at birth). Lastly, $E_{i t}$ is a

\footnotetext{
26 The Mundlak's approach involves modelling in an auxiliary equation the correlation of unobserved heterogeneity with the explanatory variables, subject to the assumption that unobserved individual characteristics are correlated with the group means of the explanatory variables only. In particular, Mundlak (1978) considers the error-term component in the following auxiliary regression where the unobservable individual specific effect $\mu_{i}$ can be written as: $\mu_{i}=\bar{X}_{l}^{\prime} \pi+\epsilon_{i}$ where $\epsilon_{i} \sim N\left(0, \sigma_{\epsilon}^{2}\right)$ and $\bar{X}_{l}^{\prime}$ is a $1 \times \mathrm{K}$ vector of observations on the explanatory variables averaged over time (Baltagi, 2008, p.133). Therefore, this auxiliary regression basically decomposes the individual-specific component into two effects: one being explained by the explanatory variables and one being assumed to be orthogonal to the explanatory variables. The individual effects are therefore uncorrelated with the explanatory variables if and only if $\pi=0$ (Baltagi, 2008).
} 
vector for local health environment characteristics (i.e. the presence of health facilities at the community level); $Z_{i}$ includes child specific and time invariant characteristics (i.e., sex, genetic endowment) and $v_{i t}$ is the time-varying error term. Interestingly, in the best-case scenario where this error term is symmetric, generalized least squares (GLS) estimators of the resulting model will be similar to fixed effects ("within") estimators and, as such, unbiased (Mundlak, 1978; Baltagi 2008). Alternatively, where $v_{i t}$ is a composite asymmetric term, the heterogeneity bias will be largely reduced, given that the correlation between individual effects and the explanatory variables is partly captured in the model.

Note, that since both $S E_{i t}$ and $I_{i t}^{h h}$ contain variables which are time-varying but common to all the children living in the same household, the coefficients $\beta_{1}$ and $\beta_{3}$ will estimate the individual (or within-households) effects while $\beta_{2}$ and $\beta_{4}$ give the additional average (or betweenhouseholds) effects.

Moreover, the within and between estimates produce reasonable approximations of the short and long run effect respectively, even in panels with a short time series dimension (Egger and Pfaffermayr, 2004; Egger and Url, 2006). Intuitively, this can be explained by recalling that the between structural parameters are based on the cross-sectional component of the panel while the within parameters rely on the time-series component (Baltagi, 2008). Therefore, the formers will capture overall trends and persisting differences between households while the latter will identify individual responses to temporal changes in the independent variables.

The use of this distinction in the interpretation of the coefficients is an important novel contribution to the previous literature on child undernutrition, as it allows us to identify the role of both temporary and long lasting household level factors in driving child health achievements.

A last issue that deserves some discussion pertains to the potential endogeneity of the income variable. To address this problem, many authors have used instrumental variable techniques to estimate two stage least squares models. Nevertheless, given the limit of data availability, it is difficult to find any relevant and exogenous instrument for expenditure. However, it should be noted that since the data used here has a longitudinal dimension and the dependent variable is actually a measure of the long-term nutritional deficiencies, it might be the case that current income is unlikely to be endogenous. Moreover, it seems improbable that poor households with stunted children have much scope to adjust their income upwards through allocating additional labour to income earning activities, as in very poor areas there are many binding constraints which prevent people from having higher wages and incomes.

Nevertheless, in my estimation approach I try to tackle any possible problem of endogeneity in the expenditure variable by: a) excluding expenses in medicine and other health goods from the 
expenditure variable and b) considering an alternative specification with household wealth (measured by a household asset index) to replace household expenditure.

Lastly, in order to reduce any possible bias stemming from the fact that real per capita expenditure was only indirectly estimated for the last year, I will include a third specification with expenditure per capita in nominal terms and interactions effects between time and provincial dummies in order to capture any possible difference in the levels and changes of prices in different provinces.

\subsection{Findings}

Before discussing the results for the full specified model for child nutrition, I present in Table 2.3 an empirical assessment of the "gross-effect" of the socio-economic determinants by estimating the simplest reduced form models where child nutritional status (i.e. the height-forage z-score) is regressed on basic child characteristics such as sex, age, genetic endowment and residence and on each of the socio-economic variables, such as: mother's education, father's education, household expenditure and household wealth (proxied by the household poorness index). The first line of Table 2.3 shows the coefficients obtained by Ordinary Least Squares (OLS) regressions where the standard errors are clustered at the household level in order to correct for serial and contemporaneous correlation (Bertrand et al., 2004). In the second and third rows the 'within' and 'between' coefficients estimated in the Mundlak regressions are reported.

The high statistical significance of the OLS coefficients clearly suggests that there are strong correlations between children's nutritional status and the socio-economic status of their family. Yet, any inference regarding causality can't be derived from these "naïve" estimates. The difference between the size of the OLS and the Mundlak coefficients shows the amount of the bias due to the correlation between the socio-economic variables and other unobservable household characteristics. Once controlling for endogeneity with the Mundlak model, some interesting findings emerge. First, we observe that all the socio-economic variables alone significantly explain between-households differences in child nutritional status.

Second, it can be noted that while there is no significant gross-short-run effect on child nutrition of parental education and household assets index, the expenditure variables display both highly significant short-run and long-run coefficients.

Whether this finding can be partly attributed to our data structure (namely to the fact that there is relatively little variation in parental education over time), it can also be argued that the bulk of the effect of parental education can only be long-term as it doesn't affect child nutritional directly but only though its impact on the intermediate variables and on household expenditure. 
Table 2. 3 The "gross-effect" of the socio-economic determinants of child nutrition

\begin{tabular}{|c|c|c|c|c|c|c|}
\hline . & & $\begin{array}{l}\text { Moth. } \\
\text { Edu. }\end{array}$ & $\begin{array}{l}\text { Fath. } \\
\text { Edu. }\end{array}$ & $\begin{array}{l}\text { Log real } \\
\text { PCE }\end{array}$ & $\begin{array}{l}\text { Log nom. } \\
\text { PCE }\end{array}$ & $\begin{array}{l}\text { HH Poorness } \\
\text { Index }\end{array}$ \\
\hline \multirow{2}{*}{\multicolumn{2}{|c|}{ OLS coefficients }} & $0.0360 * * *$ & $0.0270^{* * *}$ & $0.282^{* * *}$ & $0.297 * * *$ & $-0.107 * * *$ \\
\hline & & $(0.0049)$ & $(0.0048)$ & $(0.0243)$ & $(0.0240)$ & $(0.0109)$ \\
\hline \multirow{4}{*}{ Mundlak } & \multirow{2}{*}{$\begin{array}{c}\text { Short-term or } \\
\text { within coefficients }\end{array}$} & 0.0105 & 0.00596 & $0.166^{* * *}$ & $0.189 * * *$ & -0.0111 \\
\hline & & $(0.0136)$ & $(0.0135)$ & $(0.0272)$ & $(0.0250)$ & $(0.0153)$ \\
\hline & \multirow{2}{*}{$\begin{array}{l}\text { Long-term or } \\
\text { between coefficients }\end{array}$} & $0.0336^{* *}$ & $0.0263^{*}$ & $0.187^{* * *}$ & $0.138^{* * *}$ & $-0.119^{* * *}$ \\
\hline & & $(0.0145)$ & $(0.0143)$ & $(0.0398)$ & $(0.0318)$ & $(0.0197)$ \\
\hline
\end{tabular}

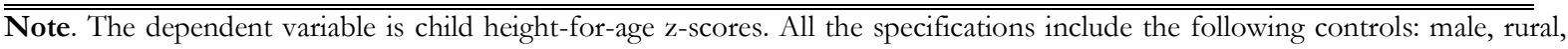
mother height, father height, age dummies. Interaction effects between time and provincial dummies are included in the specification with $\log$ nom. PCE. Standard errors in parentheses. Below the OLS coefficients are reported the robust standard errors, correct for clustering at the household level.

*** $\mathrm{p}<0.01,{ }^{* *} \mathrm{p}<0.05,{ }^{*} \mathrm{p}<0.1$

On the other hand, changes in expenditure may influence child nutritional status both directly in the short-term (by simply altering the composition of the food bundle) and indirectly, by affecting household's ability to improve its living conditions and sanitation infrastructure.

What is expected from the full-specified model is that all these average or long term effects should become not statistically different from zero as soon as the intermediate factors through which they operate are accounted for.

Table 2.4 reports the estimates for the fully-specified model. All the regressions include age dummies (not shown in the Table) to control for specific child age effects that can drive part of the results 27

For illustrative purposes, I include in Col.1-3 the "naïve" least squares regressions whose coefficients can be compared to those obtained in the Mundlak specifications (Col.4-6) in order to show the extent to which estimates change once controlling for endogeneity and it can be observed, indeed, that there is an upward bias in the OLS model which is due to unobserved household factors that are correlated with parental schooling and income.

The first specification (Col.1 and 4) provides an assessment of the effect of only the proximate determinants of child nutritional status. Next, I include mother and father education (Col.2 and 5) and household per capita expenditure (Col.3 and 6). As discussed earlier, the theoretical expectation from these full-specified regressions is that the coefficient on parental education should not be significantly different from zero as, by definition, all variation in child nutrition

\footnotetext{
27 As it may be already inferred from Fig.B1 (reported in Appendix B) and as also suggested by some related literature (i.e. in Sahn and Aldermann, 1997) there might be some specific age effects which can drive part of the results. Pathogen exposure as well as the importance of a mother's care and nurturing have both specific age dimensions so that the effect of breastfeeding or access to health facilities may be expected to differ for children in different age-groups.
} 
status should be captured by the proximate determinants. This is indeed what we find in the table.

Consistent with previous studies on Indonesia (Mani, 2014; Kevane and Levine, 2003; Levine and Ames, 2003), I don't find any evidence of a gender bias in child health; whereas a significant gap in child nutritional status can be observed between rural and urban areas. It is also worth noting that measures of parental height which are included in all the specifications to capture the role of both parents' genetic endowments on child nutritional status (see Thomas and Strauss, 2002), always display a statistically significant coefficient and the magnitude of the effect is relatively larger for mother's height. These results are consistent with earlier findings in the literature (e.g., Mani, 2014; Ghunam et al., 2005; Thomas et al., 1991). Moreover, as suggested by the coefficient on household size, the nutritional status of children from larger households is significantly worse than others children's, suggesting the presence of a quantity-quality tradeoff $^{28}$.

It can be observed that lagged health inputs such as breastfeeding and mothers' age at birth significantly positively affect child nutritional status and that also a positive and robust effect is exerted by the supply-side variables — at both the community and household level — such as the number of health posts and access to improved sanitation facilities. An improvement in household's hygienic conditions (i.e. using own toilet instead of public latrines or other outdoor devices) is significantly associated with an increase of around 0.14 standard deviations in child height-for-age z-scores. This suggests that the provision of such basic infrastructure is an essential complement to the availability of food in preventing child malnutrition as it reduces the risk of bacterial infections and diarrheal diseases that hamper the intake of calories and micronutrients.

Access to piped water, on the other hand, significantly explains only the between household variation in a child's nutritional status. One possible reason why any short term effect can't be found may be related to the fact that piped water may be as clean as well water and therefore the variable doesn't necessarily identify the effect of safe water (vis-à-vis polluted or contaminated water). The significance of the between or long term coefficient, on the other hand, suggests that this dummy variable may better reflect households' improved living conditions and, as such, it significantly explains long run improvements in a child's nutritional status.

Moreover, there are also significant complementarities existing between child and maternal health as the z-scores of children from mothers with a chronic energy deficiency (i.e. having their Body Mass Index below 18.5) are about 0.18 standard deviations worse-off than other children.

28 There might be therefore, problems of endogeneity with this variable. So, as a robustness check, models were estimated excluding $\mathrm{HH}$ size and the results on the variables of interest remain unchanged. 
Table 2. 4 The determinants of child nutrition. Full-specified model. OLS and Mundlak estimates

\begin{tabular}{|c|c|c|c|c|c|c|}
\hline & $\begin{array}{c}(1) \\
\text { OLS }\end{array}$ & $\begin{array}{c}(2) \\
\text { OLS }\end{array}$ & $\begin{array}{c}(3) \\
\text { OLS }\end{array}$ & $\begin{array}{c}(4) \\
\text { Mundlak }\end{array}$ & $\begin{array}{c}(5) \\
\text { Mundlak }\end{array}$ & $\begin{array}{c}(6) \\
\text { Mundlak }\end{array}$ \\
\hline Rural & $\begin{array}{c}-0.202^{* * *} \\
(0.0386)\end{array}$ & $\begin{array}{c}-0.169 * * * \\
(0.0403)\end{array}$ & $\begin{array}{c}-0.159 * * * \\
(0.0402)\end{array}$ & $\begin{array}{c}-0.196 * * * \\
(0.0382)\end{array}$ & $\begin{array}{c}-0.179 * * * \\
(0.0398)\end{array}$ & $\begin{array}{c}-0.173^{* * *} \\
(0.0398)\end{array}$ \\
\hline Health Posts & $\begin{array}{c}0.0139 * * * \\
(0.00269)\end{array}$ & $\begin{array}{c}0.0131 * * * \\
(0.00282)\end{array}$ & $\begin{array}{c}0.0124^{* * *} \\
(0.00281)\end{array}$ & $\begin{array}{c}0.0139 * * * \\
(0.00271)\end{array}$ & $\begin{array}{c}0.0129 * * * \\
(0.00278)\end{array}$ & $\begin{array}{c}0.0116^{* * *} \\
(0.00283)\end{array}$ \\
\hline Male & $\begin{array}{c}-0.00340 \\
(0.0361)\end{array}$ & $\begin{array}{l}0.00380 \\
(0.0374)\end{array}$ & $\begin{array}{c}-0.000191 \\
(0.0374)\end{array}$ & $\begin{array}{c}-0.00466 \\
(0.0367)\end{array}$ & $\begin{array}{c}0.000412 \\
(0.0380)\end{array}$ & $\begin{array}{c}6.29 \mathrm{e}-05 \\
(0.0379)\end{array}$ \\
\hline Mother Height & $\begin{array}{c}0.0394 * * * \\
(0.00646)\end{array}$ & $\begin{array}{c}0.0377 * * * \\
(0.00692)\end{array}$ & $\begin{array}{c}0.0369 * * * \\
(0.00686)\end{array}$ & $\begin{array}{c}0.0247 * * * \\
(0.00246)\end{array}$ & $\begin{array}{c}0.0241 * * * \\
(0.00246)\end{array}$ & $\begin{array}{c}0.0233^{* * *} \\
(0.00245)\end{array}$ \\
\hline Father Height & $\begin{array}{c}0.0214 * * * \\
(0.00351)\end{array}$ & $\begin{array}{c}0.0207 * * * \\
(0.00366)\end{array}$ & $\begin{array}{c}0.0211 * * * \\
(0.00389)\end{array}$ & $\begin{array}{c}0.0126 * * * \\
(0.00186)\end{array}$ & $\begin{array}{c}0.0116 * * * \\
(0.00188)\end{array}$ & $\begin{array}{c}0.0117^{* * * *} \\
(0.00194)\end{array}$ \\
\hline Breastfeeding & $\begin{array}{c}0.0117^{* * *} \\
(0.0423)\end{array}$ & $\begin{array}{l}0.105^{* *} \\
(0.0434)\end{array}$ & $\begin{array}{l}0.105^{* *} \\
(0.0433)\end{array}$ & $\begin{array}{c}0.127^{* * *} \\
(0.0420)\end{array}$ & $\begin{array}{c}0.114 * * * \\
(0.0432)\end{array}$ & $\begin{array}{l}0.110^{* *} \\
(0.0434)\end{array}$ \\
\hline Moth. age birth & $\begin{array}{c}0.0141 * * * \\
(0.00329)\end{array}$ & $\begin{array}{c}0.0151 * * * \\
(0.00341)\end{array}$ & $\begin{array}{c}0.0132^{* * *} \\
(0.00342)\end{array}$ & $\begin{array}{c}0.0134 * * * \\
(0.00336)\end{array}$ & $\begin{array}{c}0.0133 * * * \\
(0.00348)\end{array}$ & $\begin{array}{c}0.0115^{* * *} \\
(0.00347)\end{array}$ \\
\hline Moth. Low BMI & $\begin{array}{c}-0.263 * * * \\
(0.0683)\end{array}$ & $\begin{array}{c}-0.209 * * * \\
(0.0693)\end{array}$ & $\begin{array}{c}-0.190^{* * *} \\
(0.0695)\end{array}$ & $\begin{array}{c}-0.186 * * * \\
(0.0588)\end{array}$ & $\begin{array}{c}-0.163^{* *} \\
(0.0653)\end{array}$ & $\begin{array}{c}-0.156 * * \\
(0.0651)\end{array}$ \\
\hline $\mathrm{HH}$ size $^{\mathrm{a}}$ & $\begin{array}{c}-0.0701 * * * \\
(0.0113)\end{array}$ & $\begin{array}{c}-0.0641 * * * \\
(0.0115)\end{array}$ & $\begin{array}{c}-0.0467 * * * \\
(0.0119)\end{array}$ & $\begin{array}{c}-0.0411 * * * \\
(0.0153)\end{array}$ & $\begin{array}{c}-0.0426 * * * \\
(0.0160)\end{array}$ & $\begin{array}{l}-0.0148 \\
(0.0167)\end{array}$ \\
\hline $\mathrm{HH}$ size ${ }^{b}$ & & & & $\begin{array}{c}-0.0405^{* * *} \\
(0.0198)\end{array}$ & $\begin{array}{l}-0.0302 \\
(0.0206)\end{array}$ & $\begin{array}{c}-0.0420 * * \\
(0.0213)\end{array}$ \\
\hline Water ${ }^{\mathrm{a}}$ & $\begin{array}{c}0.0118 \\
(0.0402)\end{array}$ & $\begin{array}{c}0.0208 \\
(0.0425)\end{array}$ & $\begin{array}{c}-0.00894 \\
(0.0426)\end{array}$ & $\begin{array}{l}-0.0290 \\
(0.0548)\end{array}$ & $\begin{array}{l}-0.0540 \\
(0.0582)\end{array}$ & $\begin{array}{l}-0.0889 \\
(0.0582)\end{array}$ \\
\hline Water ${ }^{\mathrm{b}}$ & & & & $\begin{array}{c}0.0934 \\
(0.0729)\end{array}$ & $\begin{array}{c}0.127^{*} \\
(0.0763)\end{array}$ & $\begin{array}{c}0.133^{*} \\
(0.0763)\end{array}$ \\
\hline Sanitation ${ }^{\mathrm{a}}$ & $\begin{array}{c}0.189 * * * \\
(0.0364)\end{array}$ & $\begin{array}{c}0.159 * * * \\
(0.0386)\end{array}$ & $\begin{array}{c}0.114^{* * *} \\
(0.0388)\end{array}$ & $\begin{array}{c}0.141 \text { *** } \\
(0.0431)\end{array}$ & $\begin{array}{c}0.126 * * * \\
(0.0462)\end{array}$ & $\begin{array}{l}0.100 * * \\
(0.0462)\end{array}$ \\
\hline Sanitation ${ }^{b}$ & & & & $\begin{array}{c}0.0806 \\
(0.0631)\end{array}$ & $\begin{array}{c}0.0304 \\
(0.0670)\end{array}$ & $\begin{array}{l}0.00485 \\
(0.0675)\end{array}$ \\
\hline Moth.Edu. ${ }^{\mathrm{a}}$ & & $\begin{array}{c}0.0120^{*} \\
(0.00659)\end{array}$ & $\begin{array}{c}0.00719 \\
(0.00663)\end{array}$ & & $\begin{array}{c}0.0123 \\
(0.0146)\end{array}$ & $\begin{array}{l}0.00901 \\
(0.0146)\end{array}$ \\
\hline Moth.Edu. ${ }^{b}$ & & & & & $\begin{array}{l}0.00264 \\
(0.0163)\end{array}$ & $\begin{array}{c}0.000372 \\
(0.0164)\end{array}$ \\
\hline Fath.Edu. ${ }^{\mathrm{a}}$ & & $\begin{array}{c}0.00962 \\
(0.00639)\end{array}$ & $\begin{array}{c}0.00217 \\
(0.00637)\end{array}$ & & $\begin{array}{c}0.000610 \\
(0.0139)\end{array}$ & $\begin{array}{c}-0.00131 \\
(0.0139)\end{array}$ \\
\hline 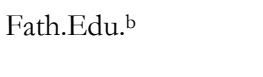 & & & & & $\begin{array}{c}0.0105 \\
(0.0156)\end{array}$ & $\begin{array}{l}0.00517 \\
(0.0156)\end{array}$ \\
\hline Log real pce & & & $\begin{array}{c}0.202^{* * *} * \\
(0.0319)\end{array}$ & & & $\begin{array}{c}0.200 * * * \\
(0.0352)\end{array}$ \\
\hline Log real pceb & & & & & & $\begin{array}{c}0.0159 \\
(0.0521)\end{array}$ \\
\hline Constant & $\begin{array}{c}-11.54^{* * * *} \\
(1.102)\end{array}$ & $\begin{array}{c}-11.36 * * * \\
(1.180)\end{array}$ & $\begin{array}{c}-13.67^{* * * *} \\
(1.205)\end{array}$ & $\begin{array}{c}-7.864 * * * \\
(0.495)\end{array}$ & $\begin{array}{c}-7.802 * * * \\
(0.501)\end{array}$ & $\begin{array}{c}-10.19^{* * *} \\
(0.664)\end{array}$ \\
\hline Observations & 4,425 & 4,425 & 4,378 & 4,425 & 4,425 & 4,378 \\
\hline $\begin{array}{l}\text { R-squared } \\
\text { No.of cross-sections }\end{array}$ & 0.161 & 0.164 & 0.175 & $\begin{array}{l}0.163 \\
2,538\end{array}$ & $\begin{array}{l}0.156 \\
2,538\end{array}$ & $\begin{array}{l}0.167 \\
2,520\end{array}$ \\
\hline
\end{tabular}

Note: Age dummies included. ${ }^{a}$ short term or within effect, ${ }^{b}$ long term or between effect.

Standard errors in parentheses. Below the OLS coefficients are reported the robust standard errors, correct for clustering at the household level. *** $\mathrm{p}<0.01,{ }^{* *} \mathrm{p}<0.05,{ }^{*} \mathrm{p}<0.1$

Turning to the socio-economic variables, it can be observed that the introduction of household per capita expenditure leads to a substantial decrease in the size of the coefficients of mothers and fathers years of schooling, suggesting that part of the effect of parental education is conveyed to the child's health via its positive impact on earnings and therefore on household income.

As expected, once controlling for all the factors that were hypothesized to channel the positive effect of income to child health improvements, no significant direct relationship can be found 
between household income and child's health. Yet, there remains a positive and significant shortrun coefficient. Whether it can be argued that this finding may be partly driven by the possible presence of other channels which are not included in the model, it is also likely that changes in household income (proxied by the $\log$ of household expenditure) directly affect a child's nutritional status, by presumably altering the quantity and quality of food available and of care devoted to children. As implied in our findings, a 100-percent increase in real per capita household expenditure contributes to a temporary improvement of 0.20 standard deviations in child height-for-age $z$-score ${ }^{29}$.

Nevertheless, while temporal increases in income allow for improved expenditure capacity and therefore to better nutritional status, there isn't any long term effect of income, apart from the one that is conveyed through the acquisition and use of the intermediate inputs.

These findings are basically confirmed in the two robustness checks (reported in Table B7 in Appendix B) done to better control for the endogeneity of income and for the fact that, as explained in Section 2.3, real per capita expenditure was only indirectly estimated for the year 2007. It is worth noting that when I estimate the full specified model with the household poorness index, I find a significant between or long-term coefficient which can be partly explained by: a) the exclusion of two proximate inputs such as water and sanitation as separate regressors, and b) by the fact that the index itself identifies ownership of durable goods and dwelling conditions which within households don't vary over time as much as expenditure does. Lastly, I ask how large and relevant the effect conveyed by maternal education to child health through child-care seeking practices such as breastfeeding is. As argued before, part of the literature has tested for the relationship between mother's education, health knowledge and/or exposure to mass media and child health. Here, I hypothesize that breastfeeding can actually be considered as a practical implementation of health knowledge and have so far seen that mother education is indeed positively associated with breastfeeding, the latter significantly improving a child's nutritional status (see Table B3 in Appendix B) and that the effect of mother's education vanishes once controlling for all the proximate determinants of child health (Table 2.4). In order to quantify the magnitude of this transmission channel I compare the base outcome coefficient on mother education reported in Table 2.3 with that resulting from a regression that additionally includes breastfeeding. Results reported in Table 2.5 indicate that the between coefficient drops

\footnotetext{
29 The size of the estimated coefficient is about 0.4 standard deviations smaller than the one obtained by Mani (2014) in her instrumental variable models of the socio-economic determinants of child nutrition in Indonesia over the period 1993-2000. The relatively smaller magnitude of the income coefficient estimated here can be attributed to the inclusion of individual and household level proximate determinants of child health which convey part of the effect that income has on child health.
} 
from 0.0336 to 0.0305 , implying that almost 10 percent of the total effect of mother education is conveyed to child's nutrition though breastfeeding.

Table 2. 5 A comparison of the maternal education coefficient in baseline regressions with and without the inclusion of the breastfeeding variable

\begin{tabular}{|c|c|c|c|}
\hline . & & 'Gross effect' & $\begin{array}{c}\text { With } \\
\text { breastfeeding }\end{array}$ \\
\hline OLS maternal education coefficients & & $\begin{array}{c}0.0360 * * * \\
(0.00492)\end{array}$ & $\begin{array}{c}0.0341 * * * \\
(0.00491)\end{array}$ \\
\hline \multirow{2}{*}{ Mundlak maternal education coefficients } & $\begin{array}{c}\text { Short-term or } \\
\text { within }\end{array}$ & $\begin{array}{c}0.0105 \\
(0.01360)\end{array}$ & $\begin{array}{c}0.0110 \\
(0.01360)\end{array}$ \\
\hline & $\begin{array}{l}\text { Long-term or } \\
\text { between }\end{array}$ & $\begin{array}{l}0.0336^{* *} \\
(0.01450)\end{array}$ & $\begin{array}{l}0.0305^{* *} \\
(0.01450)\end{array}$ \\
\hline
\end{tabular}

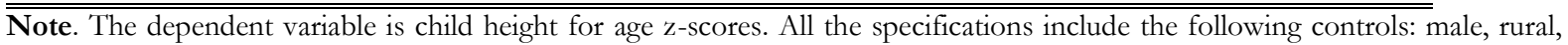
mother height, father height, age dummies. Interaction effects between time and provincial dummies are included in the specification with log nom. PCE. Standard errors in parentheses. Below the OLS coefficients are reported the robust standard errors, correct for clustering at the household level. $* * * \mathrm{p}<0.01, * * \mathrm{p}<0.05, * \mathrm{p}<0.1$

\subsection{Conclusions}

The purpose of this analysis was to investigate the role of individual, household and community characteristics in driving achievements in nutritional conditions of Indonesian children, as measured by their height-for-age z scores. In order to do so, I rely on longitudinal survey data and apply a methodology (i.e. the Mundlak approach of household-average fixed effects) which can deliver robust and unbiased estimates.

This study mainly contributes to prior literature by improving our understanding of the determinants of child nutrition. In particular, I extend the state-of-the-art of the related literature by identifying separate short and long term effects of proximate and socio-economic determinants of child health.

Although I cannot rule out the existence of strong complementarities between household wealth or income and child health, the effect of positive changes in income appears to be limited to the short term. This means that although more material resources undoubtedly help provide sufficient food and alleviate the expenditure constraints that many household face, they must be complemented by other factors in order to exert a long lasting effect on a child's health conditions. Interestingly, the supply side level factors (such as sanitation and health infrastructure) and mother's health status also significantly and robustly account for deficiencies in child health anthropometric outcomes.

The provision of sanitation appears to be an essential complement to the availability of food in preventing child malnutrition, suggesting that the rise in the availability of these services may also 
have spill-over effects to other households in the neighbourhood, as the probability of crossinfections from bacterial diseases caused by lack of hygiene will fall. On the other hand, results suggest that just as much of the variation in child health is significantly explained by the number of health posts, thus investments in such basic infrastructure will also contribute to reducing child malnutrition.

Another interesting finding in this analysis is that there are strong and long-lasting complementarities between maternal education and child health and that this effect is partially conveyed by health care giving practices such as breastfeeding. As results suggest, the bulk of the variation of child malnutrition between households is driven by differences in the level of maternal educational achievements.

Overall, the findings suggest that income poverty-alleviating policies complemented with investment in basic health infrastructure might strongly contribute to improving the health conditions of the Indonesian children. One of the greatest challenges for the country is given by the heterogeneous conditions in the regions, as our results revealed the presence of large disparities in the level of nutrition in different regions and between rural and urban areas as well as in the access to proper infrastructure. Expanding the coverage or improving the quality of such infrastructure would contribute effectively to improving the health conditions of children, particularly of those living in the most remote areas. On the other hand, as the linkages between maternal education, child nurturing practices and child health are found to be particularly strong, policies which are aimed at enhancing the quality of education can remarkably improve the nutritional status of children. 


\title{
Essay 3
}

\section{The Nutrition-Learning Nexus: Evidence from Indonesia}

\begin{abstract}
This paper investigates the effect of nutritional status on subsequent educational achievements for a large sample of Indonesians children. I use a long term panel data set and apply a maternal fixed effect plus an instrumental variables estimator in order to control for possible correlation between some of the components of the error term and the main independent variable which will likely to cause a bias in the estimates. Differences in nutritional status between siblings are identified by using exposure in the earliest months of life to the drought associated with the Indonesian wildfires of late 1997. Estimation results show that health capital (measured by height-for-age z-scores at childhood) significantly and positively affects the number of completed grades of schooling and the score on cognitive test. Nevertheless, I only find little robust evidence of an effect on the readiness to enter school.
\end{abstract}




\subsection{Introduction}

Over the last 20 years, a growing number of studies have documented the existence of positive complementarities between schooling outcomes and childhood nutrition. There are two main channels that -interacting with each other- relate these two important human development aspects.

First, as nutritional intake in early childhood contributes to determine the health capital of an individual, poorly nourished children will be likely to be more vulnerable to disease or simply physically weaker and this in turn, will affect the development of cognitive skills, their ability to learn and to regularly attend classes and thereby their education performance. Given that cognitive development and school achievements are two important components of human capital, the long term consequences of poor nutritional status will also likely be reflected in worse outcomes on labor productivity and on life time earnings.

Second, children with poor nutritional status are exposed to higher risks of morbidity and therefore may enroll later at school. This is especially true in a developing countries context where the rule enforcement on compulsory school may be relatively weak and the economic returns to investments in health capital are relatively large. Although delayed enrolment decisions are rational caregivers' responses to early childhood malnutrition (Glewwe and Jacobi, 1995), late entry is never optimal as it will result in fewer years of earnings because in order to maintain total years of schooling with delayed enrolment, an individual will have to enter the job market later ${ }^{30}$. In this paper, I conduct a micro-econometric analysis on a long term panel dataset collected in 13 Indonesian provinces over the period 1997 to 2007 in order to gauge the impact of child nutritional status on subsequent educational attainments. The econometric strategy followed here is based on an instrumental variable-mother-fixed-effects estimator where differences in nutritional status among siblings are identified by the exposure to an exogenous shock, namely to the drought associated with the late 1997's Indonesian forest fires.

This study therefore seeks to contribute to previous literature in a number of ways. First, by empirically assessing the causal relationship between nutrition and learning, it extends the literature on human capital formation and overcomes the weaknesses of cross sectional studies. The bulk of empirical evidence on this field has indeed been built on cross sectional data and/or relied on econometric strategies with low accuracy, and so it has only been able to provide evidence of strong associations between child nutrition and school attainments, yet the causal relationship has so far only been investigated in few studies (Glewwe and Miguel, 2008).

\footnotetext{
30 This implies that delayed enrolment doesn't necessarily lead to fewer years of education; despite this may be an expected outcome if one supposes that the opportunity cost of schooling increases with age.
} 
Second, this paper aims at improving current knowledge on the impact of shocks at the individual level. These kinds of adverse events can drastically affect households' welfare, by generating substantial reductions in their levels of income and consumption (Morduch, 1995; Townsed, 1995) but the magnitude and the duration of such shocks may vary substantially among households' members. By considering the effect of the drought on children nutritional status and -through this- on later educational achievements, this paper contributes to current knowledge of both short and long term consequences of exposure to transitory environmental shocks

Third, this analysis will also extend current understanding on the consequences of the Indonesian wildfires. To date, only two studies have investigated the effects of this massive environmental shock on the Indonesian population by focusing on the impact of haze on adult respiratory problems (Frankenberg et al. 2005) and of air pollution on under-3 mortality rates (Jayachandran, 2009).

Lastly, this study contributes to build knowledge on the strength of the nutrition-learning nexus in Indonesia: a country which has been growing remarkably over the last 20 years and which is recently experiencing large reductions in poverty rates. The Indonesian education sector has largely benefited from massive supply side interventions which boosted school enrolment rates (Duflo, 2001). Yet, despite these gains, there are still some challenges that the country needs to face in terms of disparities within and between provinces and regions in many quantitative and qualitative indicators of school achievement (World Bank, 2011).

The remainder of this paper is organized as follows: I present the theoretical framework and its econometric implications in Section 3.2 and then describe the data in Section 3.3. Section 3.4 deals with the empirical approach and instrumental validity and illustrates main findings and robustness checks. The final section concludes.

\subsection{Theoretical framework and econometric implications}

I start with a simple model that shows the relationship existing between child health and educational achievements.

Following Alderman et al. (2001 a, 2006); Glewwe et al. (2001); Cunha et al. (2006) and Yamauchi (2008), I begin with a dynamic process of human capital accumulation where the efficiency in the production of educational outcomes realized in a given time period is determined by physical and mental abilities and by the health and nutritional inputs which a person has cumulated up to that time. 
In other words, there is an input-output relationship between health and education which can be formally represented by the following achievement function:

$$
E_{i t}=f\left(H_{i t-1} ; X_{i t} ; \alpha ; \rho ; \tau\right)
$$

where $E_{i t}$ is the educational achievement of child $i$ (realized in time $\left.t\right) ; H_{i t-1}$ is child health formed in the preceding period, which is meant to represent the child health history up until the beginning of time $t^{31}$ and $X_{i t}$ is a set of household and community characteristics that influence educational performance (e.g. the availability of schools and learning facilities, teachers' and parents' levels of education; household wealth).

Moreover, this function shows that achievement also depends on the child endowment $(\alpha)$ which is represented by her innate ability and motivation; by a vector $\rho$ that, encompassing school fees and prices of consumption goods and of schooling materials, determine the household budget constraint and by a $\tau$ component which is common across siblings and includes parental tastes and attitudes for child education and health. Both $\rho$ and $\tau$ are supposed to influence educational performance indirectly though the effects that they exert on the supply of educational inputs and, more generally, on schooling investment.

An important consideration underlying the achievement function is that there is dynamic household behaviour which contributes to shape the simple input-output relationship between health and school and possibly interacts with the degree of complementarity or substitutability between health capital and schooling inputs (Yamauchi, 2008). ${ }^{32}$

The above-specified achievement function can be transformed into a schooling equation which can be empirically estimated:

$$
E_{i t}=\beta_{0}+\beta_{1} H_{i t-1}+\beta_{2} C_{i t}+\varepsilon_{i}
$$

where $H_{i t-1}$ can be proxied by the nutritional status of the child in the preceding period (e.g. given by her height-for-age z-scores) and $C_{i t}$ is a vector including the household and community characteristics $\left(X_{i t}\right)$ and $\rho$ prices. Lastly, $\varepsilon_{i}$ is a disturbance term which represents the sum of the

\footnotetext{
31 This health capital is partly determined by individual genetic endowment and by time invariant parental and environmental factors as well as by a vector of prices and household characteristics which may vary across siblings and determine the level and efficacy of parental investments in child health.

${ }^{32}$ As noted by Yamauchi (2008), the optimal level of schooling investment is also affected by whether health capital substitutes for schooling inputs or it accrues their productivity. Assuming perfect substitutability implies that parents will make more schooling investments in unhealthier children. On the other hand, if health capital and schooling inputs are complementary, only healthier children will attract more schooling investment.
} 
$\alpha$ component (i.e. child genetic potential, innate ability and motivation); the $\tau$ home-invariant component and the $\xi_{i t}$ white-noise error term component.

The main interest of this paper is, of course, to assess the magnitude and significance of the coefficient $\beta_{1}$ but there are a number of econometric problems entailed in the estimation of (2) which should first be addressed.

First, there may be an omitted variable bias problem, i.e. there may be other factors which relate to both height and the outcome variable that drive the association. The consumption of certain micronutrients, such as iron, vitamin A and iodized or fortified salt, for example, may affect nutritional status as well as learning abilities.

Second, parents observing the weak health status of their child, might engage in compensatory actions by increasing the amount of food or other health resources devoted to her or by diverting more resources for her educational achievement (given that the assumption of substitutability between health capital and educational inputs holds).

Third, as suggested by the medical and biology literature, not only the individual genetic endowment highly correlates with health status (see, inter alia, Preece, 1996 and Weedon et al., 2008), but also there is evidence of a shared genetic architecture between height and intelligence (Marioni et al., 2014; Keller et al., 2013; Posthuma et al., 2010; Silventoinen et al., 2006; Sundet et al., 2005; Van Dam et al., 2005). Therefore, over subsequent time periods children with higher genetic potential will be healthier than their peers while -on the other hand- less endowed children will be more likely to experience worst health conditions and might even die before the educational outcome is realized, leaving us with a "biased" sample of selected healthier individuals (Alderman et al., 2006; Yamauchi, 2008).

These considerations imply that simple ordinary least squares (OLS) estimates of $\beta_{1}$ are likely to be either upward or downward biased because the main independent variable can be not orthogonal to the error term. In other words, there is an endogeneity problem due to the possible correlation existing between $H_{i t-1}$ and $\tau$ and/or between $H_{i t-1}$ and $\alpha$ (Behrman, 1996; Alderman et al. 2006).

As suggested by Glewwe et al. (2001), the econometric approach that can best sweep out these two forms of correlation combines a sibling difference model with instrumental variable techniques: maternal fixed effects will indeed remove the bias caused by the correlation between the endogenous variable and the siblings-invariant error term component, while the use of a relevant and exogenous instrument will purge the remaining correlation with the child specific error term component. 
Lastly, as it is clear from the model, the estimation of (2) requires data measured at different points in an individual's life. Cross-sectional datasets can include such variables only if they are based on questions relying on the respondent's memory but this would easily entail problems of data reliability and measurement error. As noted by Glewwe and Miguel (2008), the vast majority of studies which were conducted using cross sectional data is indeed flawed as these rely on very strong and often untestable assumptions in order to make inference.

To date, the literature on this research field includes only four published studies (i.e. Alderman et al., 2001a; Glewwe et al., 2001; Alderman et al., 2006; Yamauchi, 2008) that have used panel data to estimate the impact of child health on later education achievements.

Table 3.1 gives an overview on these studies by summarizing the main information on the country on which the research was based, the variables used for educational achievement, the type of estimation approach, the endogenous health status variable and the variable that was chosen to instrument for it.

Table 3. 1 Review of previous panel data based studies on the nutrition-learning nexus

\begin{tabular}{|c|c|c|c|c|c|}
\hline Authors & Country & $\begin{array}{l}\text { Educational } \\
\text { outcome variable(s) }\end{array}$ & $\begin{array}{l}\text { Estimation } \\
\text { strategy }\end{array}$ & $\begin{array}{l}\text { Endogenous health } \\
\text { status variable }\end{array}$ & Instrument(s) \\
\hline $\begin{array}{l}\text { Alderman et } \\
\text { al. (2001a) }\end{array}$ & Pakistan & $\begin{array}{l}\text { Dummy }=1 \text { if } \\
\text { enrolled in time }\end{array}$ & IV & $\begin{array}{l}\text { Height for age } z \text { - } \\
\text { scores }\end{array}$ & Food Price shocks \\
\hline $\begin{array}{l}\text { Glewwe et } \\
\text { al. (2001) }\end{array}$ & Philippines & Test scores & HHFE-IV & $\begin{array}{l}\text { Height for age } z- \\
\text { scores }\end{array}$ & $\begin{array}{l}\text { Height of the older } \\
\text { sibling by the age of } \\
24 \text { months }\end{array}$ \\
\hline $\begin{array}{l}\text { Alderman et } \\
\text { al. (2006) }\end{array}$ & Zimbabwe & $\begin{array}{l}\text { Adolescent height; } \\
\text { grades attained; age } \\
\text { starting school }\end{array}$ & MFE-IV & $\begin{array}{l}\text { Height for age } z \text { - } \\
\text { scores }\end{array}$ & $\begin{array}{l}\text { Exposure to civil } \\
\text { war and to drought }\end{array}$ \\
\hline $\begin{array}{l}\text { Yamauchi } \\
(2008)\end{array}$ & $\begin{array}{l}\text { South } \\
\text { Africa }\end{array}$ & $\begin{array}{l}\text { Age starting school; } \\
\text { grades completed; } \\
\text { Mathematics test } \\
\text { scores }\end{array}$ & $\begin{array}{c}\text { HHFE-AFE- } \\
\text { IV }\end{array}$ & $\begin{array}{l}\text { Height for age } z- \\
\text { scores }\end{array}$ & $\begin{array}{l}\text { Community health } \\
\text { facilities; Weight for } \\
\text { age z scores }\end{array}$ \\
\hline
\end{tabular}

Note: IV stands for Instrumental Variable; HHFE is household-fixed effects; MFE is mother fixed effects and AFE is age fixed effects.

All these studies have found a strong and often statistically significant effect of child nutritional status on later academic achievement. However, it should be noted that-except for the Zimbabwe study- the validity or the relevance of the chosen instrument can be subject to criticism. As indeed noted by Glewwe and Miguel (2008) and Alderman et al. (2006), the use of food price shocks in the Pakistan study may be problematic because these shocks can easily affect 
household savings and therefore also schooling outcomes (via the effect on schooling investment). The Philippines study, on the other hand, is built on the questionable assumption that growth in children's height after age two is not correlated with height up to the age of two. Lastly, in the South Africa study, although weight for age was used with the purpose of sweeping out measurement error, its exogeneity may be easily subject to criticism as weight for age represents itself a facet of the (endogenous) nutritional status. Moreover, the estimation strategy followed in the majority of these studies was not always ideal: while the Pakistan study is only based on the instrumental variable (IV) strategy, the Philippines and the South Africa studies follow a household fixed effect-instrumental variable estimation approach. Household fixed effects, nevertheless, are not exactly the same as differencing across siblings of the same mother, especially in a developing country context where more than one family units share the same house.

\subsection{Data and Sample}

\subsubsection{The Indonesian Family Life Survey}

Our main source of data is the Indonesian Family Life Survey (IFLS) which is an ongoing longitudinal survey of individuals, households, communities and facilities which was conducted in 13 Indonesian provinces spread out in the islands of Sumatra, Java, Kalimantan, Sulawesi, Bali and West Nusa Tenggarra. The first wave (IFLS1) was conducted in late 1993 and surveyed 7,224 households and 22,000 individuals in 321 enumeration areas. Between August and December 1997 the second full sample wave (IFLS2) successfully managed to reinterview over 94\% of the IFLS1 households. Other two follow ups surveys were conducted in 2000 (IFLS3) and 2007 (IFLS4). Among the IFLS1 households 90.3\% were either interviewed in all the four waves or died, and $87.6 \%$ were actually interviewed in all four waves (Frankenberg and Thomas 2000).

There are interesting features in the IFLS which make this data particularly suited to my research needs. First, these high recontact rates contribute significantly to data quality by lowering the bias due to non random attrition. Second, in addition to basic demographic and socio-economic characteristics of the respondents, the IFLS collected detailed information on various educational aspects (e.g., current schooling grade; age at which the child first enrolled at school; number of correct answers given in a cognitive test) as well as on the anthropometric measures which are necessary to derive child nutritional status variables. 


\subsubsection{Description of key variables}

I consider the panel of individuals surveyed in IFLS2, IFLS3 and IFLS4 and I shrink the initial IFLS2's size by keeping only ten cohorts of individuals born between 1990 and $1997^{33}$. These children are then tracked after three years (i.e. in IFLS3) and/or after ten years (i.e. in IFLS4) in order to get information on the current educational achievement. Data show that in 2000 and/or in 2007, 936 observations were traced from an initial sample of 2181 children $^{34}$ for which there was complete information available on basic demographic and socio-economic characteristics and on anthropometric measures such as weight and height that were used to construct sex and age-standardized z-scores for height and weight based on the standards provided in 2006 by the World Health Organization (WHO) in the Multicentre Growth Reference Study (MGRS) ${ }^{35}$.

In order to consider different facets of learning achievements, education outcomes are measured by three distinct variables ${ }^{36}$ : a) completed years of schooling; b) score obtained in a cognitive test (to consider the development of cognitive and learning skills), and c) age at which primary school was started (to proxy for readiness to enter school). The first variable is observed in 2007 (IFLS4) and is measured by summing the number of grades completed at each level of school ${ }^{37}$. The score on cognitive test is measured either in 2000 or in 2007 , depending on child age. This test was indeed administered to children aged 8 to 14 years and the variable on its outcome is constructed as the ratio of correct answers on total questions ${ }^{38}$. Lastly, the information on the age at which the child started school is directly taken from the answer provided by the mothers either in IFLS3 or in IFLS4.

When observing the information available on nutritional status, it can be noted that on average the children sampled have poor height and weight for age relative to the MGRS sample of adequately nourished children. As suggested by the figures reported in Table C1 in Appendix C, given age and sex, the child height (weight) is -1.74 (-1.44) standard deviations below the median child in that age group.

Also, a relatively large percentage of children suffer from mild and moderate stunting and underweight conditions. Table 3.2 reports that -on average- while only $15.25 \%(7.15 \%)$ of

\footnotetext{
33 Despite the availability of one more wave of data from the IFLS administered in 1993, this was not used as the baseline survey, given that in my identification strategy I just needed observations whose child nutritional status was measured at one point in time during early childhood and I needed to include also children born after 1993 since the instrument used in this analysis identifies children who are aged 12-36 months in September 1997 (see Section 3.4.1 for further details).

34 More details about tracking issues are discussed in Section 3.4.3.

35 The MGRS was based on a sample of 8500 children from widely different ethnic backgrounds and cultural settings (Brazil, Ghana, India, Norway, Oman and USA). These children were breastfed during infancy, appropriately fed later on in life and raised in optimal conditions (WHO, 2006).

36 See Table C1 in Appendix C.

37 The Indonesian school system consists of six years of primary education, three years of junior secondary and other three years of senior general or vocational education. Primary school starts by law at the age six or seven.

${ }^{38}$ The test consisted of a set of 17 questions, of which 12 were cognitive and 5 were based on simple mathematics.
} 
children are severely stunted (underweight), and this figure grows of about 25-29 percentage points when considering moderate stunting and underweight conditions.

Table 3. 2 Nutritional status of children surveyed in IFLS2, by gender and place of residence

\begin{tabular}{|c|c|c|c|c|c|}
\hline & \multicolumn{2}{|c|}{ Gender } & \multicolumn{2}{|c|}{ Residence } & \multirow{2}{*}{ Total } \\
\hline & Female & Male & Urban & Rural & \\
\hline \multicolumn{6}{|l|}{ Stunting } \\
\hline $\begin{array}{c}\text { Mild } \\
\text { (Height-for-Age z-score <-1 SD) }\end{array}$ & $73.70 \%$ & $75.97 \%$ & $70.48 \%$ & $79.36 \%$ & $74.87 \%$ \\
\hline $\begin{array}{c}\text { Moderate } \\
\text { (Height-for-Age } \mathrm{z} \text {-score <-2SD) }\end{array}$ & $41.30 \%$ & $46.64 \%$ & $40.12 \%$ & $48.09 \%$ & $44.06 \%$ \\
\hline $\begin{array}{c}\text { Severe } \\
\text { (Height-for-Age z-score <-3 SD) } \\
\text { Underweight }\end{array}$ & $15.22 \%$ & $15.27 \%$ & $13.10 \%$ & $17.45 \%$ & $15.25 \%$ \\
\hline $\begin{array}{c}\text { Mild } \\
\text { (Weight-for-Age z-score <-1 SD) }\end{array}$ & $68.70 \%$ & $70.47 \%$ & $65.98 \%$ & $73.35 \%$ & $69.61 \%$ \\
\hline $\begin{array}{c}\text { Moderate } \\
\text { (Weight-for-Age z-score <-2SD) }\end{array}$ & $29.78 \%$ & $35.03 \%$ & $29.46 \%$ & $35.61 \%$ & $32.49 \%$ \\
\hline $\begin{array}{c}\text { Severe } \\
\text { (Weight-for-Age z-score <-3 SD) } \\
\end{array}$ & $7.17 \%$ & $7.13 \%$ & $7.47 \%$ & $6.82 \%$ & $7.15 \%$ \\
\hline
\end{tabular}

Source: Author's elaboration from IFLS2 and WHO-MGRS.

Lastly, as illustrated in Table 3.3, children who are suffering from moderate to severe stunting conditions are more likely to experience worst educational outcomes in later stages of their life if compared to their healthier peers.

Table 3. 3 Mean educational achievements of children above and below moderate stunting and underweight thresholds

\begin{tabular}{lccccc}
\hline \hline & $\begin{array}{c}\text { Children with } \\
\text { moderate to } \\
\text { severe } \\
\text { stunting }\end{array}$ & $\begin{array}{c}\text { Non- } \\
\text { malnourished }\end{array}$ & & $\begin{array}{c}\text { Children with } \\
\text { moderate to } \\
\text { severe } \\
\text { underweight }\end{array}$ & $\begin{array}{c}\text { Non- } \\
\text { underweight }\end{array}$ \\
\cline { 2 - 3 } Completed years of schooling & 6.55 & 6.87 & 6.20 & 6.84 & 6.67 \\
Cognitive Test Score & 6.34 & 0.76 & 0.73 & 6.76 \\
\hline \hline
\end{tabular}

Source: Author's elaboration from IFLS 2-3-4

\subsection{Findings}

\subsubsection{Estimation approach and instrumental validity}

The empirical approach pursued in this paper is based on the estimation of the afore-specified schooling equation where three alternatives measures for $E_{i t}$ are used: completed years of schooling, the score obtained in the cognitive test and the age at which primary school was started. The effect of $H_{i \neq-1}$ (measured as height-for-age $\mathrm{z}$-scores) is estimated by mainly relying on 
a mother-fixed effects-instrumental variable (MFE-IV) model, which-as argued before- addresses endogeneity in the relationship of interest.

It is important to note that the MFE-IV estimation procedure entails the choice of an instrument that should significantly affect a child nutritional status, be adequately variable across children born from the same mother and sufficiently transitory in order to not exert any direct effect on $E_{i t}$

The instrument that I use is the shock resulting from individual exposure to the drought associated to the late 1997's Indonesian forest fires.

From September to November 1997, large traits of tropical forest and arable land belonging to the islands of Sumatra and Kalimantan were severely hit by the worst fires ever recorded in Indonesia. The damage inflicted by these wildfires and the resulting haze was massive: the lives of the majority of the population living and working in rural areas were adversely affected by the destruction of farms and plantations, the interruption in transports and the bad respiratory problems which resulted from months of breathing heavy smoke-haze (Frankenberg et al. 2005; Jayachandran, 2009).

In Sumatra and Kalimantan, small and controlled burns have been traditionally used by smallscale farmers to clear land for planting new $\mathrm{crops}^{39}$. But these burns went quickly out of control from early September 1997 because of the extraordinary dry weather conditions that were brought by the El Niño Southern Oscillation (ENSO; Jim, 1999) phenomenon. Therefore, the drought associated with El Niño which exacerbated the intensity of the fires became particularly severe and prolonged. Only in mid-to-late November, when fires were quenched by the first rains, land and environmental conditions in these two islands began to recover (see Figure C1 reported in Appendix C).

The instrumental variable is therefore constructed as a dichotomous variable which equals one if the child was living in Sumatra or Kalimantan and was aged 12 to 36 months when the forest fires began (i.e. at September, $\left.5^{\text {th }}, 1997\right)$. Hence, variation in the exposure to such shock mainly comes from two sources: place of residence and age.

The choice of a specific age range is motivated by the large number of contributions provided by nutritionists, physiologists and social scientists which have posited the existence of a "critical period" in human life where brain development is most sensitive to poor nutrition (Dobbing, 1976; Waber et al., 1981; Stein et al., 1976; Villar et al., 1984; Glewwe and King, 2001). There have been mixed findings, however, concerning the exact age range where this critical period can

\footnotetext{
39 This type of "slash and burn" techniques which play an important ecological role for the local ecosystem have, nevertheless, been increasingly used in more extended areas during the Nineties because of the expansion of timber and palm oil industries in Indonesia.
} 
be identified, although the bulk of the literature agrees that the impact of shocks on children older than 36 months is zero (Hoddinott and Kinsey, 2001; Glewwe and King, 2001; Shrimpton et al., 2001).

I've therefore conducted a preliminary analysis where I tested for different age range as well as for foetal exposure ${ }^{40}$ and found that the shock experienced during the second and third year of life had the largest negative impact on child health status.

Table 3.4 reports the mother fixed effects estimates of the effect of the exposure to the forest fires on child nutritional status measured as height-for-age z-scores (Columns 1 and 2) and as weight for age $z$-scores (Columns 3 and 4$)^{41}$.

Table 3. 4 Effect of exposure to forest fires on child nutritional status. First stage estimates

\begin{tabular}{|c|c|c|c|c|}
\hline & \multicolumn{2}{|c|}{ Height for Age z-scores } & \multicolumn{2}{|c|}{ Weight for Age z-scores } \\
\hline & $\begin{array}{c}\text { (1) } \\
\text { Without } \\
\text { controls }\end{array}$ & $\begin{array}{c}\text { (2) } \\
\text { With } \\
\text { controls }\end{array}$ & $\begin{array}{c}\text { (3) } \\
\text { Without } \\
\text { controls }\end{array}$ & $\begin{array}{c}\text { (4) } \\
\text { With } \\
\text { controls }\end{array}$ \\
\hline Exposure to Forest Fires & $\begin{array}{c}-1.103^{* * *} \\
(0.220)\end{array}$ & $\begin{array}{c}-1.181 * * * \\
(0.232)\end{array}$ & $\begin{array}{c}-0.744^{* * *} \\
(0.225)\end{array}$ & $\begin{array}{c}-0.971 * * * \\
(0.232)\end{array}$ \\
\hline Boy & & $\begin{array}{l}-0.0887 \\
(0.121)\end{array}$ & & $\begin{array}{c}-0.00746 \\
(0.111)\end{array}$ \\
\hline Age & & $\begin{array}{l}-0.0374 \\
(0.0277)\end{array}$ & & $\begin{array}{c}-0.0965^{* * *} \\
(0.0285)\end{array}$ \\
\hline Constant & $\begin{array}{c}-1.668^{* * *} \\
(0.0134)\end{array}$ & $\begin{array}{c}-1.480^{* * *} \\
(0.124)\end{array}$ & $\begin{array}{c}-1.395^{* * *} \\
(0.0137)\end{array}$ & $\begin{array}{c}-1.026 * * * \\
(0.123)\end{array}$ \\
\hline $\begin{array}{l}\text { F-statistics on significance of } \\
\text { the fires' shock }\end{array}$ & $25.12^{* * *}$ & $25.95^{* * *}$ & $10.96 * * *$ & $17.50^{* * *}$ \\
\hline Observations & 936 & 936 & 936 & 936 \\
\hline R-squared & 0.092 & 0.101 & 0.048 & 0.111 \\
\hline Number of m.id & 711 & 711 & 711 & 711 \\
\hline
\end{tabular}

Note. Estimations are based on mother fixed effects.

Robust standard errors in parentheses. ${ }^{* * *} \mathrm{p}<0.01,{ }^{* *} \mathrm{p}<0.05,{ }^{*} \mathrm{p}<0.1$

Results indicate that across all the specifications, there is a negative and significant effect at the $1 \%$ level on the endogenous variables and the magnitude of the effect is relatively larger for height-for-age z-score. Moreover, as suggested by the F test statistic, the instrument's validity (at least with respect to the strong correlation with the endogenous variable) is particularly high ${ }^{42}$, and well above the thresholds recommended in Staiger and Stock (1997) and Bound et al. (1995).

\footnotetext{
40 Fetus exposure is proxied by health conditions experienced by mothers during pregnancy. All these tests, not shown in this paper, are available upon request.

${ }^{41}$ Note that weight and height were measured shortly after the beginning of the forest fires (i.e. from September 1997 to March 1998). The few observations (about 2.7\% of the sample) which were measured before September 1997 were dropped.

${ }^{42}$ Additional tests, like the Anderson canonical correlation test for under-identification and the Cragg-Donald F statistic for weak identification have been implemented and their outcome further supports the validity and exogeneity of the instrument (see Table 3.6).
} 
A last important point to be discussed concerns the second condition for instrumental validity, i.e. the exclusion restriction assumption which implies that the only way though which the instrument affects the dependent variable is via its impact on the endogenous variable.

Given that there isn't any statistical test that can be performed to check whether this assumption is violated (at least when using one instrument only), the instrument validity can't never be known with complete certainty and can only by checked indirectly or falsified by the data. Therefore, I will investigate here some auxiliary hypothesis or implications which can add plausibility to the exclusion restriction.

One can think, indeed, of different situations that can violate the exclusion restriction in this context. The forest fires, for example, may have exerted their effect on children educational achievements through two other possible channels: 1) on the supply-side, they may have destroyed books, schools and harmed teachers and 2) on the demand-side, they also could have negatively affected household income and thereby probably depleted parental resources devoted to education.

With respect to the first point, it can be argued that this channel actually doesn't seem to have mattered: the damages that were reported by the press and by the literature basically consisted in the burning of millions of hectares of wild forest and in the spread of smoke and haze. The state of emergency declared by the Government of Indonesia, that implied the temporary closing of school, government offices, business, airport and port, lasted only ten days (Dauvergne, 1998). Since in this paper, I am identifying children who were hit by the fires in their earliest months of life and who therefore went to school several years later, this supply-side channel is conceivably not relevant.

Similarly, it can be argued that whether the forest fires may have hit household income as well, as long as these economic shortages were quite temporary, parents' investments in education were likely to not be affected by these income losses.

In order to see if this argument is actually confirmed by the data, I have tested (see Table C2 in Appendix C) whether there are significant differences in the effect of exposure to forest fires on household per capita expenditure along the time period considered in this paper and whether exposure to forest fires significantly affected changes in the share of education expenditure.

Results contribute to relief further concerns on instrumental validity as they clearly indicate that the instrument neither significantly affected household income in any of the years considered nor it had any impact on education expenditure. 


\subsubsection{Empirical Estimates}

Before discussing the main findings based on the preferred MFE-IV approach, I will start by showing the estimates from three alternative and less precise econometric approaches, which despite being affected by some bias, are still interesting to the extent that they can provide a first picture on the strength of the nutrition-learning nexus, and-when compared to our core modelthey inform about the magnitude and the direction of the endogeneity bias in the relationship under investigation. These approaches are: (1) the Province-fixed effects (PFE) that essentially control for unobserved heterogeneity within each province; (2) the Province fixed effect combined with instrumental variable (PFE-IV) that address only the correlation between child height and child specific characteristics; and (3) the Mother fixed effects (MFE) which only sweep out the bias due to aspects which are common across sibling. Results are presented in Table 3.5.

The estimates from the two 'naïve' PFE and PFE-IV regressions suggest that there are large positive associations between child height and educational achievements: thereby, children with higher nutritional status tend to complete more grades, perform better in the cognitive test and enter school at younger ages. The relatively large size of these coefficients is, however, much reduced once one controls for the endogeneity bias related to the correlation between child height for age and the sibling-invariant error term component (i.e. supposing a certain degree of substitutability between nutrition and school inputs, parents can engage in compensatory actions in order to equalize learning outcomes among their kids).

Yet the simple within-sibling estimator does not account for the remaining correlation between the endogenous variable and the specific error term component. The preferred mother-fixed effects-instrumental variable estimator, however, contributes to reduce attenuation bias from measurement errors, and-relying on the assumption that the shock is independent of child specific characteristics- allow us to identify the children with greater educational achievements than average (Card, 2001; Alderman et al., 2006).

According to our initial expectations, main findings from the MFE-IV regressions reported in Table 3.6, show that greater child height significantly contributes to improved educational performance, both in terms of completed years of schooling and of cognitive skills.

Results indicate that if the children sampled in this analysis had the nutritional status of the well nourished population of reference, they would have gained on average 0.8 additional grades of school. Interestingly this estimated impact is pretty close to the one found by Alderman et al. (2006). 


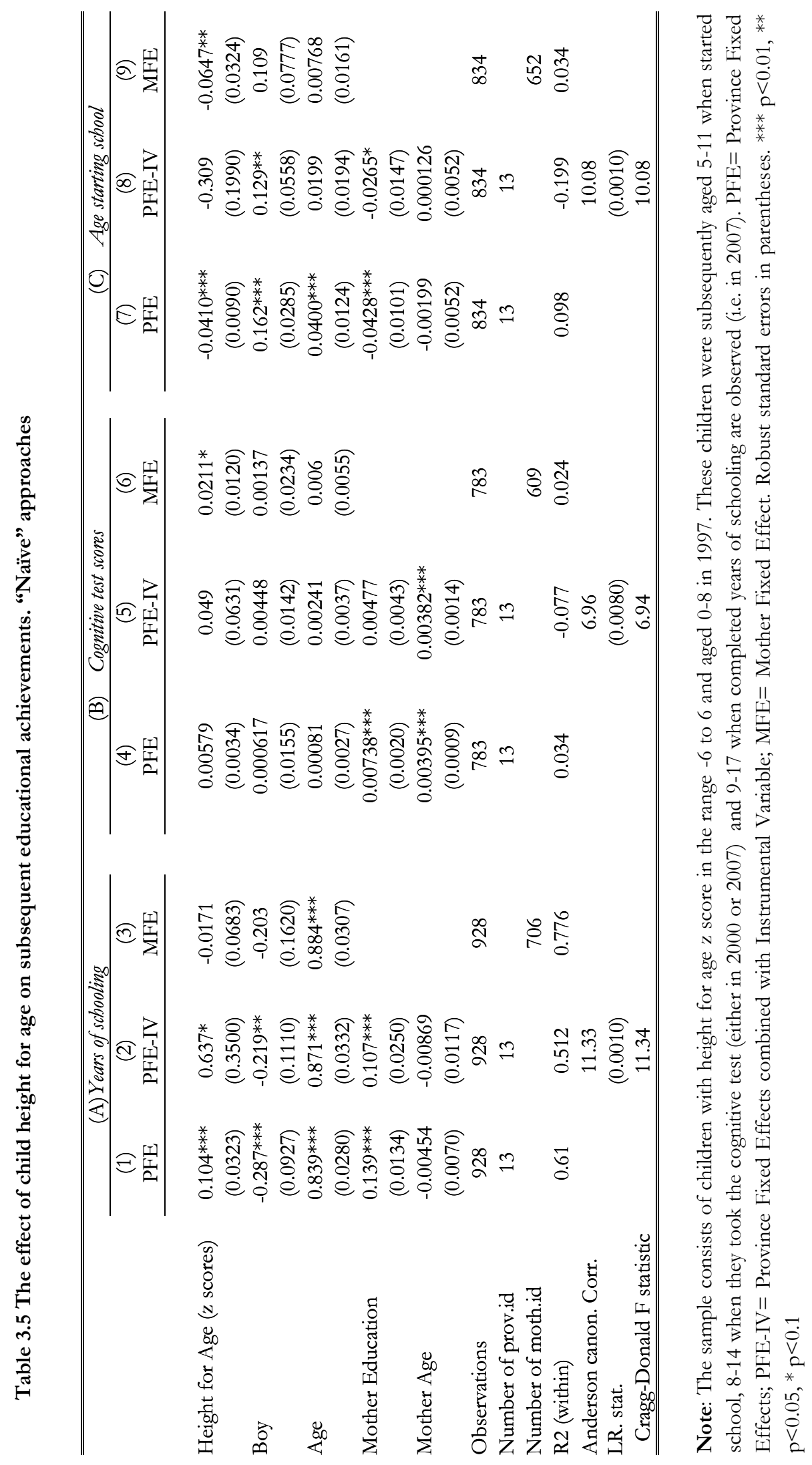


It can be assumed, however, that part of the effect that child nutritional status has on future schooling achievement is transmitted by the age at which the child entered school. In order to detect this transmission channel, a dummy indicating whether the child entered the school on time (i.e. by the age of 7) was added to the baseline MFE-IV model (see Col. 2; 3; 5; 6). Results show that the inclusion of this variable indeed mitigates the magnitude of the impact exerted by height-for-age on the dependent variable, but leaves unaltered the statistical significance of the coefficient.

Lastly, since most of the children have not completed their schooling in 2007, a further specification (Column 3; 6 and 8) replaces the age regressor with age dummies that can better standardize the years of schooling (see Yamauchi, 2008). Here again the positive and significant results are confirmed.

When we look at the estimates on the score achieved on the cognitive test (Col. 4, 5 and 6), results indicate that increased height-for-age is associated to better performance on the test: a child would have obtained $18 \%$ more in her score if she had experienced the same nutritional status of her well nourished peers.

Table 3. 6 The effect of child height for age on subsequent educational achievements. Main Findings, based on the MFE-IV estimator

\begin{tabular}{|c|c|c|c|c|c|c|c|c|}
\hline & \multicolumn{3}{|c|}{ (A) Years of schooling } & \multicolumn{3}{|c|}{ (B) Cognitive test scores } & \multicolumn{2}{|c|}{ (C) Age starting school } \\
\hline & (1) & (2) & (3) & (4) & (5) & (6) & (7) & (8) \\
\hline $\begin{array}{l}\text { Height for Age } \\
\text { (z scores) }\end{array}$ & $\begin{array}{c}0.480 * * \\
(0.236)\end{array}$ & $\begin{array}{c}0.382^{* *} \\
(0.184)\end{array}$ & $\begin{array}{c}0.455^{* *} \\
(0.227)\end{array}$ & $\begin{array}{c}0.0790 \\
(0.0589)\end{array}$ & $\begin{array}{c}0.107 * \\
(0.0612)\end{array}$ & $\begin{array}{c}0.103 * \\
(0.0586)\end{array}$ & $\begin{array}{l}-0.167 \\
(0.118)\end{array}$ & $\begin{array}{l}-0.271 \\
(0.172)\end{array}$ \\
\hline Boy & $\begin{array}{l}-0.134 \\
(0.174)\end{array}$ & $\begin{array}{l}-0.111 \\
(0.160)\end{array}$ & $\begin{array}{l}-0.141 \\
(0.177)\end{array}$ & $\begin{array}{l}0.00482 \\
(0.0259)\end{array}$ & $\begin{array}{l}0.00764 \\
(0.0251)\end{array}$ & $\begin{array}{l}0.00434 \\
(0.0234)\end{array}$ & $\begin{array}{c}0.0940 \\
(0.0787)\end{array}$ & $\begin{array}{c}0.0624 \\
(0.0802)\end{array}$ \\
\hline Age & $\begin{array}{c}0.885^{* * *} \\
(0.0330)\end{array}$ & & & $\begin{array}{c}0.00792 \\
(0.00610)\end{array}$ & & & $\begin{array}{l}0.00586 \\
(0.0169)\end{array}$ & \\
\hline $\begin{array}{l}\text { Entered school } \\
\text { by the age of } 7\end{array}$ & & $\begin{array}{l}0.0597 \\
(0.252)\end{array}$ & $\begin{array}{c}0.285 \\
(0.257)\end{array}$ & & $\begin{array}{l}-0.0306 \\
(0.0438)\end{array}$ & $\begin{array}{l}-0.0268 \\
(0.0404)\end{array}$ & & \\
\hline $\begin{array}{l}\text { Observations } \\
\text { Number of moth.id } \\
\text { Age Fixed Effects } \\
\mathrm{R}^{2} \text { (within) }\end{array}$ & $\begin{array}{l}928 \\
706\end{array}$ & $\begin{array}{l}885 \\
682 \\
0.801\end{array}$ & $\begin{array}{c}885 \\
682 \\
\text { YES } \\
0.810\end{array}$ & $\begin{array}{r}783 \\
609 \\
-0.112\end{array}$ & $\begin{array}{r}769 \\
602 \\
-0.288\end{array}$ & $\begin{array}{c}769 \\
602 \\
\text { YES } \\
-0.140\end{array}$ & $\begin{array}{r}834 \\
652 \\
-0.010\end{array}$ & $\begin{array}{c}834 \\
652 \\
\mathrm{YES} \\
0.041\end{array}$ \\
\hline $\begin{array}{l}\text { Anderson canon. } \\
\text { corr.LR.stat }\end{array}$ & $\begin{array}{l}23.08 \\
(0.000)\end{array}$ & $\begin{array}{c}25.90 \\
(0.000)\end{array}$ & $\begin{array}{c}17.64 \\
(0.000)\end{array}$ & $\begin{array}{c}17.31 \\
(0.000)\end{array}$ & $\begin{array}{c}17.52 \\
(0.000)\end{array}$ & $\begin{array}{c}15.07 \\
(0.000)\end{array}$ & $\begin{array}{c}23.64 \\
(0.000)\end{array}$ & $\begin{array}{c}12.79 \\
(0.000)\end{array}$ \\
\hline $\begin{array}{l}\text { Cragg-Donald F } \\
\text { statistic }\end{array}$ & 23.99 & 27.08 & 17.52 & 17.88 & 18.03 & 14.92 & 24.83 & 12.16 \\
\hline
\end{tabular}

Note: The sample consists of children with height for age $z$ score in the range -6 to 6 and aged 0-8 in 1997. These children were subsequently aged 5-11 when started school, 8-14 when they took the cognitive test (either in 2000 or 2007) and 917 when completed years of schooling are observed (i.e. in 2007). Robust standard errors in parentheses. ${ }^{* *} \mathrm{p}<0.01, * *$ $\mathrm{p}<0.05, * \mathrm{p}<0.1$

Consistently with the findings on years of schooling, the inclusion of the instrument variable estimator increases the magnitude of the impact, suggesting the presence of a downward bias in 
the within sibling estimator. Moreover, improvements in cognitive skills seem to be not significantly associated with readiness to enter school (see Col. 5), although they are positively associated with the age at which the test was taken, possibly implying some positive returns of years of schooling on the development of cognitive skills. The statistical significance of the estimated coefficient on height-for-age $z$-score is, nevertheless, weaker than the one found in the years of schooling models.

Lastly, as argued before, part of the positive effect that child nutrition has on schooling achievement could be transmitted by the optimal timing of entering primary school and indeed, a negative direct relationship is found between height-for-age z-score on age starting school (i.e. better nourished children start school at younger ages). Nevertheless, the hypothesis that child nutrition improves readiness to enter primary school only finds weak statistical support in our regressions (see Columns 7-8).

\subsubsection{Robustness checks}

This section presents several checks which were conducted in order to test for the validity of the findings of the present analysis. Hence, I will deal with issues related to selection bias in the data and address other concerns related to the robustness of the main results.

\section{Potential attrition bias}

One of the major concerns arising from the use of longitudinal datasets is related to the presence of selection bias which can be caused by deaths, missing data in fundamental variables or by the screening out of multiple observations recorded in the same wave and of observations with discrepant information provided across the survey's waves.

Since the main analysis of this paper is based on variations among siblings, any attrition which stems from maternal, household and community characteristics is removed by the inclusion of mother fixed effects (Ziliak and Kniesner, 1998). Yet, there remain some attrition at the individual level which is needed to be tested for.

Table 3.7 reports the determinants of attrition from the 1997-2007 waves. This test which follows the methods set out in Fitzgerald et al. (1998a, 1998b) and Alderman et al. (2001b), is based on a linear probability model where the dependent variable equals 1 if any of the educational outcome were observed in the second period and 0 otherwise. As explanatory variables, I use the same main variables included in the schooling equation: height-for-age $z$ scores; weight for age z-scores; child sex; child age and mother's years of schooling. If these are 
not significantly correlated with attrition, I can assume that there will be no bias in my estimates stemming from attrition on the observables.

Baseline and province fixed effects estimates reported in Columns (1) and (2) of Table 3.7 indicate that it is more likely to observe individuals with poorer initial height-for-age, of male sex, higher initial age (due to the higher rates of mortality during infancy) and born from more educated mothers (probably because of their better accuracy in answering the questionnaire).

The mother fixed effects estimates reported in Column 3 suggest, however, that controlling for mother's fixed effects, none of these variables has a significant effect on the probability of being observed, thereby attenuating any concern about selection bias due to attrition.

Table 3. 7 Determinants of attrition

\begin{tabular}{lccc}
\hline \hline & $(1)$ & $(2)$ & $(3)$ \\
\hline Height for Age z score & $-0.0149^{*}$ & -0.0164 & -0.0136 \\
& $(0.00817)$ & $(0.0106)$ & $(0.00857)$ \\
Weight for Age z score & 0.00501 & 0.00586 & -0.00818 \\
Boy & $(0.00985)$ & $(0.0102)$ & $(0.0107)$ \\
& 0.0228 & 0.0218 & -0.0111 \\
Age in 1997 & $(0.0200)$ & $(0.0195)$ & $(0.0175)$ \\
& $0.0107^{* *}$ & $0.00947^{* *}$ & -0.00273 \\
Mother education & $(0.00502)$ & $(0.00431)$ & $(0.00450)$ \\
Constant & $0.0139^{* * *}$ & $0.0136^{* *}$ & \\
& $(0.00278)$ & $(0.00501)$ & \\
Province Fixed Effects & $0.165^{* * *}$ & $0.170^{* * *}$ & $0.306^{* * *}$ \\
Mother Fixed Effects & $(0.0313)$ & $(0.0392)$ & $(0.0216)$ \\
Observations & $\mathrm{NO}$ & $\mathrm{YES}$ & $\mathrm{NO}$ \\
$\mathrm{R}^{2}$ & $\mathrm{NO}$ & $\mathrm{NO}$ & YES \\
Number of prov.id & 2,181 & 2,181 & 2,181 \\
Number of moth.id & 0.014 & 0.013 & 0.015 \\
& & 13 & 1,706 \\
\end{tabular}

Note: Dependent variable $=1$ if educational outcome was observed, 0 otherwise. Initial sample is 2181 children born from 1990 to 1997 that had their height for age $z$ scores or weight for age $z$ scores or both observed in 1997 and laying in the range -6 and +6 . From this sample, 936 children have their educational outcome observed in subsequent waves. Estimation method: linear probability model. Robust standard errors in parentheses. ${ }^{* * *} \mathrm{p}<0.01,{ }^{* *} \mathrm{p}<0.05,{ }^{*} \mathrm{p}<0.1$

\section{Other checks}

I address here three main concerns that could cast some doubt on the validity of the main analysis: robustness of the estimates to the inclusion of additional covariates in the MFE-IV regressions; adequacy of the indicator used for child nutritional status; and sensitivity of the results to slight changes in the timing of exposure to the shock. 
Tables C3-C5 in Appendix C report the results on the three different measures of educational attainments used in this analysis.

In the first specification, the presence of non-linearities in age has been tested for: while, as expected, there are non linear effects in completed years of schooling, the positive sign on age squared in the test scores regression, suggest that cognitive skills improves at older ages, probably due to positive complementarities with the numbers of years spent at school.

It can also be observed that boys tend to have worse educational attainments than girls, especially in school completion and readiness to school. This result is consistent with the evidence provided in many World Bank and Asian Development Bank reports (see, for example, Asian Development Bank, 2006) and may be partly explained by the higher returns to schooling (at later stages of education) for women than for men (Deolikar, 1993).

Column 3 in Tables C3 and C4 include a dummy variable for children who were already at school at the time that their height was measured. It can be indeed argued that parents may easily alter the amount of nutrition and education inputs for their kids, once they observe their school performance. Doing this check, slightly decreases the magnitude of the height-for-age coefficient but leaves unaltered its statistical significance. Next, I include birth order and interaction terms between this and sex. There might be, indeed, a concern that there is a competition over resources among siblings or that there is a gender bias in parental preferences which is mediated by birth order (Das Gupta, 1987). Results suggest that higher order children tend to perform relatively worse and that -for completed years of school- the effect is stronger among boys.

A second set of robustness checks is related to the adequacy of the measure of nutritional status considered in the main analysis, height-for-age. The measurement of children height was undertaken few months after the shock took place. Given this short time interval, it can be argued therefore that the use an indicator of chronic nutritional deprivation, such as height-forage $z$ - scores, may not be adequate to correctly identify the effect of the shock on nutritional status. The first stage regressions shown in Table 3.4, already confirm the validity of the instrument on height-for-age z-scores and exhibit a smaller impact (both in terms of magnitude and statistical validity) of the shock on the indicator for previous and current nutritional deficiencies given by the weight-for-age z-scores.

Table C6 in Appendix C summarizes the results for the MFE-IV regressions that use weight-forage $z$-scores as the endogenous variable. The estimated coefficients indicate that the magnitude of the effect is relatively larger than the one resulting in Tables 3.6 although the statistical significance is -on average- lower. 
A last concern is related to the robustness of the age range 12-36 months used to identify the exposure to the shock. As argued in Section 3.4.1, the majority of the empirical studies have excluded that ages above 36 months matter but some of them find stronger impact at the age range 12-24. In the preliminary analysis that I conducted, I found -in accordance to Glewwe and King, 2001-zero impact below the second year of life and above the third year of life, but similar results come out when using both age range 12-36 months and 12-24 months, although in the latter case, the power of the tests for instrumental validity and exogeneity is relatively lower.

Table C7 in Appendix C summarizes the results for the MFE-IV regressions using as instrument exposure to forest fires during the second year of life only. In the years of schooling and cognitive test scores regressions the magnitude and statistical significance of the coefficients is slightly higher than in the main analysis whether the weak effect on readiness to school is further confirmed.

\subsection{Conclusions}

This paper investigated empirically the relationship between child nutrition and subsequent educational attainments using longitudinal data from Indonesia. By applying a sibling difference model combined with instrumental variable estimation, the estimates obtained address endogeneity biases. There are three relevant remarks which emerge from this study. First, results suggest that good nutritional status in childhood significantly contributes to improved, school attainments. Well nourished children complete 0.8 grades more than their less fortunate peers and perform better in cognitive tests $(+18 \%)$. Poor nutritional status also tends to delay enrolment, although the strength of this relationship has weak statistical support. The main findings, which are confirmed by robustness checks, imply that from a policy perspective school and nutrition objectives should not be seen as competing goals but are closely interlinked. Many countries-including Indonesia- have been struggling with the full realization of the Millennium Development Goals. Although remarkable progress has been made, there is still consistent space to be improved and there is need to continue on stable and durable paths of development. Financial resources devoted to child nutrition policies do not necessarily compete with those for the education agenda; instead, as implied in this study, they can be regarded as a more cost effective way to raise present and future socio-economic development.

Second, in line with the growing body of scientific studies on the long-run impact of childhood shocks (see, inter alia, Akresh et al. 2012; Almond and Currie, 2011a, 2011b; Bhalotra, 2010), exposure to environmental disasters may have long lasting effects on individuals, despite any 
compensatory actions which they or their caregivers may undertake to alleviate the impact of the shock.

Third, consistent with Glewwe and King (2001), I do not find any support for the hypothesis that prenatal and first six months of life's nutritional conditions have long term effects on cognitive and education outcomes. Instead, the critical period where health shocks may have permanent consequences on human capital development is found in the second and third years of life.

An important implication of these two last remarks is that nutrition interventions or broader food security programs that target children in this critical period of their life not only substantially contribute to protect vulnerable people against uninsured shocks but they can also deliver positive long term outcomes in educational achievements and thereby contribute to future socio-economic development. 


\section{Appendix A}

Appendix on Essay "Identifying Synergies and Complementarities Between MDGs: Results from Cluster Analysis". 


\section{Relative-Performance Indicators}

Figure A 1 Relative annual changes in primary completion rate between 1990 and 2008 against initial levels

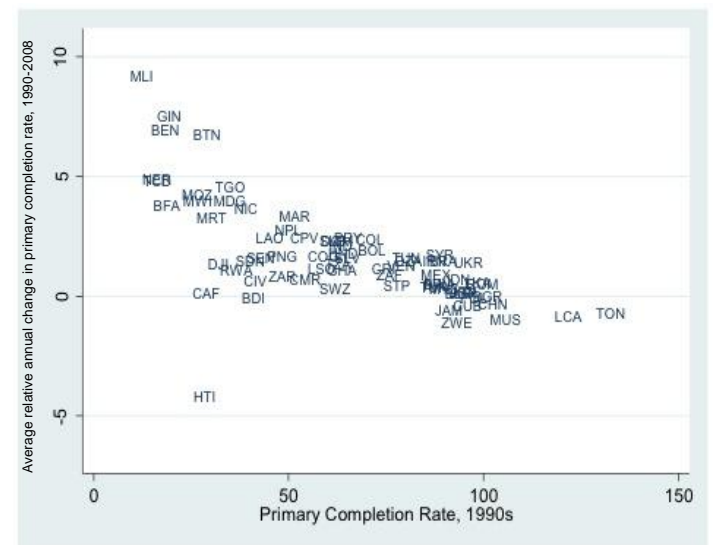

Figure A 3 Relative annual changes in under-five mortality rate(per 1,000 live births) between 1990 and 2008 against initial levels

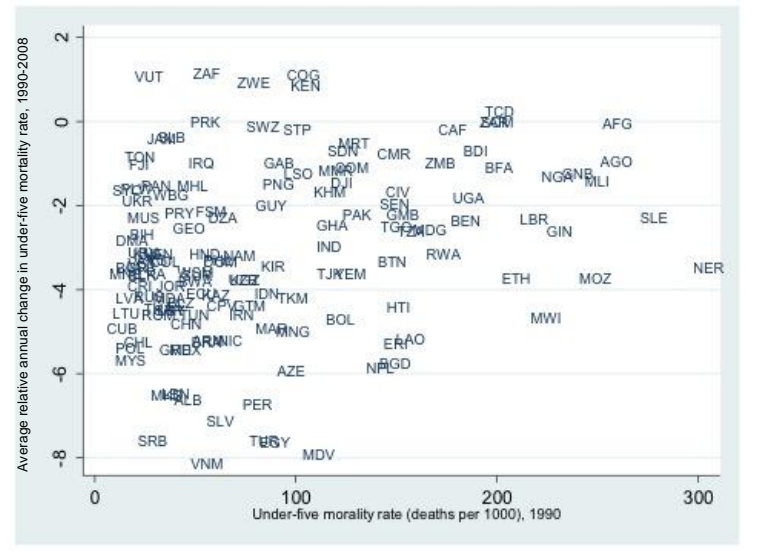

Figure A 2 Relative annual changes in female-to-male ratio of gross secondary school enrolment between 1990 and 2008 against initial levels

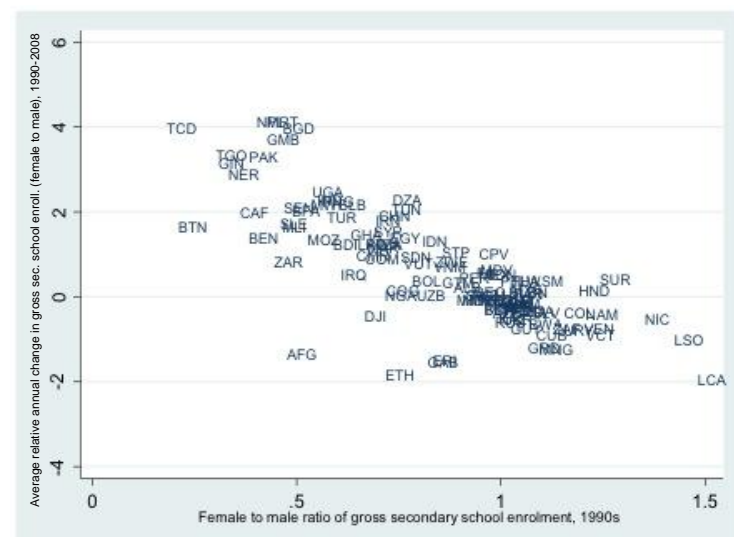

Figure A 4 Relative annual changes in maternal mortality rate between 1990 and 2008 against initial levels

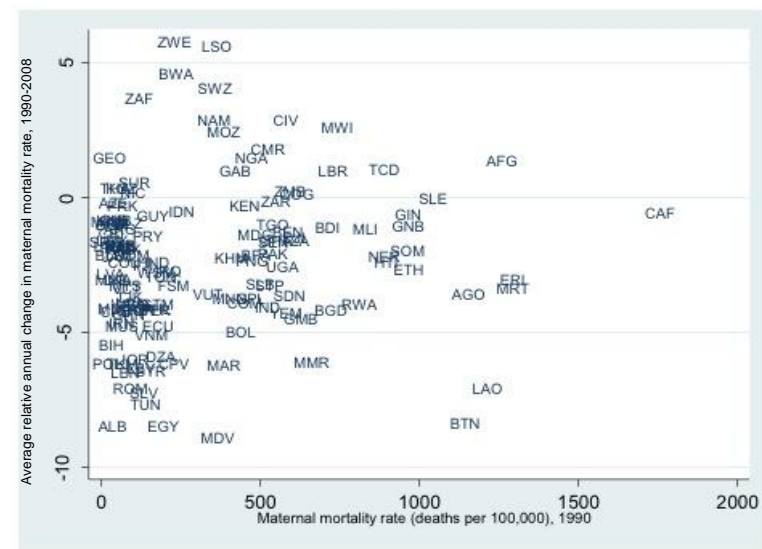

Table A 1 Regression results for the relative performance indicators

\begin{tabular}{lcc}
\hline \hline \multirow{2}{*}{ Dependent variable: } & $\begin{array}{c}\text { Average relative annual change in primary } \\
\text { completion rate, } 1990-2008\end{array}$ & $\begin{array}{c}\text { Average relative annual change in under- } \\
\text { five mortality rate, 1990-2008 }\end{array}$ \\
\hline Intercept & 4.84 & -3.83 \\
& 10.22 & -13.70 \\
Initial value & -.048 & .008 \\
& -7.26 & 3.34 \\
$\mathrm{R}^{2}$ & 0.43 & 0.07 \\
$\mathrm{~N}$ & 71 & 140 \\
\hline \multirow{3}{*}{ Dependent variable: } & Average relative annual change in female & Average relative annual change in \\
& to male ratio of gross secondary school & maternal mortality rate, $1990-2008$ \\
\hline Intercept & enrolment, 1990-2008 & -2.64 \\
& 3.98 & -7.63 \\
Initial value & 15.18 & .000 \\
& -3.89 & 1.19 \\
$\mathrm{R}^{2}$ & -13.35 & 0.01 \\
$\mathrm{~N}$ & 0.62 & 134 \\
\hline \hline
\end{tabular}

Note: T-statistics in italics 


\section{Cluster analyses}

Table A 2 Primary Completion and Child mortality

\begin{tabular}{|c|c|c|c|c|c|c|}
\hline Group & Variable: RPI & $\begin{array}{c}\text { Number of } \\
\text { countries }\end{array}$ & Mean & $\begin{array}{l}\text { Std. } \\
\text { Dev. }\end{array}$ & Min & Max \\
\hline \multirow{2}{*}{1} & Child Mortality & \multirow{2}{*}{22} & -0.972 & 0.464 & -2.24 & -0.46 \\
\hline & Primary Completion & & 0.252 & 0.302 & -0.34 & 0.752 \\
\hline \multirow{2}{*}{2} & Child Mortality & \multirow{2}{*}{22} & 0.318 & 0.528 & -0.185 & 1.61 \\
\hline & Primary Completion & & 0.284 & 0.286 & -0.082 & 0.876 \\
\hline \multirow{2}{*}{3} & Child Mortality & \multirow{2}{*}{22} & 0.999 & 0.676 & -0.344 & 2.31 \\
\hline & Primary Completion & & -0.744 & 0.538 & -2.05 & -0.068 \\
\hline \multicolumn{3}{|c|}{ Number of clusters } & \multicolumn{4}{|c|}{ Calinski/ Harabasz Pseudo F } \\
\hline 2 & \multicolumn{6}{|c|}{58.45} \\
\hline 3 & \multicolumn{6}{|c|}{62.7} \\
\hline 4 & \multicolumn{6}{|c|}{58.43} \\
\hline
\end{tabular}

Table A 3 Performance in primary completion and in child mortality. Cluster Membership

\begin{tabular}{lll}
\hline \hline G1: Good & $\begin{array}{l}\text { G2: Partial (child-mortality } \\
\text { lopsided) }\end{array}$ & G3: Bad \\
\hline Bolivia & Algeria & Burkina Faso \\
Brazil & Belarus & Burundi \\
Cape Verde & Botswana & Cameroon \\
China & Bulgaria & Central African Republic \\
Cuba & Chad & Congo, Dem. Rep. \\
El Salvador & Colombia & Congo, Rep. \\
Indonesia & Costa Rica & Cote d'Ivoire \\
Iran, Islamic Rep. & Dominican Republic & Djibouti \\
Lao PDR & Honduras & Ghana \\
Malawi & India & Jamaica \\
Malaysia & Jordan & Lesotho \\
Mexico & Madagascar & Mauritania \\
Morocco & Paraguay & Mauritius \\
Mozambique & Philippines & Papua New Guinea \\
Nepal & Solomon Islands & Rwanda \\
Nicaragua & Sri Lanka & Sao Tome and Principe \\
Niger & St. Lucia & Senegal \\
Poland & Togo & South Africa \\
Romania & Tonga & Sudan \\
Syrian Arab Republic & Ukraine & Swaziland \\
Tunisia & Uruguay & Tanzania \\
Turkey & Venezuela, RB & Zimbabwe \\
\hline \hline
\end{tabular}

Table A 4 Primary Completion and Maternal mortality

\begin{tabular}{clccccc}
\hline \hline Group & Variable: RPI & $\begin{array}{c}\text { Number of } \\
\text { countries }\end{array}$ & Mean & Std. Dev. & Min & Max \\
\hline \multirow{2}{*}{1} & Maternal Mortality & \multirow{2}{*}{25} & -0.915 & 0.52 & -1.94 & -0.152 \\
& Primary Completion & & 0.166 & 0.313 & -0.4 & 0.752 \\
\hline \multirow{2}{*}{2} & Maternal Mortality & \multirow{2}{*}{28} & 0.437 & 0.462 & -0.143 & 1.7 \\
& Primary Completion & & 0.146 & 0.423 & -0.705 & 0.876 \\
\hline \multirow{2}{*}{3} & Maternal Mortality & \multirow{2}{*}{7} & 2.28 & 0.542 & 1.42 & 2.93 \\
& Primary Completion & & -0.669 & 0.476 & -1.32 & 0.011 \\
\hline \multirow{2}{*}{4} & Maternal Mortality & \multirow{2}{*}{4} & 0.375 & 0.244 & 0.204 & 0.732 \\
& Primary Completion & & -1.52 & 0.487 & -2.05 & -1.02 \\
\hline Number of clusters & & Calinski/ Harabasz Pseudo F & \\
\hline 2 & & & 49.45 \\
3 & & 54.85 & & \\
4
\end{tabular}


Table A 5 Performance in primary completion and in maternal mortality. Cluster Membership

\begin{tabular}{|c|c|c|c|}
\hline G1: Good & $\begin{array}{l}\text { G2: Partial } \\
\text { (maternal mortality- } \\
\text { lopsided) }\end{array}$ & G3: Bad & G4: Quasi-Bad \\
\hline Algeria & Belarus & Botswana & Burundi \\
\hline Bolivia & Bulgaria & Cameroon & Central African Rep \\
\hline Brazil & Burkina Faso & Cote d'Ivoire & Congo, Dem. Rep. \\
\hline Cape Verde & Chad & Lesotho & Djibouti \\
\hline China & Colombia & South Africa & \\
\hline El Salvador & Congo, Rep. & Swaziland & \\
\hline India & Costa Rica & Zimbabwe & \\
\hline Iran, Islamic Rep. & Cuba & & \\
\hline Jordan & Dominican Republic & & \\
\hline Lao PDR & Ghana & & \\
\hline Malaysia & Honduras & & \\
\hline Mauritania & Indonesia & & \\
\hline Mauritius & Jamaica & & \\
\hline Morocco & Madagascar & & \\
\hline Nepal & Malawi & & \\
\hline Philippines & Mexico & & \\
\hline Poland & Mozambique & & \\
\hline Romania & Nicaragua & & \\
\hline Sao Tome and Principe & Niger & & \\
\hline Solomon Islands & Papua New Guinea & & \\
\hline Sri Lanka & Paraguay & & \\
\hline St. Lucia & Senegal & & \\
\hline Syrian Arab Republic & Tanzania & & \\
\hline Tunisia & Togo & & \\
\hline \multirow[t]{4}{*}{ Turkey } & Tonga & & \\
\hline & Ukraine & & \\
\hline & Uruguay & & \\
\hline & Venezuela, RB & & \\
\hline
\end{tabular}

Table A 6 Primary Completion and gender gap in education

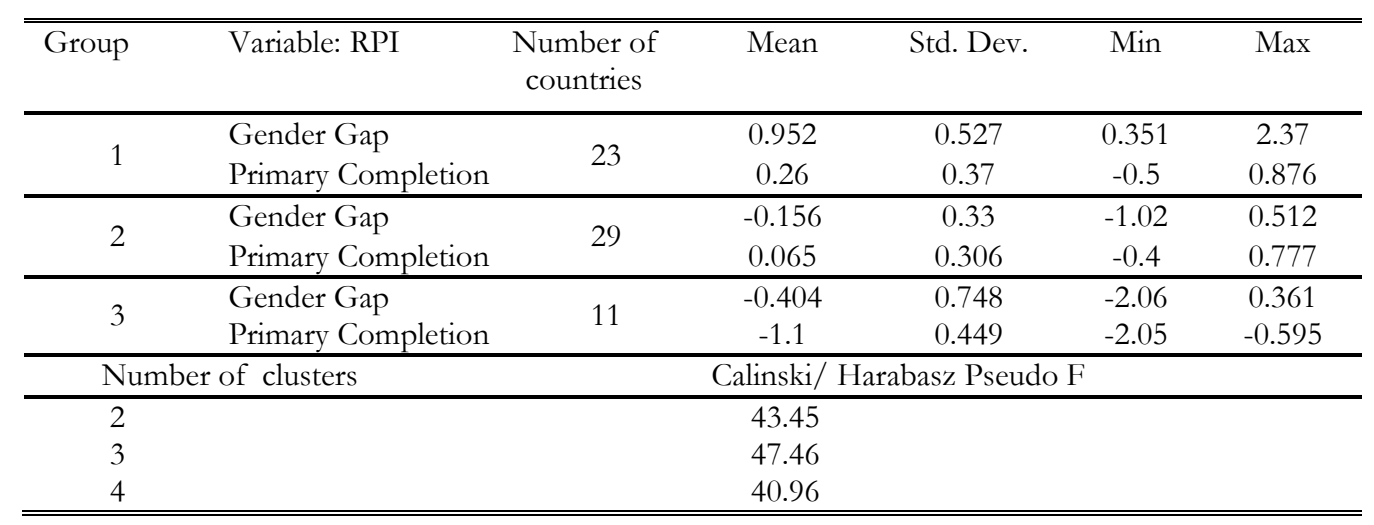


Table A 7 Performance in female-to male ratio of gross secondary school enrolment and in primary completion rate. Cluster Membership

\begin{tabular}{lll}
\hline \hline G1: Good & G2: Partial (education-lopsided) & G3: Bad \\
\hline Algeria & Belarus & Burundi \\
Cape Verde & Bolivia & Cameroon \\
Chad & Botswana & Central African Republic \\
China & Bulgaria & Congo, Dem. Rep. \\
Colombia & Burkina Faso & Djibouti \\
Honduras & Congo, Rep. & Jamaica \\
India & Costa Rica & Rwanda \\
Indonesia & Cuba & Senegal \\
Iran, Islamic Rep. & El Salvador & Sudan \\
Lesotho & Ghana & Swaziland \\
Malawi & Jordan & Zimbabwe \\
Mauritania & Lao PDR & \\
Mexico & Madagascar & \\
Nepal & Malaysia & \\
Nicaragua & Mauritius & \\
Niger & Morocco & \\
Papua New Guinea & Mozambique & \\
Sao Tome and Principe & Paraguay & \\
Solomon Islands & Philippines & \\
Syrian Arab Republic & Poland & \\
Togo & Romania & \\
Tonga & South Africa & \\
Tunisia & Sri Lanka & \\
& St. Lucia & \\
& Tanzania & \\
& Turkey & \\
\hline \hline
\end{tabular}

Table A 8 Gender gap in education and child mortality

\begin{tabular}{|c|c|c|c|c|c|c|}
\hline Group & Variable: RPI & Number of countries & Mean & Std. Dev. & Min & Max \\
\hline \multirow{2}{*}{1} & Child Mortality & \multirow{2}{*}{15} & -1.65 & 0.514 & -2.51 & -0.981 \\
\hline & Gender Gap & & 0.207 & 0.336 & -0.449 & 0.648 \\
\hline \multirow{2}{*}{2} & Child Mortality & \multirow{2}{*}{22} & -0.179 & 0.388 & -0.966 & 0.529 \\
\hline & Gender Gap & & 0.922 & 0.435 & 0.282 & 1.9 \\
\hline \multirow{2}{*}{3} & Child Mortality & \multirow{2}{*}{38} & -0.2 & 0.455 & -0.982 & 0.671 \\
\hline & Gender Gap & & -0.249 & 0.306 & -1.03 & 0.141 \\
\hline \multirow{2}{*}{4} & Child Mortality & \multirow{2}{*}{13} & 1.01 & 0.54 & 0.587 & 2.09 \\
\hline & Gender Gap & & -0.94 & 0.376 & -2.62 & -0.367 \\
\hline \multirow{2}{*}{5} & Child Mortality & \multirow{2}{*}{14} & 1.49 & 0.726 & 0.829 & 2.37 \\
\hline & Gender Gap & & 0.38 & 0.422 & -0.231 & 1.02 \\
\hline \multicolumn{2}{|c|}{ Number of clusters } & \multicolumn{5}{|c|}{ Calinski/ Harabasz Pseudo F } \\
\hline 2 & & \multicolumn{5}{|c|}{67.99} \\
\hline 3 & & \multicolumn{5}{|c|}{64.38} \\
\hline 4 & & \multicolumn{5}{|c|}{71.07} \\
\hline 5 & & \multicolumn{5}{|c|}{80.51} \\
\hline
\end{tabular}


Table A 9 Performance in female-to male ratio of gross secondary school enrolment and in Child Mortality. Cluster Membership

\begin{tabular}{|c|c|c|c|c|}
\hline $\begin{array}{l}\text { G1: Partial-Good } \\
\text { (child health- } \\
\text { lopsided) }\end{array}$ & $\begin{array}{l}\text { G2: Partial-Good } \\
\text { (educational gender } \\
\text { equity-lopsided) }\end{array}$ & $\begin{array}{l}\text { G3: Partial-bad } \\
\text { (educational } \\
\text { gender gap- } \\
\text { lopsided) }\end{array}$ & G4: Bad & $\begin{array}{l}\text { G5: Partial Bad (child } \\
\text { mortality-lopsided) }\end{array}$ \\
\hline $\begin{array}{l}\text { Albania } \\
\text { Azerbaijan } \\
\text { Egypt, Arab Rep. } \\
\text { El Salvador } \\
\text { Lao PDR } \\
\text { Lebanon } \\
\text { Macedonia, FYR } \\
\text { Malawi } \\
\text { Malaysia } \\
\text { Maldives } \\
\text { Mexico } \\
\text { Niger } \\
\text { Peru } \\
\text { Turkey } \\
\text { Vietnam }\end{array}$ & $\begin{array}{l}\text { Algeria } \\
\text { Belize } \\
\text { Cape Verde } \\
\text { China } \\
\text { Colombia } \\
\text { Gambia, The } \\
\text { Guinea } \\
\text { Honduras } \\
\text { India } \\
\text { Indonesia } \\
\text { Iran, Islamic Rep. } \\
\text { Namibia } \\
\text { Nicaragua } \\
\text { Pakistan } \\
\text { Philippines } \\
\text { Samoa } \\
\text { Suriname } \\
\text { Syrian Arab Republic } \\
\text { Thailand } \\
\text { Togo } \\
\text { Tunisia } \\
\text { Uganda }\end{array}$ & $\begin{array}{l}\text { Belarus } \\
\text { Bolivia } \\
\text { Botswana } \\
\text { Bulgaria } \\
\text { Burkina Faso } \\
\text { Chile } \\
\text { Costa Rica } \\
\text { Cuba } \\
\text { Ecuador } \\
\text { Georgia } \\
\text { Ghana } \\
\text { Grenada } \\
\text { Guatemala } \\
\text { Jordan } \\
\text { Kazakhstan } \\
\text { Kyrgyz Republic } \\
\text { Latvia } \\
\text { Madagascar } \\
\text { Mali } \\
\text { Moldova } \\
\text { Mongolia } \\
\text { Morocco } \\
\text { Mozambique } \\
\text { Paraguay } \\
\text { Poland } \\
\text { Romania } \\
\text { Russian Federation } \\
\text { Rwanda } \\
\text { Senegal } \\
\text { Sierra Leone } \\
\text { Sri Lanka } \\
\text { St. Kitts and Nevis } \\
\text { St. Lucia } \\
\text { St. Vincent and the } \\
\text { Grenadines } \\
\text { Tanzania } \\
\text { Uruguay } \\
\text { Uzbekistan } \\
\text { Venezuela, RB }\end{array}$ & $\begin{array}{l}\text { Burundi } \\
\text { Cameroon } \\
\text { Central African Republic } \\
\text { Comoros } \\
\text { Congo, Dem. Rep. } \\
\text { Congo, Rep. } \\
\text { Djibouti } \\
\text { Gabon } \\
\text { Guyana } \\
\text { Iraq } \\
\text { Mauritius } \\
\text { Myanmar } \\
\text { Ukraine }\end{array}$ & $\begin{array}{l}\text { Chad } \\
\text { Fiji } \\
\text { Jamaica } \\
\text { Lesotho } \\
\text { Panama } \\
\text { Papua New Guinea } \\
\text { Sao Tome and Principe } \\
\text { Solomon Islands } \\
\text { South Africa } \\
\text { Sudan } \\
\text { Swaziland } \\
\text { Tonga } \\
\text { Vanuatu } \\
\text { Zimbabwe }\end{array}$ \\
\hline
\end{tabular}


Table A 10 Gender gap in education and maternal mortality

\begin{tabular}{clccccc}
\hline \hline Group & Variable: RPI & $\begin{array}{c}\text { Number of } \\
\text { countries }\end{array}$ & Mean & Std. Dev. & Min & Max \\
\hline \multirow{2}{*}{1} & Maternal Mortality & \multirow{2}{*}{16} & -0.575 & 0.529 & -1.82 & 0.052 \\
& Gender Gap & & 0.975 & 0.396 & 0.332 & 1.9 \\
\hline \multirow{2}{*}{2} & Maternal Mortality & \multirow{2}{*}{29} & -0.869 & 0.552 & -2.07 & -0.065 \\
& Gender Gap & & -0.19 & 0.376 & -1.15 & 0.463 \\
\hline \multirow{2}{*}{3} & Maternal Mortality & \multirow{2}{*}{25} & 0.36 & 0.374 & -0.24 & 1.1 \\
& Gender Gap & 0.408 & 0.439 & -0.149 & 1.75 \\
\hline \multirow{2}{*}{4} & Maternal Mortality & \multirow{2}{*}{23} & 0.904 & 0.693 & 0.2 & 2.5 \\
& Gender Gap & -0.517 & 0.309 & -1.53 & -0.063 \\
\hline Number of clusters & \multicolumn{5}{c}{ Calinski/ Harabasz Pseudo F } \\
\hline 2 & & 47.06 \\
3 & & 55.3 \\
4
\end{tabular}

Table A 11 Performance in female-to male ratio of gross secondary school enrolment and in Maternal Mortality. Cluster Membership

\begin{tabular}{|c|c|c|c|}
\hline $\begin{array}{l}\text { G1: Quasi-Good } \\
\text { (educational gender } \\
\text { equity -lopsided) }\end{array}$ & $\begin{array}{l}\text { G2: Partial (maternal health- } \\
\text { lopsided) }\end{array}$ & $\begin{array}{l}\text { G3: Partial } \\
\text { (educational } \\
\text { gender equity- } \\
\text { lopsided) }\end{array}$ & G4: Bad \\
\hline $\begin{array}{l}\text { Algeria } \\
\text { Cape Verde } \\
\text { China } \\
\text { Gambia, The } \\
\text { Honduras } \\
\text { India } \\
\text { Iran, Islamic Rep. } \\
\text { Pakistan } \\
\text { Papua New Guinea } \\
\text { Philippines } \\
\text { Samoa } \\
\text { Sao Tome and Principe } \\
\text { Solomon Islands } \\
\text { Tunisia } \\
\text { Turkey } \\
\text { Uganda }\end{array}$ & $\begin{array}{l}\text { Albania } \\
\text { Bolivia } \\
\text { Chile } \\
\text { Comoros } \\
\text { Ecuador } \\
\text { El Salvador } \\
\text { Grenada } \\
\text { Guatemala } \\
\text { Iraq } \\
\text { Jordan } \\
\text { Lao PDR } \\
\text { Latvia } \\
\text { Lebanon } \\
\text { Mauritius } \\
\text { Moldova } \\
\text { Mongolia } \\
\text { Morocco } \\
\text { Myanmar } \\
\text { Peru } \\
\text { Poland } \\
\text { Romania } \\
\text { Rwanda } \\
\text { Sri Lanka } \\
\text { St. Lucia } \\
\text { St. Vincent and the Grenadines } \\
\text { Sudan } \\
\text { Syrian Arab Republic } \\
\text { Vanuatu } \\
\text { Vietnam }\end{array}$ & $\begin{array}{l}\text { Belarus } \\
\text { Belize } \\
\text { Burkina Faso } \\
\text { Chad } \\
\text { Colombia } \\
\text { Costa Rica } \\
\text { Fiji } \\
\text { Ghana } \\
\text { Guinea } \\
\text { Indonesia } \\
\text { Jamaica } \\
\text { Malaysia } \\
\text { Mexico } \\
\text { Nicaragua } \\
\text { Niger } \\
\text { Panama } \\
\text { Paraguay } \\
\text { Senegal } \\
\text { Suriname } \\
\text { Tanzania } \\
\text { Thailand } \\
\text { Togo } \\
\text { Tonga } \\
\text { Uruguay } \\
\text { Venezuela, RB }\end{array}$ & $\begin{array}{l}\text { Azerbaijan } \\
\text { Botswana } \\
\text { Bulgaria } \\
\text { Burundi } \\
\text { Cameroon } \\
\text { Central African Republic } \\
\text { Congo, Dem. Rep. } \\
\text { Congo, Rep. } \\
\text { Cuba } \\
\text { Georgia } \\
\text { Guyana } \\
\text { Kazakhstan } \\
\text { Kyrgyz Republic } \\
\text { Macedonia, FYR } \\
\text { Madagascar } \\
\text { Mali } \\
\text { Mozambique } \\
\text { Russian Federation } \\
\text { Sierra Leone } \\
\text { South Africa } \\
\text { Swaziland } \\
\text { Ukraine } \\
\text { Uzbekistan }\end{array}$ \\
\hline
\end{tabular}


Table A 12 Child Mortality and Maternal Mortality

\begin{tabular}{clccccc}
\hline \hline Group & Variable: RPI & $\begin{array}{c}\text { Number of } \\
\text { countries }\end{array}$ & Mean & Std. Dev. & Min & Max \\
\hline \multirow{2}{*}{1} & Child Mortality & \multirow{2}{*}{34} & -1.1 & 0.627 & -2.52 & -0.185 \\
& Maternal Mortality & & -1.06 & 0.648 & -2.38 & -0.099 \\
\hline \multirow{2}{*}{2} & Child Mortality & \multirow{2}{*}{27} & 0.986 & 0.46 & 0.208 & 2.37 \\
& Maternal Mortality & & -0.301 & 0.482 & -1.42 & 0.395 \\
\hline \multirow{2}{*}{3} & Child Mortality & \multirow{2}{*}{50} & -0.168 & 0.38 & -1.31 & 0.37 \\
& Maternal Mortality & & 0.257 & 0.561 & -0.79 & 1.7 \\
\hline \multirow{2}{*}{4} & Child Mortality & \multirow{2}{*}{20} & 1.07 & 0.703 & -0.18 & 2.31 \\
& Maternal Mortality & & 1.45 & 0.751 & 0.641 & 2.93 \\
\hline Number of clusters & \multicolumn{7}{c}{ Calinski/ Harabasz Pseudo F } & \\
\hline 2 & & 91.74 \\
3 & 78.7 & & \\
4 & & 93.33 \\
\hline \hline
\end{tabular}

Table A 13 Performance in child mortality and in maternal mortality. Cluster Membership

\begin{tabular}{|c|c|c|c|}
\hline G1: Good & $\begin{array}{l}\text { G2: Partial (child } \\
\text { mortality-lopsided) }\end{array}$ & $\begin{array}{l}\text { G3: Partial (child } \\
\text { mortality-lopsided) }\end{array}$ & G4: Bad \\
\hline Albania & Algeria & Argentina & Afghanistan \\
\hline Bangladesh & Angola & Armenia & Botswana \\
\hline Bhutan & Bosnia and Herzegovina & Belarus & Cameroon \\
\hline Bolivia & Burkina Faso & Belize & Chad \\
\hline Brazil & Burundi & Benin & Congo, Dem. Rep. \\
\hline Cape Verde & Cambodia & Bulgaria & Congo, Rep. \\
\hline Chile & Central African Republic & Colombia & Cote d'Ivoire \\
\hline China & Comoros & Costa Rica & Gabon \\
\hline Egypt, Arab Rep. & Djibouti & Cuba & Georgia \\
\hline El Salvador & Fiji & Dominican Republic & Guyana \\
\hline Eritrea & Gambia, The & Ecuador & Kenya \\
\hline Ethiopia & Iraq & Ghana & Korea, Dem. Rep. \\
\hline Grenada & Jamaica & Guinea & Lesotho \\
\hline Guatemala & Mauritania & Guinea-Bissau & Namibia \\
\hline Haiti & Mauritius & Honduras & Nigeria \\
\hline Iran, Islamic Rep. & Micronesia, Fed. Sts. & India & South Africa \\
\hline Jordan & Myanmar & Indonesia & Swaziland \\
\hline Lao PDR & Panama & Kazakhstan & Ukraine \\
\hline Lebanon & Papua New Guinea & Kyrgyz Republic & Zambia \\
\hline Libya & Paraguay & Latvia & Zimbabwe \\
\hline Malaysia & Sao Tome and Principe & Liberia & \\
\hline Maldives & Solomon Islands & Lithuania & \\
\hline Mongolia & Somalia & Madagascar & \\
\hline Morocco & Sudan & Malawi & \\
\hline Nepal & Tonga & Mali & \\
\hline Niger & Vanuatu & Mexico & \\
\hline Peru & West Bank and Gaza & Moldova & \\
\hline Poland & & Montenegro & \\
\hline Romania & & Mozambique & \\
\hline Syrian Arab Republic & & Nicaragua & \\
\hline Tunisia & & Pakistan & \\
\hline Turkey & & Philippines & \\
\hline Turkmenistan & & Russian Federation & \\
\hline \multirow[t]{9}{*}{ Vietnam } & & Rwanda & \\
\hline & & Samoa & \\
\hline & & Senegal & \\
\hline & & Sierra Leone & \\
\hline & & Sri Lanka & \\
\hline & & St. Lucia & \\
\hline & & St. Vincent and the $G$ & adines \\
\hline & & Suriname & \\
\hline & & Tajikistan & \\
\hline
\end{tabular}




\section{Appendix B}

Appendix on Essay "What drives child health improvements in Indonesian households? A longitudinal analysis". 
Table B 1 Description of variables used

\begin{tabular}{|c|c|}
\hline Variable & Description \\
\hline ZHFA & Height-for-Age z-scores \\
\hline Father Height & Father height (in centimetres) \\
\hline Mother Height & Mother height (in centimetres) \\
\hline Male & Dummy equals 1 if male, 0 otherwise \\
\hline Rural & Dummy equals 1 if place of residence is in rural areas, 0 otherwise \\
\hline Moth.Edu. & Mother's completed years of schooling \\
\hline Fath.Edu. & Father's completed years of schooling \\
\hline Log real PCE & $\begin{array}{l}\text { Log of real per capita expenditure (excluding expenses on medicine } \\
\text { and health goods) }\end{array}$ \\
\hline Log nom. PCE & $\begin{array}{l}\text { Log of nominal per capita expenditure (excluding expenses on } \\
\text { medicine and health goods) }\end{array}$ \\
\hline $\mathrm{HH}$ poorness index & Household poorness index \\
\hline Breastfeeding & $\begin{array}{l}\text { Dummy equals } 1 \text { if the child was ever breastfed and no other food was } \\
\text { introduced before the first month of life, } 0 \text { otherwise }\end{array}$ \\
\hline HH size & Number of members living in the same household \\
\hline Water & Dummy equals 1 if household has piped water, 0 otherwise \\
\hline Sanitation & Dummy equals 1 if household has a toilet, 0 otherwise \\
\hline Moth.age birth & Mother's age when she gave birth \\
\hline Moth.low BMI & $\begin{array}{l}\text { Dummy equals } 1 \text { if the mother's BMI is equals or below the } 18.5 \\
\text { threshold, } 0 \text { otherwise }\end{array}$ \\
\hline Midwives & Number of midwives in the community \\
\hline Health Posts & Number of health posts in the community \\
\hline
\end{tabular}

Figure B 1 Mean stunting z-score by age (three-month interval)

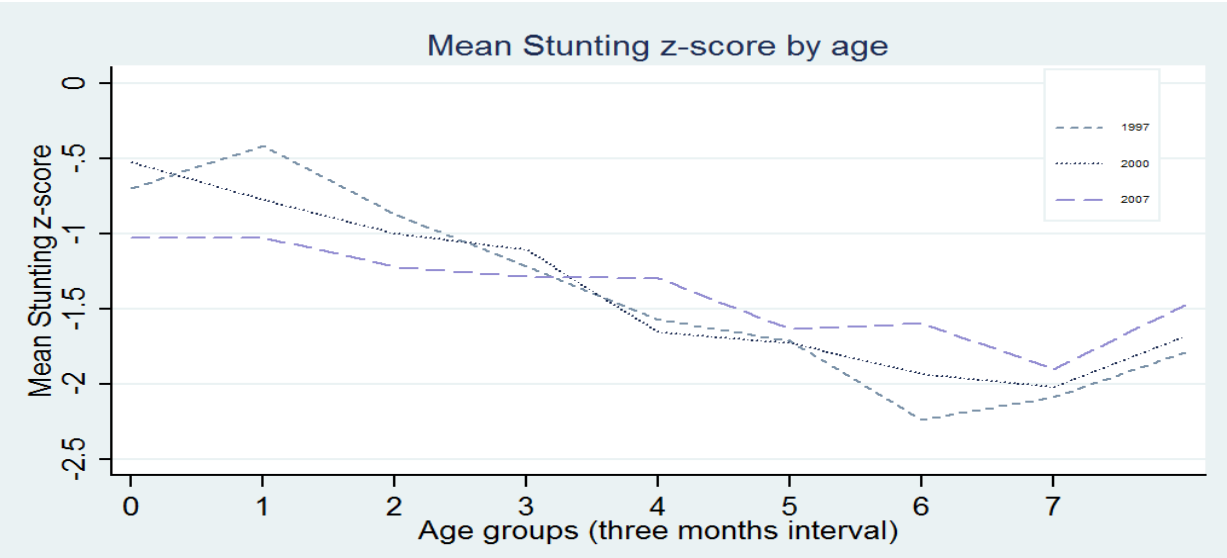


Table B 2 Test for systematic differences in sample composition

\begin{tabular}{lllll}
\hline \hline & \multicolumn{3}{c}{$(1)$} & \multicolumn{3}{c}{$(2)$} \\
\cline { 2 - 5 } ZHFA (mean) & -0.00294 & $(0.0081)$ & -0.0129 & $(0.0218)$ \\
Male & 0.0102 & $(0.0159)$ & -0.00046 & $(0.0312)$ \\
Rural & $-0.0429 * *$ & $(0.0167)$ & 0.267 & $(0.333)$ \\
Fath.Edu. (mean) & -0.00376 & $(0.0028)$ & -0.00694 & $(0.0328)$ \\
Moth.Edu. (mean) & 0.00317 & $(0.0029)$ & -0.0148 & $(0.0364)$ \\
Initial Age (in months) & $-0.00488^{* * *}$ & $(0.0002)$ & $-0.006^{* * *}$ & $(0.0031)$ \\
Constant & $0.662^{* * *}$ & $(0.0320)$ & 0.359 & $(0.380)$ \\
Number of children & 2,648 & & 2,648 & \\
R-squared & 0.206 & & 0.625 & \\
Household Dummies included & \multicolumn{3}{c}{ NO ES } \\
\hline \hline
\end{tabular}

Note: Dependent variable $=1$ if child was observed in all the three waves.

Estimation method: linear probability model. Robust standard errors in parentheses.

Table B 3 Effect of mother education on the probability of breastfeeding

\begin{tabular}{lccc}
\hline \hline & $(1)$ & $(2)$ & $(3)$ \\
\hline Midwives & 0.00643 & 0.00824 & -0.00914 \\
& $(0.0171)$ & $(0.0170)$ & $(0.00891)$ \\
Male & 0.0363 & 0.0366 & 0.0162 \\
& $(0.0238)$ & $(0.0238)$ & $(0.0216)$ \\
Rural & -0.00144 & 0.000347 & -0.0212 \\
& $(0.0262)$ & $(0.0262)$ & $(0.0241)$ \\
Moth.Edu. & $0.0144^{* * *}$ & $0.0172^{* * *}$ & $0.00960^{* * *}$ \\
& $(0.00353)$ & $(0.00379)$ & $(0.00338)$ \\
Log real pce & & $-0.0495^{* *}$ & \\
& & $(0.0218)$ & \\
HH poorness index & & & 0.000822 \\
Constant & & & $(0.00755)$ \\
& $0.254^{* * *}$ & $0.830^{* * *}$ & $0.109^{* * *}$ \\
Observations & $(0.0371)$ & $(0.256)$ & $(0.0282)$ \\
R-squared & 1,619 & 1,618 & 1,077 \\
\hline \hline
\end{tabular}

Note: Dependent Variable $=$ Dummy equals 1 if the child was breastfed, 0 otherwise. Estimation method: linear probability model. Robust standard errors in parentheses. ${ }^{* * *} \mathrm{p}<0.01,{ }^{* *} \mathrm{p}<0.05,{ }^{*} \mathrm{p}<0.1$ 
Table B 4 Average percentage change in household-level variables between waves

\begin{tabular}{llll}
\hline \hline & Change between & Change between & Change between \\
& 1997 and 2007 & 1997 and 2000 & $\begin{array}{l}2000 \text { and } 2007 \\
\text { Household size }\end{array}$ \\
Number of households having access to piped water & $-2.93 \%$ & $4.49 \%$ & $9.96 \%$ \\
Number of households having own toilet & $16.23 \%$ & $-0.09 \%$ & $-1.76 \%$ \\
Mothers' years of schooling & $1.24 \%$ & $3.43 \%$ & $14.60 \%$ \\
Fathers' years of schooling & $2.20 \%$ & $1.16 \%$ & $2.65 \%$ \\
Real per capita expenditure & $70.71 \%$ & $4.87 \%$ & $6.61 \%$ \\
HH Poorness index & $-21.73 \%$ & $18.80 \%$ & $59.63 \%$ \\
Observations followed in: & Waves 1, 2 and 3 & $-6.94 \%$ & $-38.94 \%$ \\
\hline \hline
\end{tabular}

Note: Total Sample Size is 2,648 children: 822 children are followed in waves 1,2 and 3; 1020 children are followed in waves 1 and 2; 806 children are followed in waves 2 and 3. Waves 1, 2 and 3 correspond to years 1997, 2000 and 2007 respectively. Source: own elaboration on IFLS data

Table B 5 Scoring Coefficients for the HH Poorness Index (Principal Component Analysis)

\begin{tabular}{lccc}
\hline \hline & 1997 & 2000 & 2007 \\
\hline Car & -0.24 & -0.23 & -0.26 \\
Low roof material & 0.22 & 0.18 & 0.18 \\
Low floor material & 0.27 & 0.28 & 0.25 \\
Low wall material & - & - & 0.24 \\
Electricity & -0.33 & -0.31 & -0.27 \\
Piped drinking water & -0.24 & -0.23 & -0.11 \\
Well water w/pump & -0.21 & -0.22 & -0.22 \\
Well water (no pump) & 0.17 & 0.28 & 0.25 \\
Spring and surface water & 0.32 & 0.17 & 0.22 \\
Own toilet & -0.48 & -0.51 & -0.51 \\
Public toilet & 0.06 & 0.10 & 0.20 \\
Out defec. & 0.06 & 0.48 & 0.44 \\
\hline \hline
\end{tabular}

Source: own elaboration on IFLS data

Table B 6 Between-households and within-household variation in time-varying variables

\begin{tabular}{lcccc}
\hline & & \multicolumn{3}{c}{ Variation (Std.Dev.) } \\
\cline { 3 - 5 } & Mean value & Overall & Between & Within \\
ZHFA & -1.56 & 1.09 & 0.95 & Households \\
Moth.Edu & 6.8 & 3.68 & 3.63 & 0.58 \\
Fath.Edu & 7.6 & 3.77 & 3.72 & 0.75 \\
HH size & 4.9 & 1.6 & 1.41 & 0.76 \\
Water & 0.24 & 0.42 & 0.37 & 0.79 \\
Sanitation & 0.69 & 0.46 & 0.38 & 0.22 \\
Log real PCE & 12.32 & 0.67 & 0.59 & 0.26 \\
HH Poorness Index & -0.15 & 1.47 & 1.38 & 0.35 \\
\hline \hline
\end{tabular}

Note: Total Sample Size is 2,648 children: 822 children are followed in waves 1,2 and 3; 1020 children are followed in waves 1 and 2; 806 children are followed in waves 2 and 3 . Waves 1,2 and 3 correspond to years 1997, 2000 and 2007 respectively. Source: own elaboration on IFLS data. 
Table B 7 Robustness checks with alternative measures of household income and wealth

\begin{tabular}{|c|c|c|c|c|}
\hline & $\begin{array}{c}\text { (1) } \\
\text { OLS }\end{array}$ & $\begin{array}{c}\text { (2) } \\
\text { OLS }\end{array}$ & $\begin{array}{c}\text { (3) } \\
\text { Mundlak }\end{array}$ & $\begin{array}{c}(4) \\
\text { Mundlak }\end{array}$ \\
\hline Rural & $\begin{array}{c}-0.146^{* * *} \\
(0.0418)\end{array}$ & $\begin{array}{c}-0.155^{* * *} \\
(0.0420)\end{array}$ & $\begin{array}{c}-0.161 * * * \\
(0.0409)\end{array}$ & $\begin{array}{c}-0.162 * * * \\
(0.0408)\end{array}$ \\
\hline Health Posts & $\begin{array}{c}0.0111 * * * \\
(0.00316)\end{array}$ & $\begin{array}{c}0.0107 * * * \\
(0.00307)\end{array}$ & $\begin{array}{c}0.00841^{* * *} \\
(0.00308)\end{array}$ & $\begin{array}{c}0.0116^{* * *} \\
(0.00291)\end{array}$ \\
\hline Male & $\begin{array}{l}-0.0109 \\
(0.0368)\end{array}$ & $\begin{array}{c}-0.00835 \\
(0.0386)\end{array}$ & $\begin{array}{l}-0.0116 \\
(0.0375)\end{array}$ & $\begin{array}{c}-0.00949 \\
(0.0383)\end{array}$ \\
\hline Mother Height & $\begin{array}{l}0.0368 * * * \\
(0.00684)\end{array}$ & $\begin{array}{c}0.0344 * * * \\
(0.00723)\end{array}$ & $\begin{array}{c}0.0237 * * * \\
(0.00244)\end{array}$ & $\begin{array}{c}0.0232^{* * *} \\
(0.00247)\end{array}$ \\
\hline Father Height & $\begin{array}{c}0.0214 * * * \\
(0.00360)\end{array}$ & $\begin{array}{c}0.0193 * * * \\
(0.00369)\end{array}$ & $\begin{array}{c}0.0129 * * * \\
(0.00188)\end{array}$ & $\begin{array}{c}0.0115^{* * *} \\
(0.00185)\end{array}$ \\
\hline Breastfeeding & $\begin{array}{c}0.0618 \\
(0.0460)\end{array}$ & $\begin{array}{l}0.152^{* * *} \\
(0.0454)\end{array}$ & $\begin{array}{c}0.0496 \\
(0.0468)\end{array}$ & $\begin{array}{c}0.159 * * * \\
(0.0439)\end{array}$ \\
\hline Moth. age birth & $\begin{array}{c}0.0121^{* * *} * \\
(0.00347)\end{array}$ & $\begin{array}{c}0.0128^{* * * *} \\
(0.00356)\end{array}$ & $\begin{array}{c}0.00973 * * * \\
(0.00353)\end{array}$ & $\begin{array}{c}0.0121^{* * *} \\
(0.00348)\end{array}$ \\
\hline Moth. Low BMI & $\begin{array}{c}-0.204 * * * \\
(0.0690)\end{array}$ & $\begin{array}{c}-0.185^{* * *} \\
(0.0692)\end{array}$ & $\begin{array}{c}-0.167 * * \\
(0.0649)\end{array}$ & $\begin{array}{c}-0.146^{* *} \\
(0.0697)\end{array}$ \\
\hline $\mathrm{HH}$ size ${ }^{\mathrm{a}}$ & $\begin{array}{c}-0.0401 * * * \\
(0.0122)\end{array}$ & $\begin{array}{c}-0.0613^{* * *} \\
(0.0118)\end{array}$ & $\begin{array}{c}-0.00713 \\
(0.0167)\end{array}$ & $\begin{array}{c}-0.0384 * * \\
(0.0183)\end{array}$ \\
\hline $\mathrm{HH}$ size ${ }^{\mathrm{b}}$ & & & $\begin{array}{c}-0.0434 * * \\
(0.0214)\end{array}$ & $\begin{array}{l}-0.0352 \\
(0.0221)\end{array}$ \\
\hline Watera & $\begin{array}{c}0.0149 \\
(0.0444)\end{array}$ & & $\begin{array}{l}-0.0835 \\
(0.0584)\end{array}$ & \\
\hline Water ${ }^{b}$ & & & $\begin{array}{c}0.179 * * \\
(0.0778)\end{array}$ & \\
\hline Sanitation ${ }^{a}$ & $\begin{array}{c}0.128^{* * *} \\
(0.0395)\end{array}$ & & $\begin{array}{c}0.0500 \\
(0.0474)\end{array}$ & \\
\hline Sanitation ${ }^{b}$ & & & $\begin{array}{c}0.0975 \\
(0.0686)\end{array}$ & \\
\hline Moth.Edu.a & $\begin{array}{c}0.00886 \\
(0.00669)\end{array}$ & $\begin{array}{c}0.00935 \\
(0.00673)\end{array}$ & $\begin{array}{l}0.00931 \\
(0.0146)\end{array}$ & $\begin{array}{l}0.00495 \\
(0.0151)\end{array}$ \\
\hline Moth.Edu. ${ }^{\text {b }}$ & & & $\begin{array}{l}0.00194 \\
(0.0164)\end{array}$ & $\begin{array}{l}0.00513 \\
(0.0168)\end{array}$ \\
\hline Fath.Edu. ${ }^{a}$ & $\begin{array}{c}0.00561 \\
(0.00633)\end{array}$ & $\begin{array}{c}0.00495 \\
(0.00664)\end{array}$ & $\begin{array}{l}0.00101 \\
(0.0139)\end{array}$ & $\begin{array}{l}-0.0150 \\
(0.0151)\end{array}$ \\
\hline Fath.Edu.b & & & $\begin{array}{l}0.00753 \\
(0.0156)\end{array}$ & $\begin{array}{c}0.0230 \\
(0.0167)\end{array}$ \\
\hline Log nom pce & $\begin{array}{c}0.191 * * * \\
(0.0330)\end{array}$ & & $\begin{array}{l}0.209 * * * \\
(0.0332)\end{array}$ & \\
\hline Log nom pce & & & $\begin{array}{l}-0.0420 \\
(0.0428)\end{array}$ & \\
\hline HH poorness index ${ }^{a}$ & & $\begin{array}{c}-0.0845^{* * *} \\
(0.0140)\end{array}$ & & $\begin{array}{l}-0.0241 \\
(0.0186)\end{array}$ \\
\hline $\begin{array}{l}\text { HH poorness } \\
\text { index }\end{array}$ & & & & $\begin{array}{c}-0.0673^{* * *} \\
(0.0245)\end{array}$ \\
\hline Constant & $\begin{array}{c}-13.37 * * * \\
(1.230)\end{array}$ & $\begin{array}{c}-10.07 * * * \\
(1.224)\end{array}$ & $\begin{array}{c}-9.459 * * * \\
(0.715)\end{array}$ & $\begin{array}{c}-7.066 * * * \\
(0.493)\end{array}$ \\
\hline Time*Prov.Dum. & YES & $\mathrm{NO}$ & YES & $\mathrm{NO}$ \\
\hline Observations & 4,400 & 3,642 & 4,400 & 3,642 \\
\hline $\begin{array}{l}\text { R-squared } \\
\text { No.of cross- } \\
\text { sections }\end{array}$ & 0.199 & 0.158 & 0.19 & 0.152 \\
\hline
\end{tabular}

Note: Age dummies included. a short term or within effect, ${ }^{\mathrm{b}}$ long term or between effect. Standard errors in parentheses. Below the OLS coefficients are reported the robust standard errors, correct for clustering at the household level.*** $\mathrm{p}<0.01,{ }^{* *} \mathrm{p}<0.05,{ }^{*} \mathrm{p}<0.1$ 


\section{Appendix C}

Appendix on Essay “The Nutrition-Learning Nexus: Evidence from Indonesia”. 
Table C 1 Description of the variables used and descriptive statistics, IFLS (2-3-4)

\begin{tabular}{|c|c|c|c|c|c|c|}
\hline Variable & Definition & Obs & Mean & Std.Dev. & Min & $\operatorname{Max}$ \\
\hline Gender (male) & $\begin{array}{l}1=\text { Child is a boy; } \\
0=\text { Child is a girl }\end{array}$ & 936 & .52 & .50 & 0 & 1 \\
\hline Age (first period) & Child's age (in years) & 936 & 3.67 & 2.06 & 0 & 8 \\
\hline Height-for-Age z-score & $\begin{array}{l}\text { Height-for-Age(first period) z- } \\
\text { score statistics }\end{array}$ & 936 & -1.74 & 1.34 & -5.8 & 4.2 \\
\hline Weight-for-Age z-score & $\begin{array}{l}\text { Weight-for-Age(first period) z- } \\
\text { score statistics }\end{array}$ & 936 & -1.44 & 1.19 & -5.7 & 4.1 \\
\hline Age (second period) & Child's age (in years) & 936 & 13.5 & 2.0 & 9 & 17 \\
\hline Age start school & $\begin{array}{l}\text { Age (years) at which the child } \\
\text { entered school }\end{array}$ & 834 & 6.3 & .65 & 5 & 11 \\
\hline Cognitive Test Score & $\begin{array}{l}\text { Score obtained for the cognitive } \\
\text { test (range from } 0 \text { to } 1 \text { ) }\end{array}$ & 783 & .76 & .18 & 0 & 1 \\
\hline Age C.T. score & $\begin{array}{l}\text { Estimated age (years) at which } \\
\text { the child took the cognitive test }\end{array}$ & 783 & 10.93 & 2.07 & 8 & 14 \\
\hline Years of schooling & $\begin{array}{l}\text { Completed years of education } \\
\text { realized in the second period }\end{array}$ & 928 & 6.7 & 2.22 & 0 & 12 \\
\hline Mother Education & $\begin{array}{l}\text { Completed years of education } \\
\text { realized by the mother }\end{array}$ & 936 & 7.08 & 3.5 & 0 & 12 \\
\hline Mother age & Mother's age in years & 936 & 30.13 & 5.3 & 15 & 50 \\
\hline Rural & $\begin{array}{l}1=\text { household located in rural } \\
\text { areas; } 0=\text { household located in } \\
\text { urban areas }\end{array}$ & 936 & .49 & .50 & 0 & 1 \\
\hline Fires Shock & $\begin{array}{l}\text { 1= Child was living in Sumatra or } \\
\text { Kalimantan and was aged } 12-36 \\
\text { months at the date } 05.09 .1997\end{array}$ & 936 & .061 & .24 & 0 & 1 \\
\hline
\end{tabular}


Figure C 1 Location and timing of the Indonesian wildfires
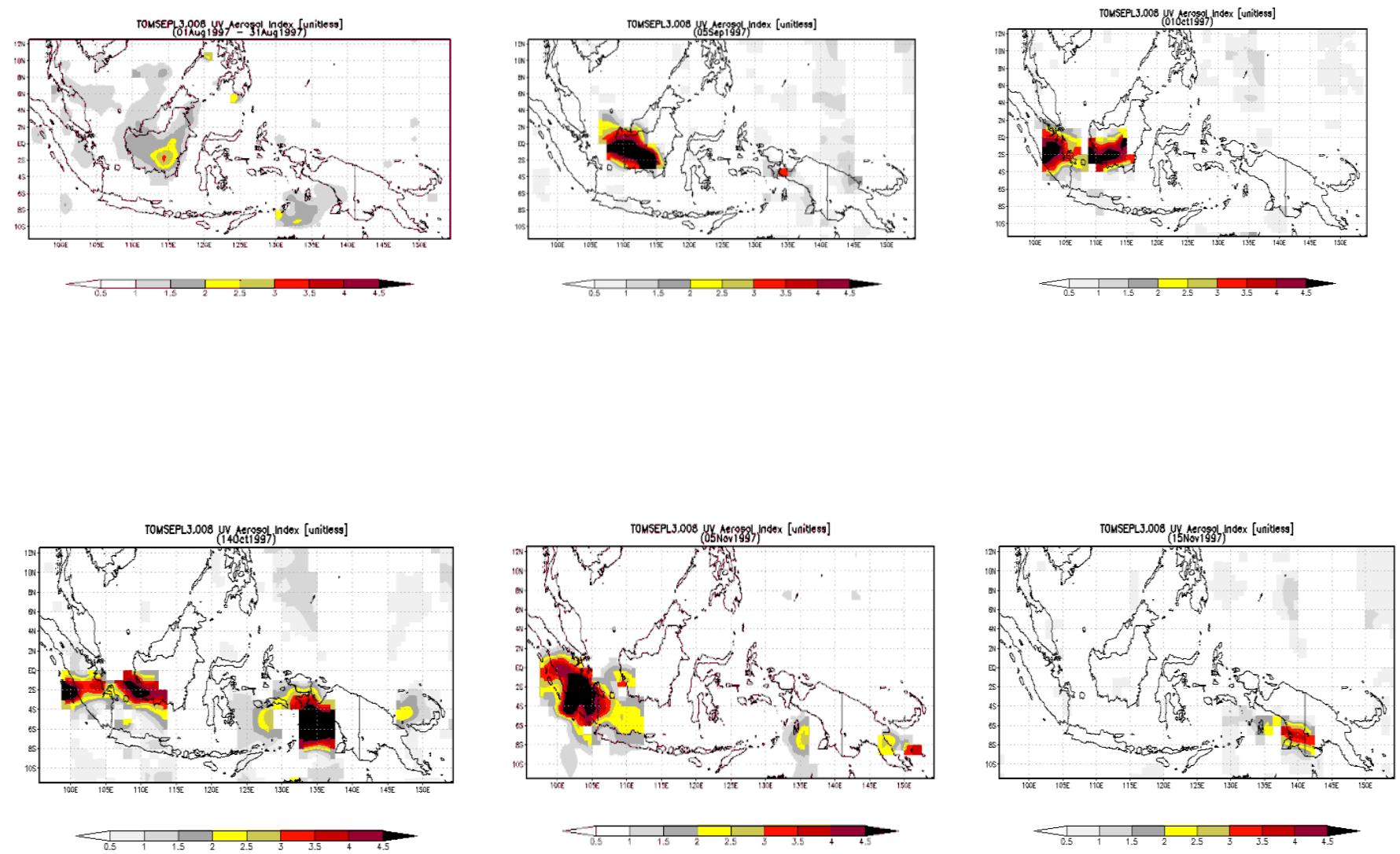

Note: Figures display levels of haze and smoke in August 1997 (monthly average), September, $5^{\text {th }} 1997$; October, $1^{\text {st }} 1997$; October, 14th 1997; November, 5 1997 and November, 15 th 1997. Haze is measured using the UV aerosol index. Data Source: NASA Total Ozone Mapping Spectrometer (TOMS) 
Table C 2 The effect of forest fires on income and education expenditure. A test for the assumption of exclusion restriction.

\begin{tabular}{|c|c|c|c|c|c|}
\hline & \multicolumn{3}{|c|}{$\begin{array}{l}\text { Dep. Var.: Log of Household } \\
\text { Per Capita Expenditure.. }\end{array}$} & \multicolumn{2}{|c|}{$\begin{array}{l}\text { Dep. Var.: Change in the share } \\
\text { of education expenditure.. }\end{array}$} \\
\hline & $\begin{array}{c}(1) \\
\text {.in } 1997\end{array}$ & $\begin{array}{c}(2) \\
\text {..in } 2000\end{array}$ & $\begin{array}{c}(3) \\
\text {..in } 2007\end{array}$ & $\begin{array}{c}(4) \\
. . \text { between } 1997 \text { and } \\
2000\end{array}$ & $\begin{array}{c}\text { (5) } \\
\text {..between } 1997 \text { and } \\
2007 \\
\end{array}$ \\
\hline $\begin{array}{l}\text { Exposure to Forest } \\
\text { Fires }\end{array}$ & $\begin{array}{c}-0.0788 \\
(0.103)\end{array}$ & $\begin{array}{c}0.116 \\
(0.0978)\end{array}$ & $\begin{array}{l}-0.0772 \\
(0.0983)\end{array}$ & $\begin{array}{l}-0.802 \\
(0.849)\end{array}$ & $\begin{array}{c}0.829 \\
(1.419)\end{array}$ \\
\hline Constant & $\begin{array}{l}11.28 * * * \\
(0.0226)\end{array}$ & $\begin{array}{l}11.90 * * * \\
(0.0216)\end{array}$ & $\begin{array}{l}12.85^{* * *} \\
(0.0216)\end{array}$ & $\begin{array}{c}2.456 * * * \\
(0.208)\end{array}$ & $\begin{array}{c}7.556 * * * \\
(0.344)\end{array}$ \\
\hline Observations & 934 & 932 & 919 & 930 & 917 \\
\hline R-squared & 0.001 & 0.002 & 0.001 & 0.001 & 0.000 \\
\hline
\end{tabular}

Note: Household Per capita expenditure is measured in nominal terms. Provincial dummies are included in regressions (1), (2), and (3) in order to control for differences in price levels among provinces.

Standard errors in parentheses $* * * \mathrm{p}<0.01,{ }^{* *} \mathrm{p}<0.05,{ }^{*} \mathrm{p}<0.1$

Table C 3 Robustness check 1: MFE-IV estimates of height-for-age on years of schooling. Additional covariates added

\begin{tabular}{|c|c|c|c|c|c|c|}
\hline & $(1)$ & $(2)$ & $(3)$ & $(4)$ & $(5)$ & $(6)$ \\
\hline Height for Age (z scores) & $\begin{array}{c}0.445^{* *} \\
(0.197)\end{array}$ & $\begin{array}{c}0.643 * * \\
(0.309)\end{array}$ & $\begin{array}{c}0.377^{* *} \\
(0.177)\end{array}$ & $\begin{array}{c}0.225 \\
(0.162)\end{array}$ & $\begin{array}{c}0.219 \\
(0.162)\end{array}$ & $\begin{array}{c}0.226 \\
(0.161)\end{array}$ \\
\hline Boy & $\begin{array}{l}-0.103 \\
(0.162)\end{array}$ & $\begin{array}{c}-1.123^{* *} \\
(0.465)\end{array}$ & $\begin{array}{l}-0.117 \\
(0.157)\end{array}$ & $\begin{array}{l}-0.145 \\
(0.152)\end{array}$ & $\begin{array}{l}-0.350 \\
(0.368)\end{array}$ & $\begin{array}{c}-0.00938 \\
(0.260)\end{array}$ \\
\hline Age & $\begin{array}{c}1.169 * * * \\
(0.137)\end{array}$ & $\begin{array}{c}0.927 * * * \\
(0.0311)\end{array}$ & $\begin{array}{c}0.964 * * * \\
(0.0446)\end{array}$ & $\begin{array}{c}0.760 * * * \\
(0.0690)\end{array}$ & $\begin{array}{c}0.756^{* * *} \\
(0.0681)\end{array}$ & $\begin{array}{c}0.780^{* * *} \\
(0.0831)\end{array}$ \\
\hline Entered school by the age of 7 & $\begin{array}{c}0.00363 \\
(0.246)\end{array}$ & $\begin{array}{l}0.0216 \\
(0.264)\end{array}$ & $\begin{array}{c}0.131 \\
(0.263)\end{array}$ & $\begin{array}{c}0.160 \\
(0.250)\end{array}$ & $\begin{array}{c}0.154 \\
(0.253)\end{array}$ & $\begin{array}{c}0.151 \\
(0.259)\end{array}$ \\
\hline $\mathrm{Age}^{2}$ & $\begin{array}{c}-0.0355^{*} \\
(0.0199)\end{array}$ & & & & & \\
\hline ZHFA*Boy & & $\begin{array}{c}-0.537 * * \\
(0.246)\end{array}$ & & & & \\
\hline At school in 1997 & & & $\begin{array}{l}-0.357 \\
(0.315)\end{array}$ & & & \\
\hline Birth Order & & & & $\begin{array}{c}-0.556^{* *} \\
(0.232)\end{array}$ & $\begin{array}{c}-0.624 * * \\
(0.243)\end{array}$ & $\begin{array}{r}-0.556^{* *} \\
(0.231)\end{array}$ \\
\hline Birth Order* Boy & & & & & $\begin{array}{c}0.107 \\
(0.171)\end{array}$ & \\
\hline Age*Boy & & & & & & $\begin{array}{l}-0.0375 \\
(0.0722)\end{array}$ \\
\hline Observations & 885 & 885 & 885 & 819 & 819 & 819 \\
\hline Number of moth.id & 682 & 682 & 682 & 626 & 626 & 626 \\
\hline $\mathrm{R}^{2}$ (within) & 0.798 & 0.792 & 0.804 & 0.823 & 0.824 & 0.823 \\
\hline Anderson canon.corr.LR.stat & $\begin{array}{c}22.89 \\
(0.000)\end{array}$ & $\begin{array}{c}18.68 \\
(0.000)\end{array}$ & $\begin{array}{c}27.72 \\
(0.000)\end{array}$ & $\begin{array}{c}21.97 \\
(0.000)\end{array}$ & $\begin{array}{c}21.93 \\
(0.000)\end{array}$ & $\begin{array}{c}22.03 \\
(0.000)\end{array}$ \\
\hline Cragg-Donald F statistic & 23.64 & 19.08 & 28.97 & 22.66 & 22.50 & 22.61 \\
\hline
\end{tabular}

Note: The sample consists of children aged 0-8 in 1997 and 9-17 in 2007, with height for age $z$ score in the range -6 to 6 in 1997 and aged 5 to 11 years when started school. ZHFA= Height for age $z$ scores.

Robust standard errors in parentheses. ${ }^{* * *} \mathrm{p}<0.01,{ }^{* *} \mathrm{p}<0.05,{ }^{*} \mathrm{p}<0.1$ 
Table C 4 Robustness check 1: MFE-IV estimates of height-for-age on cognitive test score. Additional covariates added

\begin{tabular}{|c|c|c|c|c|c|c|}
\hline & (1) & (2) & (3) & (4) & (5) & (6) \\
\hline Height for Age (z scores) & $\begin{array}{c}0.0803 \\
(0.0500)\end{array}$ & $\begin{array}{c}0.147 \\
(0.0943)\end{array}$ & $\begin{array}{c}0.105^{*} \\
(0.0612)\end{array}$ & $\begin{array}{l}0.0809 * \\
(0.0487)\end{array}$ & $\begin{array}{l}0.0865^{*} \\
(0.0483)\end{array}$ & $\begin{array}{l}0.0802^{*} \\
(0.0484)\end{array}$ \\
\hline Boy & $\begin{array}{l}0.00593 \\
(0.0219)\end{array}$ & $\begin{array}{l}-0.158 \\
(0.134)\end{array}$ & $\begin{array}{l}0.00674 \\
(0.0249)\end{array}$ & $\begin{array}{l}0.00286 \\
(0.0228)\end{array}$ & $\begin{array}{l}0.128 * * \\
(0.0602)\end{array}$ & $\begin{array}{c}-0.0155 \\
(0.138)\end{array}$ \\
\hline Age & $\begin{array}{c}-0.195^{* *} \\
(0.0767)\end{array}$ & $\begin{array}{c}0.00546 \\
(0.00632)\end{array}$ & $\begin{array}{c}0.00609 \\
(0.00669)\end{array}$ & $\begin{array}{c}0.00925 \\
(0.00609)\end{array}$ & $\begin{array}{c}0.00869 \\
(0.00597)\end{array}$ & $\begin{array}{l}0.00830 \\
(0.0100)\end{array}$ \\
\hline Entered school by the age of 7 & $\begin{array}{l}-0.0238 \\
(0.0391)\end{array}$ & $\begin{array}{l}-0.0383 \\
(0.0463)\end{array}$ & $\begin{array}{l}-0.0348 \\
(0.0452)\end{array}$ & $\begin{array}{l}-0.0214 \\
(0.0395)\end{array}$ & $\begin{array}{l}-0.0184 \\
(0.0386)\end{array}$ & $\begin{array}{l}-0.0213 \\
(0.0395)\end{array}$ \\
\hline $\mathrm{Age}^{2}$ & $\begin{array}{c}0.00902^{* * *} \\
(0.00349)\end{array}$ & & & & & \\
\hline ZHFA*Boy & & $\begin{array}{l}-0.0969 \\
(0.0797)\end{array}$ & & & & \\
\hline At school in 1997 & & & $\begin{array}{c}0.0188 \\
(0.0349)\end{array}$ & & & \\
\hline Birth Order & & & & $\begin{array}{c}-0.0410^{* *} \\
(0.0192)\end{array}$ & $\begin{array}{c}-0.00276 \\
(0.0213)\end{array}$ & $\begin{array}{c}-0.0408^{* *} \\
(0.0191)\end{array}$ \\
\hline Birth Order* Boy & & & & & $\begin{array}{c}-0.0710^{* *} \\
(0.0297)\end{array}$ & \\
\hline Age*Boy & & & & & & $\begin{array}{l}0.00168 \\
(0.0124)\end{array}$ \\
\hline Observations & 769 & 769 & 769 & 769 & 769 & 769 \\
\hline Number of moth.id & 602 & 602 & 602 & 602 & 602 & 602 \\
\hline $\mathrm{R}^{2}$ (within) & -0.045 & -0.367 & -0.270 & -0.065 & -0.065 & -0.062 \\
\hline Anderson canon.corr.LR.stat & $\begin{array}{c}20.94 \\
(0.000)\end{array}$ & $\begin{array}{c}14.49 \\
(0.000)\end{array}$ & $\begin{array}{c}17.48 \\
(0.000)\end{array}$ & $\begin{array}{c}22.45 \\
(0.000)\end{array}$ & $\begin{array}{c}22.24 \\
(0.000)\end{array}$ & $\begin{array}{c}22.85 \\
(0.000)\end{array}$ \\
\hline Cragg-Donald F statistic & 21.64 & 14.69 & 17.88 & 23.31 & 22.94 & 23.61 \\
\hline
\end{tabular}

Note: The sample consists of children aged 0-8 in 1997 and 8-14 when they took the cognitive test (either in 2000 or in 2007), with height for age $z$ score in the range -6 to 6 in 1997 and aged 5 to 11 years when started school. ZHFA= Height for age $z$ scores. Robust standard errors in parentheses. ${ }^{* * *} \mathrm{p}<0.01,{ }^{* *} \mathrm{p}<0.05,{ }^{*} \mathrm{p}<0.1$ 
Table C 5 Robustness check 1: MFE-IV estimates of height-for-age on age starting school. Additional covariates added

\begin{tabular}{|c|c|c|c|c|c|}
\hline & (1) & (2) & (4) & (5) & (6) \\
\hline Height for Age (z scores) & $\begin{array}{l}-0.198 \\
(0.138)\end{array}$ & $\begin{array}{c}-0.311^{*} \\
(0.180)\end{array}$ & $\begin{array}{c}-0.212^{*} \\
(0.128)\end{array}$ & $\begin{array}{l}-0.207 \\
(0.128)\end{array}$ & $\begin{array}{c}-0.212^{*} \\
(0.128)\end{array}$ \\
\hline Boy & $\begin{array}{c}0.0856 \\
(0.0796)\end{array}$ & $\begin{array}{c}0.602^{* *} \\
(0.272)\end{array}$ & $\begin{array}{c}0.0912 \\
(0.0827)\end{array}$ & $\begin{array}{c}0.250 \\
(0.204)\end{array}$ & $\begin{array}{l}0.0626 \\
(0.139)\end{array}$ \\
\hline Age & $\begin{array}{c}-0.118 \\
(0.0917)\end{array}$ & $\begin{array}{l}0.00287 \\
(0.0164)\end{array}$ & $\begin{array}{l}-0.0418 \\
(0.0460)\end{array}$ & $\begin{array}{l}-0.0368 \\
(0.0452)\end{array}$ & $\begin{array}{l}-0.0460 \\
(0.0512)\end{array}$ \\
\hline Age $^{2}$ & $\begin{array}{c}0.0188 \\
(0.0135)\end{array}$ & & & & \\
\hline ZHFA*Boy & & $\begin{array}{l}0.275^{*} \\
(0.148)\end{array}$ & & & \\
\hline Birth Order & & & $\begin{array}{l}-0.139 \\
(0.133)\end{array}$ & $\begin{array}{c}-0.0810 \\
(0.139)\end{array}$ & $\begin{array}{l}-0.138 \\
(0.132)\end{array}$ \\
\hline Birth Order*Boy & & & & $\begin{array}{c}-0.0808 \\
(0.0901)\end{array}$ & \\
\hline Age*Boy & & & & & $\begin{array}{l}0.00857 \\
(0.0352)\end{array}$ \\
\hline Observations & 834 & 834 & 772 & 772 & 772 \\
\hline Number of moth.id & 652 & 652 & 600 & 600 & 600 \\
\hline $\mathrm{R}^{2}$ (within) & -0.019 & 0.023 & -0.041 & -0.031 & -0.041 \\
\hline Anderson canon.corr.LR.stat & $\begin{array}{c}19.94 \\
(0.000)\end{array}$ & $\begin{array}{c}15.86 \\
(0.000)\end{array}$ & $\begin{array}{c}20.25 \\
(0.000)\end{array}$ & $\begin{array}{c}20.08 \\
(0.000)\end{array}$ & $\begin{array}{c}20.33 \\
(0.000)\end{array}$ \\
\hline Cragg-Donald F statistic & 20.61 & 16.21 & 20.99 & 20.68 & 20.95 \\
\hline
\end{tabular}

Note: The sample consists of children that in 1997 were aged 0-8 and had height for age $z$ score in the range -6 to 6 in 1997 and were subsequently aged 5 to 11 years when started school. The difference between age started school and age at which height was measured is larger or equal than zero. ZHFA $=$ Height for age $\mathrm{z}$ scores. Robust standard errors in parentheses. ${ }^{* * *} \mathrm{p}<0.01,{ }^{* *}$ $\mathrm{p}<0.05, * \mathrm{p}<0.1$

Table C 6 Robustness check 2: MFE-IV estimates of weight-for-age in baseline and alternative specifications

\begin{tabular}{|c|c|c|c|c|c|c|c|}
\hline \multirow[b]{3}{*}{ (0) } & \multirow[b]{3}{*}{ Baseline } & \multicolumn{4}{|c|}{ Educational Outcome: } & & \\
\hline & & \multicolumn{2}{|c|}{ Years of schooling } & \multicolumn{2}{|c|}{$\begin{array}{l}\text { Cognitive Test } \\
\text { Score }\end{array}$} & \multicolumn{2}{|c|}{$\begin{array}{l}\text { Age starting } \\
\text { school }\end{array}$} \\
\hline & & $0.525^{*}$ & $(0.279)$ & 0.065 & $(0.060)$ & -0.189 & $(0.138)$ \\
\hline (1) & $\begin{array}{l}\text { Entered school by the age } \\
\text { of } 7 \text { included }\end{array}$ & $0.452^{* *}$ & $(0.223)$ & $0.103^{*}$ & $(0.058)$ & - & - \\
\hline (2) & Age fixed effects included & 0.266 & $(0.224)$ & $0.097 *$ & $(0.056)$ & -0.384 & $(0.254)$ \\
\hline (3) & Age squared included & $0.509 * *$ & $(0.232)$ & 0.073 & $(0.047)$ & -0.224 & $(0.156)$ \\
\hline (4) & ZHFA* boy included & $0.967 * *$ & $(0.485)$ & $0.171 *$ & $(0.102)$ & $-0.418^{*}$ & $(0.224)$ \\
\hline (5) & At school in 1997 included & $0.448^{* *}$ & $(0.220)$ & $0.101 *$ & $(0.058)$ & - & - \\
\hline (6) & Birth order included & 0.281 & $(0.220)$ & 0.069 & $(0.044)$ & -0.257 & $(0.161)$ \\
\hline (7) & Birth order*Boy included & 0.269 & $(0.213)$ & 0.0703 & $(0.043)$ & -0.247 & $(0.155)$ \\
\hline (8) & $\begin{array}{l}\text { Birth order and age* Boy } \\
\text { included }\end{array}$ & 0.284 & $(0.219)$ & 0.0665 & $(0.044)$ & -0.257 & $(0.160)$ \\
\hline
\end{tabular}

Note: ZHFA = Height for age $\mathrm{z}$ scores. Robust standard errors in parentheses. ${ }^{* * *} \mathrm{p}<0.01,{ }^{* *} \mathrm{p}<0.05,{ }^{*} \mathrm{p}<0.1$ 
Table C 7 Robustness check 3: MFE-IV estimates of height-for-age instrumented with exposure to forest fires during the 12-24 first months of life in baseline and alternative specifications

\begin{tabular}{|c|c|c|c|c|c|c|c|}
\hline \multirow[b]{3}{*}{$(0)$} & \multirow[b]{3}{*}{ Baseline } & \multicolumn{4}{|c|}{ Educational Outcome: } & & \\
\hline & & \multicolumn{2}{|c|}{ Years of schooling } & \multicolumn{2}{|c|}{$\begin{array}{l}\text { Cognitive Test } \\
\text { Score }\end{array}$} & \multicolumn{2}{|c|}{$\begin{array}{l}\text { Age starting } \\
\text { school }\end{array}$} \\
\hline & & $0.661 * *$ & $(0.289)$ & 0.152 & $(0.105)$ & -0.053 & $(0.152)$ \\
\hline (1) & $\begin{array}{l}\text { Entered school by the age } \\
\text { of } 7 \text { included }\end{array}$ & $0.583^{* * *}$ & $(0.222)$ & $0.192 *$ & $(0.103)$ & - & - \\
\hline (2) & Age fixed effects included & $0.462^{*}$ & $(0.265)$ & $0.160^{*}$ & $(0.084)$ & -0.176 & $(0.171)$ \\
\hline (3) & Age squared included & $0.551 * * *$ & $(0.202)$ & $0.147 *$ & $(0.082)$ & -0.046 & $(0.141)$ \\
\hline (4) & ZHFA* boy included & $1.179 * *$ & $(0.496)$ & $0.364 *$ & $(0.221)$ & -0.190 & $(0.318)$ \\
\hline (5) & At school in 1997 included & $0.534 * * *$ & $(0.200)$ & $0.190 *$ & $(0.103)$ & - & - \\
\hline (6) & Birth order included & $0.368^{*}$ & $(0.205)$ & $0.141 *$ & $(0.079)$ & -0.130 & $(0.169)$ \\
\hline (7) & Birth order*Boy included & $0.376^{*}$ & $(0.203)$ & $0.130 *$ & $(0.072)$ & -0.137 & $(0.164)$ \\
\hline (8) & $\begin{array}{l}\text { Birth order and age* Boy } \\
\text { included }\end{array}$ & $0.369 *$ & $(0.204)$ & $0.141 *$ & $(0.078)$ & -0.130 & $(0.169)$ \\
\hline
\end{tabular}

Note: ZHFA $=$ Height for age $\mathrm{z}$ scores. Robust standard errors in parentheses. ${ }^{* * *} \mathrm{p}<0.01,{ }^{* *} \mathrm{p}<0.05,{ }^{*} \mathrm{p}<0.1$ 


\section{Bibliography}

Abu-Ghaida, D., \& Klasen, S. (2004). The cost of missing the Millennium Development Goal on gender equity. World Development, 32 (7): 1075-1107.

Akresh, R., Bhalotra, S., Leone,M., \& Osili, U.O. (2012). War and stature: growing up during the Nigerian Civil War. The American Economic Review, 102 (3): 273-277.

Alderman, H. (1990). Nutritional status in Ghana and its determinants. Washington DC: The World Bank.

Alderman, H., Behrman, J.R., Lavy, V., \& Menon, R. (2001a). Child health and school enrolment: A longitudinal analysis. Journal of Human Resources, 36: 185-205.

Alderman, H., Behrman, J., Kohler, H-P., Maluccio, J., \& Watkins, S. (2001b). Attrition in longitudinal household survey data: some tests for three developing country samples. Demographic Research, 5: 78-124.

Alderman, H., Hoddinott, J., \& Kinsey, B. (2006). Long term consequences of early child malnutrition. Oxford Economic Papers, 58: 450-74.

Alesina, A., Devleeschauwer, A., Easterly, W., Kurlat, S., \& Wacziarg, R. (2003). Fractionalization. Journal of Economic Growth, 8: 155-194.

Almond, D., \& Currie, J. (2011a). Human capital development before age five, In Handbook of Labor Economics, ed. David Card \& Orley Ashenfelter. Amsterdam Elsevier.

. (2011b). Killing me softly: the fetal origins hypothesis. Journal of Economic Perspectives 25

(3): 153-72.

Anderson, E. (2007). Identifying chronically deprived countries: Results from cluster analysis. Working Paper No. 70, Chronic Poverty Research Centre, University of Manchester.

Anderson, E., \& Morrissey, O. (2006). A statistical approach to identifying poor performers. Journal of Development Studies, 42 (3): 469-489. 
Asian Development Bank. (2006). Indonesia: country gender assessment. Manila: Asian Development Bank.

Aslam, M., \& Kingdon, G. (2012). Parental Education and Child Health- Understanding the Pathways of Impact in Pakistan. World Development, 40 (10): 2014-2032.

Baltagi, B. (2008). Econometric analysis of panel data (Vol. 1). John Wiley \& Sons.

Barro, R. J., \& Lee, J. W. (2010). A new data set of educational attainment in the world, 1950-2010. NBER Working Paper 15902.

Basuni, A. (1989). Preschool Malnutrition Rates by Province and Gender from the Indonesian 1986 SUSENAS. Manuscript Center for Research and Development in Nutrition, Ministry of Health, Indonesia (1989).

Bertrand, M., Duflo, E. \& Mullainathan, S. (2004). How Much Should We Trust Differences-InDifferences Estimates? The Quarterly Journal of Economics, 119 (1): 249-275.

Bhalotra, S. (2010). Fatal fluctuations? Cyclicality in infant mortality in India. Journal of Development Economics, 93 (1): 7-19.

Behrman, J. (1996). The impact of health and nutrition and education. World Bank Research Observer, 11, 23-77.

Behrman, J., Alderman, H., \& Hoddinott, J. (2004). Hunger and Malnutrition. In Global crises, Global solutions, ed. B. Lomborg. Cambridge University Press, Cambridge UK.

Boerma, J. T., Sommerfelt, A. E., et al. (1991). Childhood morbidity and treatment patterns. Columbia, MD: Institute for Resource Development/Macro International.

Bound, J., Jaeger, D., \& Baker, R. (1995). Problems with instrumental variables estimation when the correlation between the instruments and the endogenous explanatory variables is weak. Journal of the American Statistical Association, 90: 443-50.

Bourguignon, F., \& Chakravarty, S. (2003). The measurement of multidimensional poverty. Journal of Economic Inequality, 1: 25-49. 
Bourguignon, F., Bénassy-Quéré, A., Dercon, S., Estaché, A., Gunning, J., Kanbur, R., Maxwell, S., Platteau, J., \& Spadaro, A. (2008a). Millenium Development Goals at midpoint: Where do we stand and where do we need to go? European Report on Development.

Bourguignon, F., Diaz-Bonilla, C., \& Logfren, H. (2008b). Aid, service delivery and the Millennium Development Goals in an economy-wide framework. World Bank Policy Research Working Paper, 4683, July.

Bourne, K. L., \& Walker, G. M. (1991). The differential effect of mother's education on mortality of boys and girls in India. Population Studies, 45: 203-219.

Boyden, J., Dercon, S., \& Singh, A. (2014). Child development in a changing world: risks and opportunities. The World Bank Research Observer, September 2014, doi: 10.1093/wbro/lku009.

Caldwell , J. C. (1979). Education as a factor in mortality decline: an examination of Nigerian data. Population Studies, 33 (3): 395-413.

Caldwell, J. C. (1992). Old and new factors in health transition. Health Transition Review, 2 (supplement): 205-216.

Calinski, T., \& Harabasz, J. (1974). A dendrite method for cluster analysis. Communications in Statistics, 3: 1-27.

Caputo, A., Foraita, R., Klasen, S. \& I. Pigeot, I. (2003). Undernutrition in Benin--an analysis based on graphical models. Social Science \& Medicine, 56 (8): 1677-1691.

Card, D. (2001). Estimating the return to schooling: progress on some persistent econometric problems. Econometrica, 69: 1127-60.

Cleland, J.G \& Van Ginneken, J.V. (1988). Maternal education and child survival in developing countries: The search for pathways of influence. Social Science \& Medicine, 27 (12): $1357-$ 1368. 
Clemens, M., \& Demombynes, G. (2011). When does rigorous impact evaluation make a difference? The case of the Millennium Villages. The Journal of Development Effectiveness, 3 (3): 305-339.

Clemens, M., Kenny, C., \& Moss, T. (2007). The trouble with the MDGs: Confronting expectations of aid and development success. World Development, 35 (5): 735-751.

Conde-Agudelo, A., Belizan, J., \& C. Lammers, C. (2005). Maternal-perinatal morbidity and mortality associated with adolescent pregnancy in Latin America: Cross-sectional study. American Journal of Obstetrics and Gynecology, 192 (2): 342-349.

Cunha, F., Heckman, J., Lochner, L., \& Masterov. D. (2006). Interpreting the evidence on life cycle skill formation. In Handbook of the Economics of Education, ed. Eric Hanushek and Finis Welch. Amsterdam: Elsevier.

Das Gupta, M. (1987). Selective discrimination against female children in rural Punjab, India. Population and Development Review, 13 (1): 77-100.

Dauvergne, P. (1998). The political economy of Indonesia’s 1997 forest fires. Australian Journal of International Affairs, 52 (1): 13-17.

Defo, B. K. (1997). Effects of socioeconomic disadvantage and women's status on women's health in Cameroon. Social Science \& Medicine, 44 (7): 1023-1042.

Deininger, K. (2003). Does cost of schooling affect enrolment by the poor? Universal primary education in Uganda. Economics of Education Review, 22, 292-305.

Deolalikar, A. B. (1990). Gender discrimination in the intrahousehold allocation of health inputs and distribution of bealth outcomes among children under 5: results from Indonesia, 1987. Paper presented to the Annual NW regional Consortium for Southeast Asian Studies. University of Washington, Seattle, October (1990).

Deolalikar, A. B. (1993). Gender differences in the returns to schooling and in school enrolment rates in Indonesia. The Journal of Human Resources 28 (4): 899-932. 
Desai, S., \& Alva, S. (1998). Maternal education and child health: is there a strong causal relationship? Demography, 35(1): 71-81.

Dibley, M. J.,.Goldsby, J. B., Staehling, N.W., \& Trowbridge, F.L. (1987). Development of normalized curves for the international growth reference: historical and technical considerations. The American journal of clinical nutrition, 46 (5): 736-748.

Dobbing, J. (1976). Vulnerable periods in brain growth and somatic growth. In D. F. Roberts and A. M. Thomson, eds. The Biology of Human Fetal Growth. London: Taylor and Francis.

Duflo, E. (2001). Schooling and labor market consequences of school construction in Indonesia: evidence from an unusual policy experiment. American Economic Review, 91 (4): 795-813.

Easterly, W. (2009). How the Millennium Development Goals are Unfair to Africa. World Development, 37 (1): 26-35.

Egger, P. \& Pfaffermay, M. (2004). Estimating long run and short run effects in static panel models. Econometric Reviews, 23 (3): 199-214.

Egger, P., \& Url, T. (2006). Public export credit guarantees and foreign trade structure: Evidence from Austria. The World Economy, 29 (4): 399-418.

Esrey, S. A., Potash, J. B., Roberts, L., \& Shiff, C. (1991). Effects of improved water supply and sanitation on ascariasis, diarrhoea, dracunculiasis, hookworm infection, schistosomiasis, and trachoma. Bulletin of the World Health organization, 69 (5): 609.

Everitt, B. S. (1993). Cluster analysis (3rd ed.). London: Arnold.

Fedorov, L., \& Sahn, D.E. (2005). Socioeconomic determinants of child health in Russia: a longitudinal study. Economic Development and cultural change, 53 (2): 479-500.

Filmer, D., \& Pritchett, L.H. (2001). Estimating wealth effects without expenditure data- or tears: an application to educational enrolments in states of India. Demography, 38 (1): 115-132.

Fitzgerald, J., Gottschalk, P., \& Moffitt, R. (1998a). An analysis of sample attrition in panel data: the Michigan Panel Study of Income Dynamics. Journal of Human Resources, 33: 251-99. 
(1998b). The impact of attrition in the panel study of income dynamics on intergenerational analysis. Journal of Human Resources, 33: 300-344.

Foraita, R., Klasen, S. \& I. Pigeot, I. (2008). Using graphical chain models to analyze differences in structural correlates of undernutrition in Benin and Bangladesh. Economics \& Human Biology, 6 (3): 398-419.

Forste, R. (1998). Infant feeding practices and child health in Bolivia. Journal of biosocial science, 30 (1): 107-125.

Frankenberg, E., Surisatini, W., \& Thomas, D. (1996). Nutritional status in Indonesia: evidence from the 1993 Indonesian Family Life Survey.: RAND, 1996. Labor and Population Program, 96-01.

Frankenberg, E., \& Thomas. D. (2000). The Indonesia Family Life Survey (IFLS): study design and results from waves 1 and 2. Technical Report DRU-2238. RAND, Santa Monica, CA.

Frankenberg, E., McKee, D. \& Thomas, D. (2005). Health consequences of forest fires in Indonesia. Demography, 42 (1): 109-129.

Fraser, A., Brockert, J. \& R. Ward, R. (1995). Association of young maternal age with adverse reproductive outcomes. The New England Journal of Medicine, 332 (17): 1113-1117.

Frost, M. B., Forste, R., \& Haas, D.W. (2005). Maternal education and child nutritional status in Bolivia. Social Science \& Medicine, 60 (2): 395-407.

Fukuda-Parr, S. (2004). Millennium Development Goals: Why They Matter. Global Governance: A Review of Multilateralism and International Organizations, 10 (4): 395-402.

Fukuda-Parr, S., \& Greenstein, J. (2010). How should MDG implementation be measured: Accelerating progress or achieving target. International Policy Centre for Inclusive Growth Working Paper 63.

Fukuda-Parr, S., Yamin, A.E., \& Greenstein, J. (2014). The power of numbers: a critical review of Millennium Development Goal targets for human development and human rights. Journal of Human Development and Capabilities, 15 (2-3): 105-117. 
Ghuman, S., Behrman, J. R., Borja, J., Gultiano, S., \& King, E. (2005). Family background, service providers, and early childhood development in Philippines: Proxies and interactions. Economic Development and Cultural Change, 54 (1): 129-64.

Gilbert, W.M., Jandial, D., Field, N., Bigelow, P., \& Danielsen, B. (2004). Birth outcomes in teenage pregnancies. The Journal of Maternal-Fetal and Neonatal Medicine, 16 (5): 265-270.

Gillespie, S. \& Haddad, L. (2001). Attacking the double burden of malnutrition in Asia and the Pacific. ADB Nutrition and Development Series, no. 4. Geneva: ACC/SNC, and Manila: Asian Development Bank.

Glewwe, P., \& Jacoby, H. (1995). An economic analysis of delayed primary school enrollment and childhood malnutrition in a low income country. Review of Economics and Statistics, 77 (1): 156-69.

Glewwe, P. (1999). Why does mother's schooling raise child health in developing countries? Evidence from Morocco. Journal of Human Resources, 34 (1): 124-159.

Glewwe, P., Jacoby, H. \& King, E. (2001). Early childhood nutrition and academic achievement: a longitudinal analysis. Journal of Public Economics, 81: 345-68.

Glewwe, P. \& King, E. (2001). The impact of early childhood nutritional status on cognitive development: does the timing of malnutrition matter? World Bank Economic Review, 15: $81-114$.

Glewwe, P., \& Miguel, E. A. (2008). The impact of child health and nutrition on education in less developed countries. In Handbook of Development Economics, ed. T.P. Schultz and J. Strauss. Amsterdam: Elsevier.

Grossman, M. (2006). Education and non market outcomes. In E. Hanushek, \& F. Welch (Eds.). Handbook of the economics of education (Vol.1). Elsevier.

Harttgen, K. \& Misselhorn, M. (2006). A multilevel approach to explain child mortality and undernutrition in South Asia and sub-Saharan Africa. Ibero America Institute for Econ. Research (IAI) Discussion Papers 152, Ibero-America Institute for Economic Research. 
Harttgen, K., \& Klasen, S. (2012). Do fragile countries lag in MDG progress? Journal of Development Studies, 49 (1): 134-159.

Harttgen, K., Klasen, S. \& Vollmer, S. (2013). Economic growth and child undernutrition in subSaharan Africa. Population and Development Review, 39 (3): 397-412.

Hill, K., Bicego, G., \& Mahy, M. (2001). Childhood mortality in Kenya: an examination of trends and determinants in the late 1980 to mid 1990s. Hopkins Population Center Working Paper. J. H. University. No. WP 01-01.

Hoddinott, J. \& Kinsey, B. (2001). Child growth in the time of drought. Oxford Bulletin of Economics and Statistics, 63: 409-36.

Hogan, M. C., Foreman, K. G., Naghavi, M. et al. (2010). Maternal mortality for 181 countries, 1980-2008: A systematic analysis of progress towards Millenium Development Goal 5. The Lancet, 375 (9726): 1609-1623.

Jayachandran S. (2009). Air quality and early-life mortality during Indonesia's massive wildfires in 1997. Journal of Human Resources, 44 (4): 916-954.

Jim, C.Y. (1999). The forest fires in Indonesia 1997-1998: possible causes and pervasive consequences. Geography, 84 (364): 251-60.

Kakwani, N. (1993). Performance in living standards: An international comparison. Journal of Development Economics, 41: 307-336.

Kaufmann, D., Kraay, A., \& Mastruzzi, M. (2003). Governance matters III: Governance indicators for 1996-2002. Policy Research Working Paper 3106, World Bank.

Kazianga, H., de Walque, D., \& Alderman, H. (2009). Educational and health impacts of two school feeding schemes: Evidence from a randomized trial in rural Burkina Faso. Policy Research Working Paper Series 4976, The World Bank.

Keller, M.C., Garver-Apgar, C.E., Wright, M.J., Martin, N.G., Corley, R.P., et al. (2013). The Genetic Correlation between Height and IQ: Shared Genes or Assortative Mating? PLoS Genet 9 (4). 
Kevane, M. \& Levine, D. (2003). Changing status of daughters in Indonesia. Center for International and Development Economics Research, Working Paper Series No. C03-126, Center for International and Development Economics Research, Institute for Business and Economic Research, UC Berkeley.

King, E. M., Klasen, S., \& Porter, M. (2009). Women and development in global crises, global solutions. In B. Lomborg (Ed) (2nd ed.). Cambridge: Cambridge University Press.

Klasen, S. (1996). Nutrition, health and mortality in sub-Saharan Africa: Is there a gender bias? The Journal of Development Studies, 32 (6): 913-932.

Klasen, S. (2005). Bridging the gender gap to promote economic and social development. Journal of International Affairs, 58 (2): 245-256.

Klasen, S. (2008). Poverty, undernutrition, and child mortality: some inter-regional puzzles and their implications for research and policy. The Journal of Economic Inequality, 6 (1): 89-115.

Kramer, M. S., \& Kakuma, R. (2007). Optimal Duration of Exclusive Breastfeeding (Review). Geneva: World Health Organization.

Labbok, M. H., \& Krasovec, K. (1990). Towards Consistency in Breastfeeding Definitions. Studies in Family Planning, 21 (4): 226-30.

Lange, S., \& Klasen, S. (2011). Getting progress right: Measuring progress towards the mdgs against historical trends. Courant Research Centre: Poverty, Equity and Growth-Discussion Papers 87, Courant Research Centre PEG.

Lay, J. (2010). MDG achievements, determinants, and resource needs: What has been learnt? German Institute for Global and Area Studies Working Paper 137.

Lay, J., \& Robilliard, A.S. (2009). The complementarity of MDG achievements. The case of child mortality in Sub-Saharan Africa. World Bank Policy Research Working Paper No.5062.

Levine, D. \& Ames, M. (2003). Gender bias and the Indonesian financial crisis: Were girls hit hardest? Center for International and Development Economics Research. 
Lo Bue, M.C., \& Klasen, S. (2013). Identifying Synergies and Complementarities Between MDGs: Results from Cluster Analysis. Social Indicators Research, 113 (2): 647-670.

Mani, S. (2014). Socioeconomic determinants of child health: empirical evidence from Indonesia. Asian Economic Journal, 28 (1): 81-104.

Marioni, R.E., Batty, G.D., Hayward, C., Kerr, S.M., Campbell, A., Hocking, L.J., Porteous, D.J., Visscher, P.M., Deary, I.J. (2014). Common genetic variants explain the majority of the correlation between height and intelligence: the Generation Scotland Study. Behavior Genetics, 44: 91-96.

Marshall, M. G., \& Cole, B. R. (2011). Global Report 2011: Conflict, governance, and state fragility. Vienna, VA: Centre for Systemic Peace.

Milligan, G. W., \& Cooper, M. C. (1985). An examination of procedures for determining the number of clusters in a data set. Psychometrika, 50 (2): 159-179.

Minujin, A., \& Delamonica, E. (2003). Mind the gap! Widening child mortality disparities. Journal of Human Development, 4 (3): 397-418.

Morduch, J. (1995). Income smoothing and consumption smoothing. Journal of Economic Perspectives, 9 (3): 103-114.

Mosley, W. H., \& Chen, L. (1984). An analytical framework for the study of child survival in developing countries. Child survival: strategies for research. Population and Development Review, 10 (Supplement): 25-48.

Mundlak, Y. (1978). On the Pooling of Time Series and Cross-section Data. Econometrica, 46: 6985.

Nerlove, M. (2002). Essays in Panel Data Econometrics, Cambridge University Press, New York 2002.

Nishimura, M., Yamano, T., \& Sasaoka, Y. (2008). Impacts of the universal primary education policy on educational attainment and private costs in rural Uganda. International Journal of Educational Development, 28 (2): 168-175. 
O'Donnell, O., Van Doorslaer, E., Wagstaff; A., \& Lindelow, M. (2008). Analyzing bealth equity using household survey data. World Bank Institute, Washington DC: World Bank.

Pangaribowo, E.H., \& Tsegai, D. (2011). Food Demand Analysis of Indonesian Households with Particular Attention to the Poorest. ZEF Discussion Papers on Development Policy No. 151, Center for Development Research, Bonn. ISSN 1436-9931.

Pelletier, D.L., Frongillo, E.A., Schroeder, D.G., \& Habicht, J.H. (1995). The effects of maluntrition on child mortality in developing counries. Bulletin of the World Health Organization, 73 (4): 443-448.

Posthuma, D., de Geus, E.J., Neale, M.C., Hulsho Pol, H.E., Baare, W.E.C., Kahn, R.S., Boomsma, D. (2000). Multivariate genetic analysis of brain structure in an extended twin design. Behavior Genetics, 30: 311-319.

Prennushi, G., Rubio, G., \& Subbarao, K. (2002). Monitoring and evaluation. In J. Klugman (Ed.), A sourcebook for poverty reduction strategies. Washington, DC: World Bank.

Preece, M.A. (1996). The genetic contribution to stature. Hormone Research, 45: 56-58.

Ralston, K. (1997). Children's health as an input to labor: Intrahousehold food distribution in Rural Indonesia. Journal of Policy Modelling, 19 (5): 567-586.

Rutstein, S. O. (2000). Factors associated with trends in infant and child mortality in developing countries during the 1990s. Bulletin of the World Health organization, 78 (10): 1256-1270.

Sahn, D., \& Alderman, H. (1997). On the determinants of nutrition in Mozambique: The importance of age-specific effects. World Development, 25 (4): 577-588.

Schultz, T. P. (1984). Studying the impact of household economic and community variables on child mortality. Population and Development Review, 10 (Supplement): 215-35.

Sen, A.K. (1992). Inequality Reexamined. Oxford University Press, Oxford.

Sen, A.K. (1999). Development as freedom. Oxford University Press, Oxford. 
Sen, A.K. (2003). Development as Capability Expansion. In Fukuda-Parr, S. and Kumar, A.S., editors, Readings in Human Development, pages 41-58. Oxford University Press, New Delhi, New York.

Shrimpton, R., Victora, C., de Onis M., Costa Lima, R., Blössner, M., \& Clugston, G. (2001). Worldwide timing of growth faltering: implications for nutritional interventions, Pediatrics, 107: 75-81.

Silventoinen, K, Posthuma, D, van Beijsterveldt, T, Bartels, M, Boomsma, D.I. (2006). Genetic contributions to the association between height and intelligence: evidence from Dutch twin data from childhood to middle age. Genes, Brain and Behavior, 5: 585-595.

Smith, L., Ramakrishnan, U., Ndiaye, A., Haddad, L., \& Martorell, R. (2003). The importance of women's status for child nutrition in developing countries. Research Report 131. International Food Policy Research Institute, Washington, DC.

Sommerfelt, A. E., \& Stewart, M. K. (1994). Children's nutritional status, Calverton, MD: Macro International, Inc.

Staiger, D., Stock J.H. (1997). Instrumental variables regression with weak instruments. Econometrica 65, 557-586.

Stein, Z., Susser, M., Saenger, G., \& F. Marolla, F. (1975). Famine and buman development: the Dutch bunger winter of 1944-45. New York: Oxford University Press.

Strauss, J., Witoelar, F., et al. (2009). The fourth wave of the Indonesia Family Life Survey: Overview and field report, Volume 1. Working Paper WR-675/1-NIA/NICHD, Labor and Population Program, RAND Corporation, Santa Monica, CA.

Strauss, J. (1990). Households, communities, and preschool child nutrition outcomes: Evidence from Cote d'Ivoire. Economic Development and Cultural Change, 38 (2): 231-261.

Summers, L. (1994). Investing in all the people. The World Bank, Washington DC UNDP (2003) Human Development Report 2003. 
Sundet, J.M., Tambs, K., Harris, J.R., Magnus, P., Torjussen, T.M. (2005). Resolving the genetic and environmental sources of the correlation between height and intelligence: a study of nearly 2600 Norwegian male twin pairs. Twin Research and Human Genetics, 8 (4), 307-311.

Thomas, D., Strauss, J., \& Henriques, M.H. (1991). How does mother's education affect child height? Journal of Human Resources, 26 (2): 183-211.

Townsend, R. (1995). Consumption insurance: an evaluation of risk-bearing systems in lowincome countries. Journal of Economic Perspectives, 9, 83-102.

UNDP. (1991). Human Development Report 1991, New York: United Nations.

UNDP. (2003). Human Development Report 2003, New York: United Nations.

UNDP. (2013). Annual Report UNDP Indonesia 2012/2013, Jakarta: UNDP, 2013.

UNICEF. (2013). Improving child nutrition: the achievable imperative for global progress. New York: UNICEF, 2013.

UN General Assembly. (1989). Convention on the Rights of the Child.

UN Millennium Project. (2005). Investing in development: A practical plan to achieve the Millennium Development Goals. New York.

United Nations. (2014). The Millennium Development Goals Report 2014. United Nations: New York.

United Nations, Department of Economic and Social Affairs, Population Division. (2013). World Population Ageing 2013. ST/ESA/SER.A/348.

van Dam, P.S., de Winter, C.F., de Vries, R., van der Grond, J., Drent, M.L., Lijffijt, M., Kenemans, L.J., Aleman, A., de Haan, E.H.F., Koppeschaar, H.P.F. (2005) Childhoodonset growth hormone deficiency cognitive function and brain $\mathrm{N}$-acetylaspartate. Psychoneuroendocrinology 30: 357-363.

Victora, C.G., Smith, P.G., Vaughan, J.P., Nobre, L.C., Lombardi, C., Teixeira, A.M.B., Fuchs, S.C., Moreira, L.B., Gigante, L.P., \& Barros, F.C. (1986). Social and environmental 
influences on child mortality in Brazil: logistic regression analysis of data from census files. Journal of biosocial science, 18 (01): 87-102.

Villar, J., Smeriglio, V., Martorell, R., Brown, C.H. \& Klein, R.E. (1984). Heterogeneous growth and mental development of intrauterine growth-retarded infants during the first 3 Years of Life. Pediatrics 74 (5): 783-91.

Waage, J., Banerji, R., Campbell, O., Chirwa, E., Collender, G., Dieltiens, V., et al. (2010). The Millennium Development Goals: A Cross-Sectoral Analysis and Principles for Goal Setting After 2015. The Lancet, 376 (9745): 991-1023.

Waber, D., Vuori-Christiansen, L., Ortiz, N., Clement, J., Christiansen, N., Mora, J., Reed, R., \& Herrera, M.G. (1981). Nutritional supplementation, maternal education, and cognitive development of infants at risk of malnutrition. American Journal of Clinical Nutrition 34: $807-13$.

Wang, L. (2003). Determinants of child mortality in LDCs: empirical findings from demographic and health surveys. Health policy, 65 (3): 277-299.

Weedon, N.M. et al. (2008). Genome-wide association analysis identifies 20 loci that influence adult height. Nature Genetics, 39: 1245-1250.

White, H., \& Blöndal, N. (2007). Projecting progress toward the Millennium Development Goals. MPRA Paper 5687, University Library of Munich, Germany.

White, H., \& Masset, E. (2006). Assessing interventions to improve child nutrition: A theorybased impact evaluation of the Bangladesh integrated nutrition project. Journal of International Development, 19 (5): 627-652.

Wooldridge, J.M. (2002). Econometric analysis of cross section and panel data. Cambridge, Mass.: The MIT Press.

World Bank. (2000). World Development Report 2000-Attacking Poverty, World Bank, Washington DC. 
World Bank. (2010). World Development Indicators, 2010 Edition. CD-ROM, World Bank, Washington DC.

World Bank. (2011). Gender Equality. Kesetaraan Gender. Policy Brief No. 73031. World Bank, Jakarta.

World Health Organization. (1995). Physical Status. The use and interpretation of anthropometry. Report of a WHO Expert Committee. World Health Organ Tech Rep Ser 854: 1-452.

World Health Organization. (2006). WHO Multicentre Growth Reference Study Group: WHO Child Growth Standards: Length/height-for-age, weight-for-age, weight-for-length, weight-for-height and body mass index-for-age: Methods and development. Geneva, World Health Organization, 2006.

World Health Organization. (2008). Indicators for Assessing Infant and Young Child Feeding Practices Part 1: Definitions. Geneva, World Health Organization, 2008.

Yamauchi, F. (2008). Early childhood nutrition, schooling, and sibling inequality in a dynamic context: evidence from South Africa. Economic Development and Cultural Change, 56 (3): 657-682.

Ziliak, J. \& Kneiser, T. (1998). The importance of sample attrition in life cycle labor supply estimation, Journal of Human Resources, 33: 507-30. 


\section{Curriculum Vitae}

\section{Personal Information}

Name: Maria Carmela Lo Bue

Date of Birth: April, 23 $3^{\text {rd }} 1984$

Nationality: Italian

\section{Education}

July 2010-February 2015

September 2006-February 2010

September 2002- April 2006

September 1997-June 2002

\section{Job experience}

February 2014-April 2014

February 2013-May 2013

February 2009-September 2009

October 2005-January 2006

August 2003
August 2006

$\mathrm{PhD}$ Student, Faculty of Economics, University of Göttingen

Master in Advanced Development Economics, Faculty of Economics, University of Florence (Italy).

Title of thesis: Sources of Dutch Disease: evidence from transition economies, 1990-2007.

Bachelor in Economic Development and International Cooperation, Faculty of Economics, University of Palermo (Italy).

Title of thesis: Main indicators of poverty and development used for international comparisons.

Secondary school specializing in modern languages and humanities, Centro Educativo Ignaziano, Palermo (Italy)

Consultant at TNP2K, Government of Indonesia

Research Intern at UNU-WIDER, Helsinki

Tutor Junior/Student assistant at Faculty of economics, University of Florence

Volunteer field work in Dominican Republic

Internship at the NGO "Fundação Gonzalo da Silveira" in Lisbon, Portugal

Internship at the NGO "International Voluntary Service" in Edinburgh, UK.

\section{Conferences and Workshops}

Italian Economists Associations (SIE) Annual Conference, University of Bologna.

ADB-Sogang University Workshop Poverty Reduction in Asia:

Drivers, Best Practices and Policy Initiatives, Seoul.

OECD-Joint Universities Conference New Directions in Welfare III, Paris.

EADI-DSA General Conference, York.

AISSEC XVIIIth Scientific Conference Re-Starting Growth:

Protectionism versus International Governance, Macerata.

EADI and UNU-CRIS Workshop on Transformations in the World System, Bruges. 


\section{Eidesstattliche Erklärung}

Hiermit versichere ich, dass ich die vorliegende Arbeit selbständig und ohne Benutzung anderer als der angegebenen Hilfsmittel angefertigt habe. Alle Stellen, die wörtlich oder sinngemäß aus veröffentlichten und nicht veröffentlichten Schriften entnommen sind, sind als solche kenntlich gemacht.

Göttingen, 08.12.2014 